Supporting Information: Stanic et al., Characterization of deoxynivalenol (DON) and cysteine adducts

\title{
Preparation and Characterization of Cysteine Adducts of Deoxynivalenol
}

Ana Stanic, Silvio Uhlig, Anita Solhaug, Frode Rise, Alistair L. Wilkins, Christopher O.

Miles 
Figure S1. ${ }^{1} \mathrm{H}$ spectrum of $\mathbf{1}(\mathrm{DON}) \quad$ S4

Figure S2. COSY NMR spectrum of $1(\mathrm{DON}) \quad$ S5

$\begin{array}{ll}\text { Figure S3. TOCSY NMR spectrum of } 1(\mathrm{DON}) & \text { S6 }\end{array}$

$\begin{array}{ll}\text { Figure S4. HSQC NMR spectrum of } \mathbf{1}(\mathrm{DON}) & \text { S7 }\end{array}$

Figure S5. HMBC NMR spectrum of $1(\mathrm{DON}) \quad$ S8

Figure S6. Selected HMBC area of 1 (DON) showing correlations from major and minor H-16 methyl singlets to C-8 ketone and hemiketal S9

$\begin{array}{ll}\text { Figure S7. ROESY NMR spectrum of } 1(\mathrm{DON}) & \text { S10 }\end{array}$

$\begin{array}{ll}\text { Figure S8. DEPT135 spectrum of } \mathbf{1}(\mathrm{DON}) . & \mathrm{S} 11\end{array}$

$\begin{array}{lr}\text { Figure S9. }{ }^{13} \mathrm{C} \text { NMR spectrum of } \mathbf{1}(\mathrm{DON}) & \mathrm{S} 12\end{array}$

Figure S10. ${ }^{1} \mathrm{H}$ NMR spectrum of 3 (DON-Cys Michael adduct) S13

Figure S11. ${ }^{13} \mathrm{C}$ NMR spectrum of $\mathbf{3}$ (DON-Cys Michael adduct) $\quad$ S14

Figure S12. DEPT135 NMR spectrum of $\mathbf{3}$ (DON-Cys Michael adduct) S15

Figure S13. COSY NMR spectrum of 3 (DON-Cys Michael adduct) S16

$\begin{array}{ll}\text { Figure S14. TOCSY NMR spectrum of } \mathbf{3} \text { (DON-Cys Michael adduct) } & \text { S17 }\end{array}$

Figure S15. HSQC NMR spectrum of $\mathbf{3}$ (DON-Cys Michael adduct) S18

$\begin{array}{ll}\text { Figure S16. HMBC NMR spectrum of } 3 \text { (DON-Cys Michael adduct) } & \text { S19 }\end{array}$

Figure S17. ROESY NMR spectrum of $\mathbf{3}$ (DON-Cys Michael adduct) $\quad$ S20

Figure S18. NOESY NMR spectrum of $\mathbf{3}$ (DON-Cys Michael adduct) $\quad$ S21

Figure S19. ${ }^{1} \mathrm{H}$ NMR spectrum of $\mathbf{2}$ (DON-Cys epoxide conjugate) $\quad$ S22

Figure S20. DEPT 135 NMR spectrum of 2 (DON-Cys epoxide conjugate) S23

$\begin{array}{ll}\text { Figure S21. COSY NMR spectrum of } 2 \text { (DON-Cys epoxide conjugate) } & \text { S24 }\end{array}$

Figure S22. TOCSY NMR spectrum of 2 (DON-Cys epoxide conjugate) $\quad$ S25

Figure S23. HSQC NMR spectrum of 2 (DON-Cys epoxide conjugate) S26

$\begin{array}{ll}\text { Figure S24. HMBC NMR spectrum of } \mathbf{2} \text { (DON-Cys epoxide conjugate) } & \text { S27 }\end{array}$

Figure S25. ROESY NMR spectrum of 2 (DON-Cys epoxide conjugate) S28

Figure S26. Selected area of HMBC spectrum of $\mathbf{3}$ showing correlations from H-16 to $\begin{array}{ll}\text { hemiketal or ketone carbon } & \text { S29 }\end{array}$

Figure S27. Selected HMBC area of 2 (DON-Cys epoxide conjugate) showing preserved $\begin{array}{ll}\text { double bond } & \text { S30 }\end{array}$

Figure S28. Selected HMBC area of 2 (DON-Cys epoxide conjugate) showing correlations between $\mathrm{H}-13$ protons and attached cysteine, $\mathrm{C}-1^{\prime}$ carbon. $\quad \mathrm{S} 31$

Figure S29. Selected HMBC area of 3 (DON-Cys Michael conjugate) showing correlations from attached cysteine $\mathrm{C}-1^{\prime}$ atom to $\mathrm{C}-10$ atom of DON and C-3', and C-2'

Figure S30. Selected HMBC area of 2 (DON-Cys epoxide conjugate) showing correlations from $\mathrm{H}-16$ of a major isomer to a hemiketal carbon $\mathrm{C}-8$ and minor isomer to ketone carbon C -8

S33

Figure S31. Selected NOE correlations of 3a and 3b (DON-Cys Michael conjugate) S34

Figure S32. Selected NOE correlations of $\mathbf{2 b}$ (DON-Cys epoxide adduct) $\quad$ S35 
Figure S33. Selected HMBC correlations of 3a and 3b (DON-Cys Michael conjugates) S36

Figure S34. Selected HMBC correlations of $\mathbf{2 b}$ (DON-Cys epoxide adduct)

Table S1. HRMS data for DON (1), DON-Cys adducts (2-4), DON-(Cys) $)_{2}$ (7-10), 2sulfoxide and $\mathbf{3}$-sulfoxide

Figure S35. Extracted ion chromatogram of $\mathbf{2}$ and $\mathbf{2}$-sulfoxides

Figure S36. Extracted ion chromatogram of $\mathbf{3}$ and $\mathbf{3}$-sulfoxides

Figure S37. HRMS ${ }^{2}$ of 2 -sulfoxides in negative mode

Figure S38. HRMS ${ }^{2}$ of sulfoxides-2 in positive mode

Figure S39. HRMS ${ }^{2}$ of 3 -sulfoxides in positive mode

Figure S40. HRMS ${ }^{2}$ of $\mathbf{3}$-sulfoxides in negative mode

Figure S41.Chemical structures of double adducts of DON-Cys (7-10)

Figure S42. Proposed fragmentation in negative mode of 2

Figure S43. Proposed fragmentation of 2 in positive mode $\quad$ S48

Figure S44. Proposed fragmentation pathway of 3 in positive mode $\quad$ S49

Figure S45. LC-MS extracted ion chromatograms of $m / z 539$ in positive mode from the followed reaction of DON and cysteine

Figure S46. Reaction followed in negative mode, extracted ion chromatogram $\mathrm{m} / \mathrm{z} 416.2$ S51

Figure S47. Reaction followed in negative mode, extracted ion chromatogram $m / z 537$, double adduct

Figure S48. $\mathrm{MS}^{\mathrm{n}}(2-4)$ of 2 in positive mode

Figure S49. $\mathrm{MS}^{\mathrm{n}}(2-4)$ of 2 in negative mode

Figure S50. Proliferation of THP-1 monocytes after treatment with 2, 4 and $6 \mu \mathrm{M}$ DON or 2 and $\mathbf{3}$ for 24, 48 and 72 hours

Figure S51. Extracted ion chromatograms showing DON-Cys after being treated with $\mathrm{H}_{2} \mathrm{O}_{2}$ Michael adduct, $\mathbf{3}$ and $\mathbf{3}$-sulfoxides and $\mathbf{3}$-sulfones

Figure S52. 3-D model of the hemiketal form of DON-Cys Michael adduct 3b, showing 
Supporting Information: Stanic et al., Characterization of deoxynivalenol (DON) and cysteine adducts

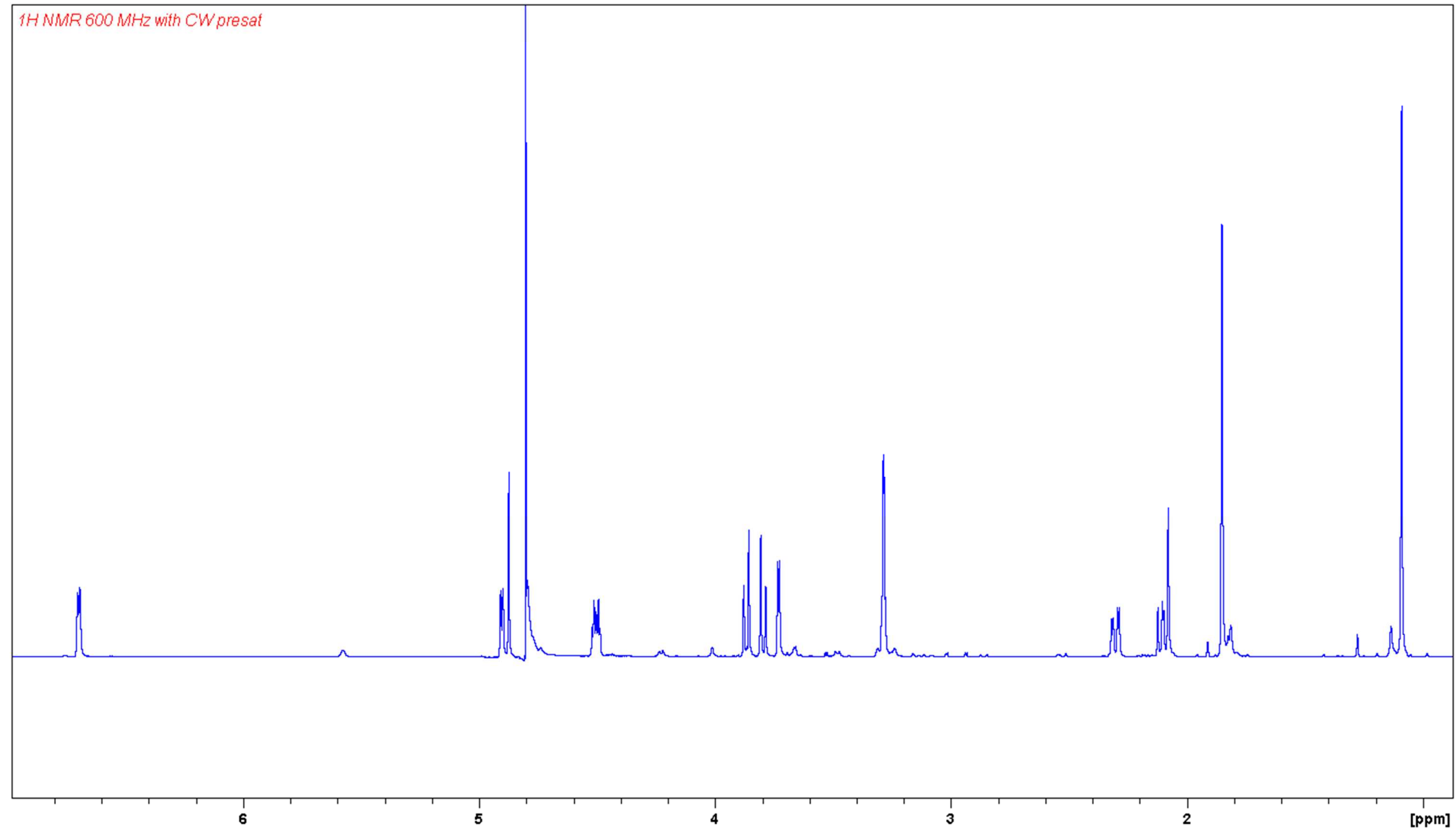

Figure S1. ${ }^{1} \mathrm{H}$ NMR spectrum of $\mathbf{1}(\mathrm{DON})$. 
Supporting Information: Stanic et al., Characterization of deoxynivalenol (DON) and cysteine adducts

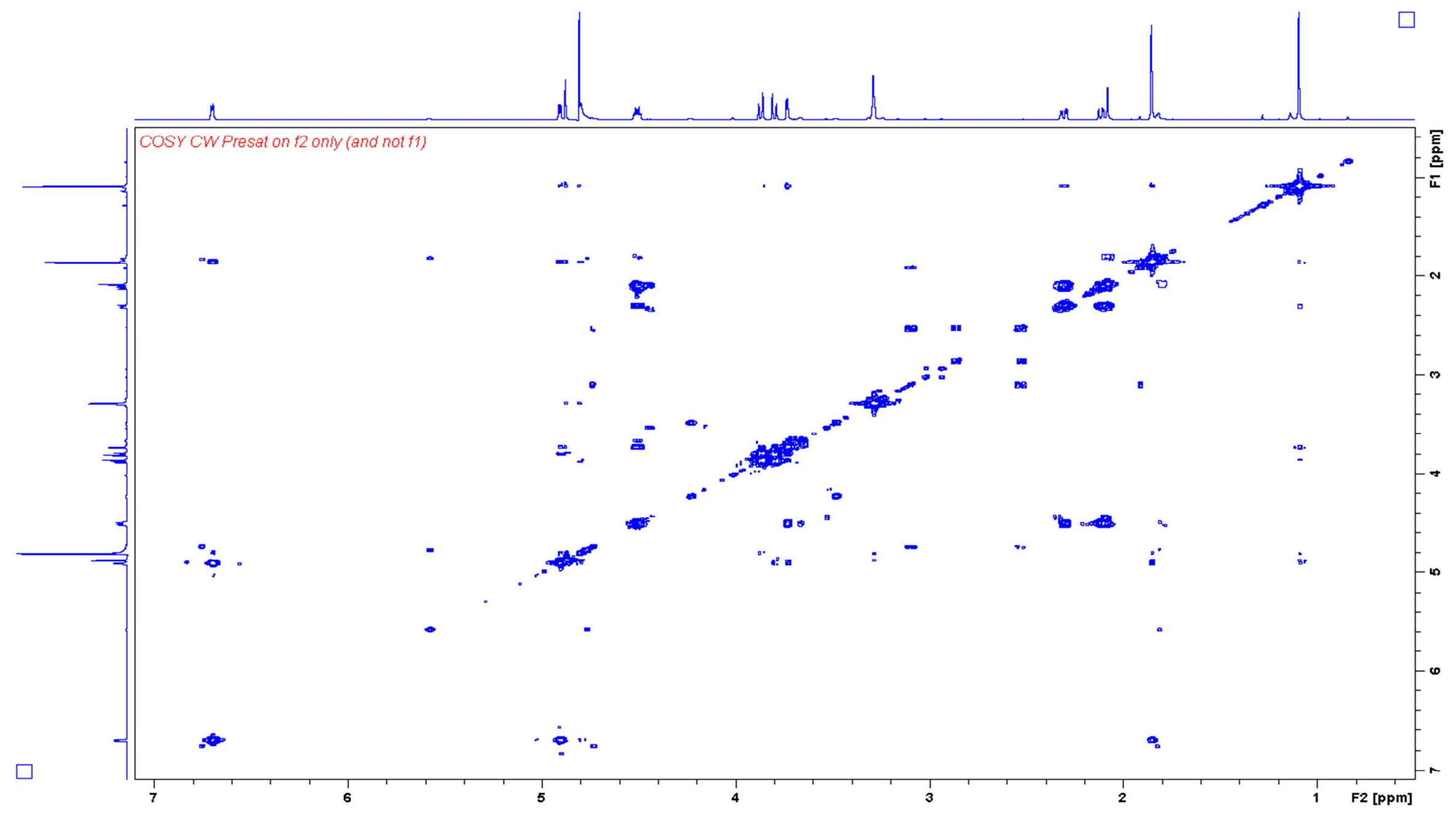

Figure S2. COSY NMR spectrum of 1 (DON). 


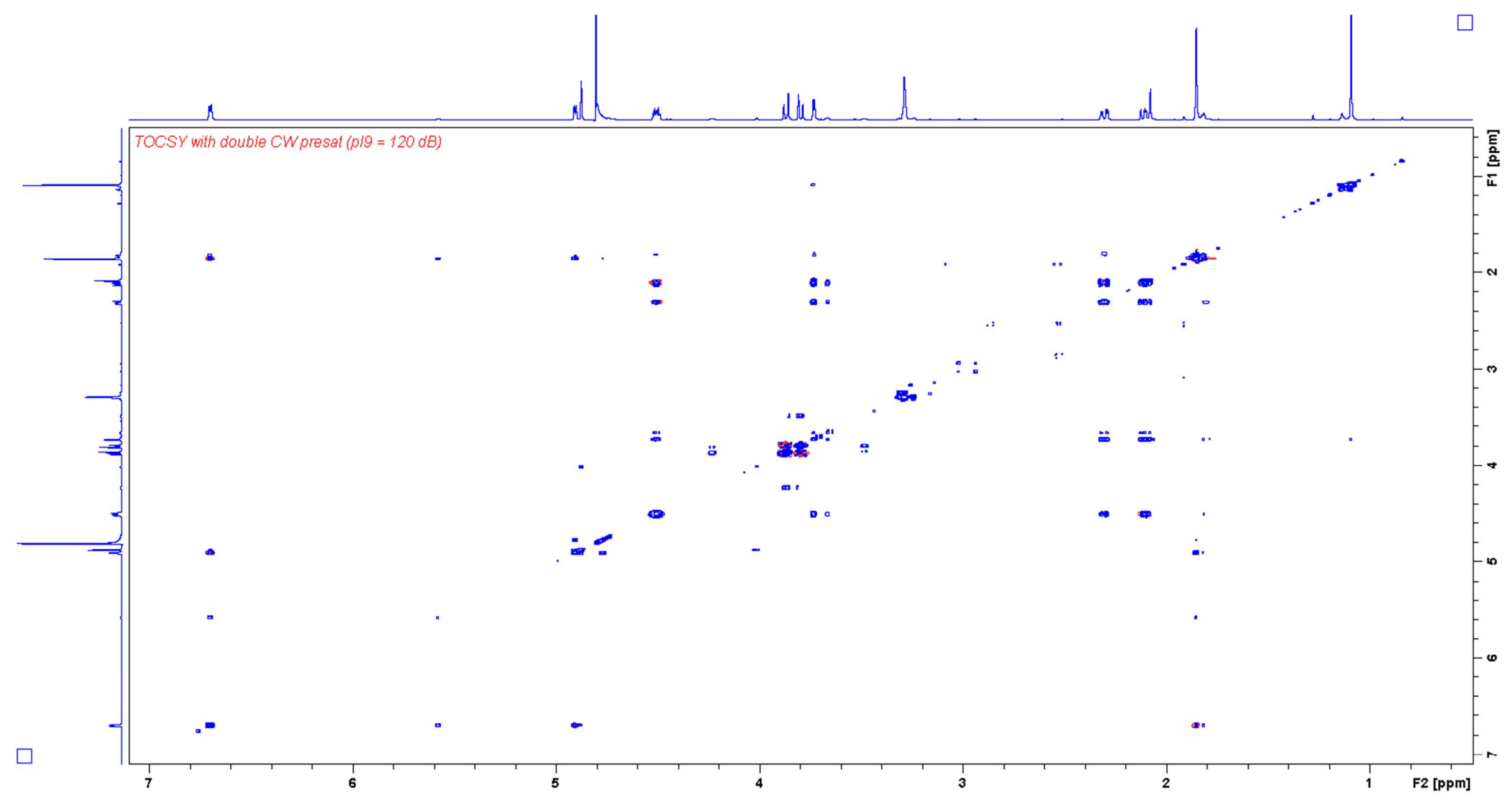

Figure S3. TOCSY NMR spectrum of $\mathbf{1}(\mathrm{DON})$. 


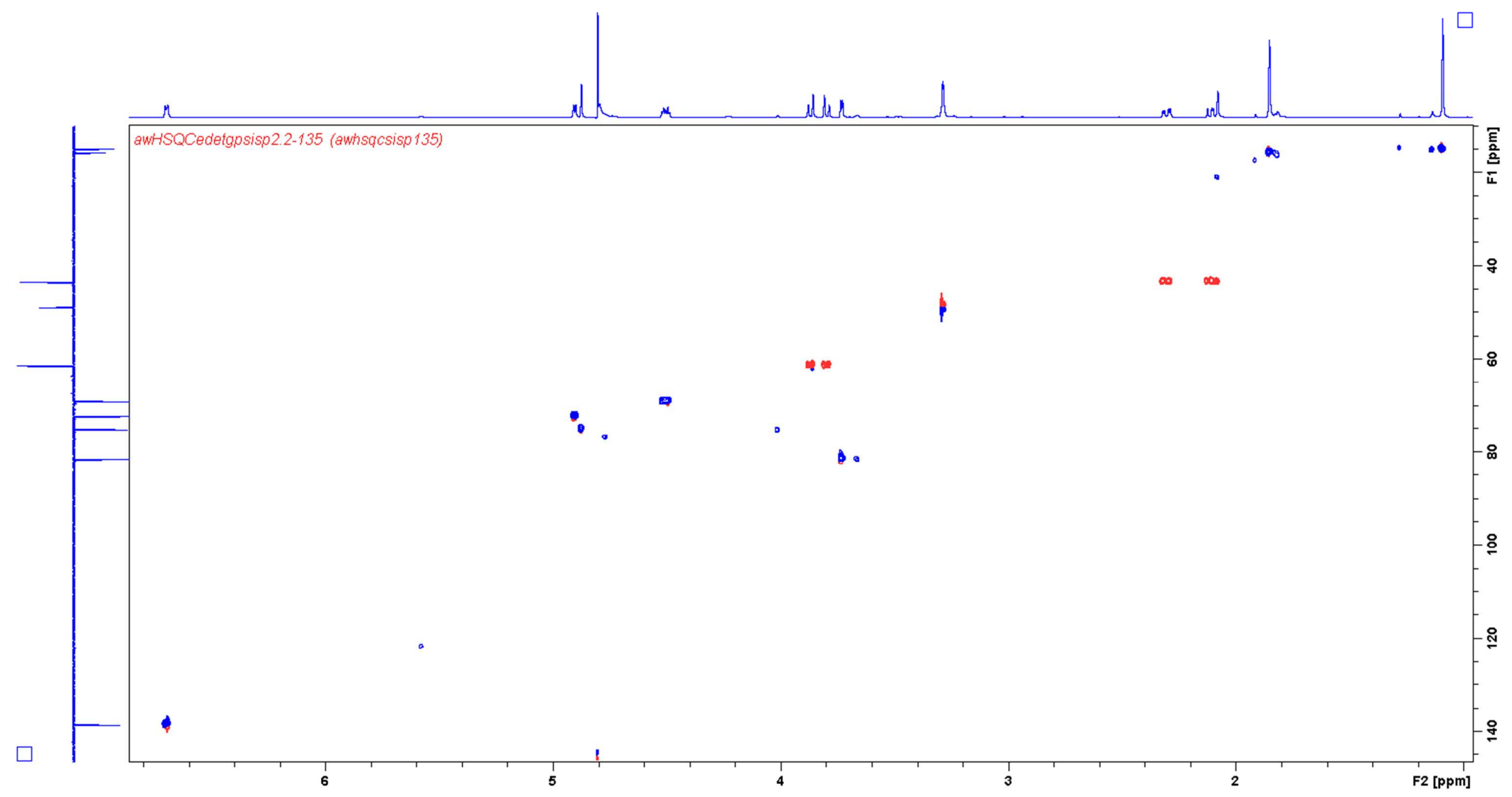

Figure S4. HSQC NMR spectrum of $\mathbf{1}(\mathrm{DON})$. 
Supporting Information: Stanic et al., Characterization of deoxynivalenol (DON) and cysteine adducts

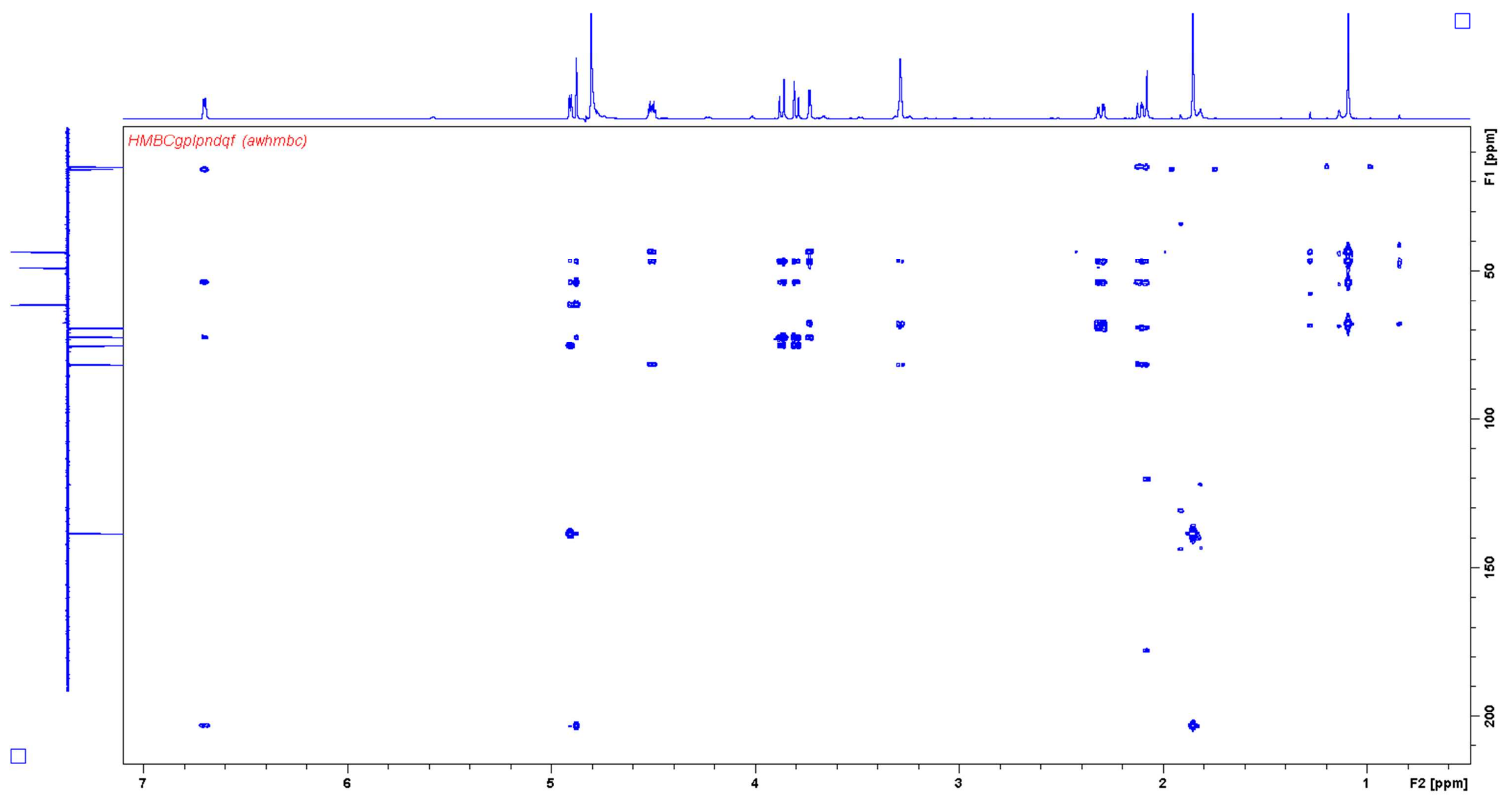

Figure S5. HMBC NMR spectrum of 1 (DON). 
Supporting Information: Stanic et al., Characterization of deoxynivalenol (DON) and cysteine adducts

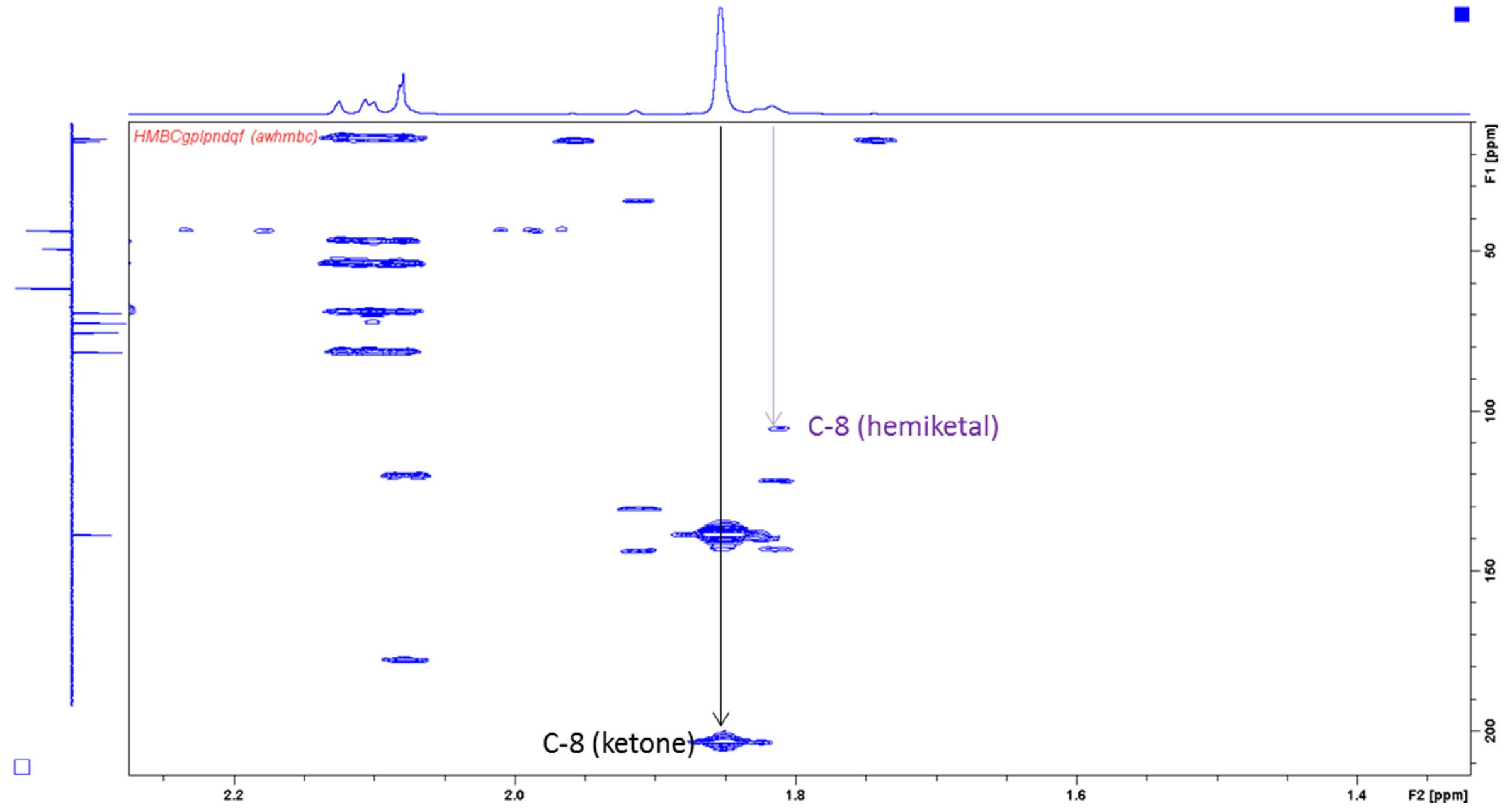

Figure S6. Selected HMBC area of 1 (DON) showing correlations from major and minor H-16 methyl singlets to C-8 a 203.5 ppm (ketone) and 105.7 ppm (hemiketal). 


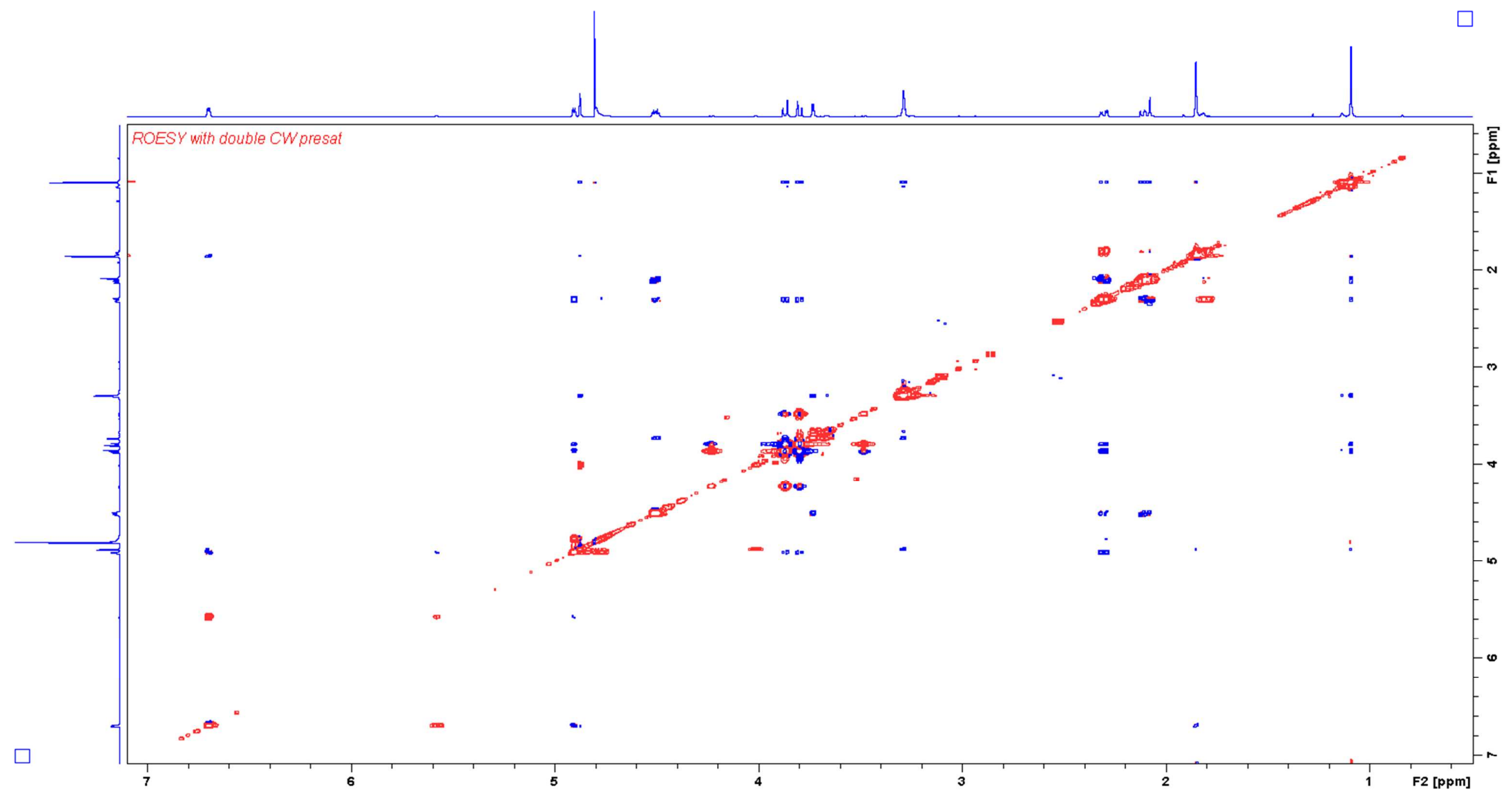

Figure S7. ROESY NMR spectrum of $\mathbf{1}(\mathrm{DON})$. 
Supporting Information: Stanic et al., Characterization of deoxynivalenol (DON) and cysteine adducts

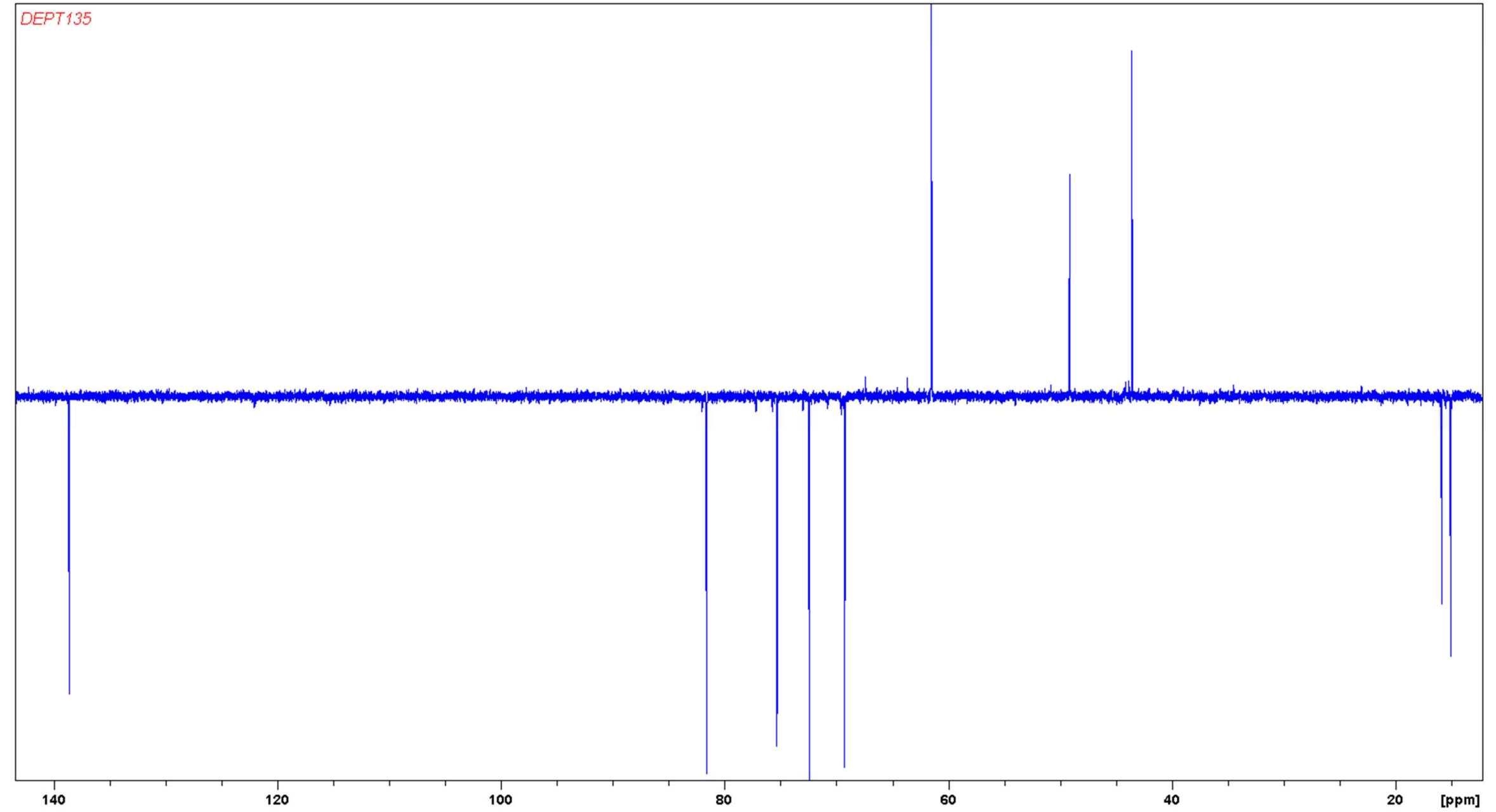

Figure S8. DEPT135 NMR spectrum of $\mathbf{1}(\mathrm{DON}) ; \mathrm{CH}_{3}$ and $\mathrm{CH}$ groups are in negative phase and $\mathrm{CH}_{2}$ is in positive phase. 
Supporting Information: Stanic et al., Characterization of deoxynivalenol (DON) and cysteine adducts

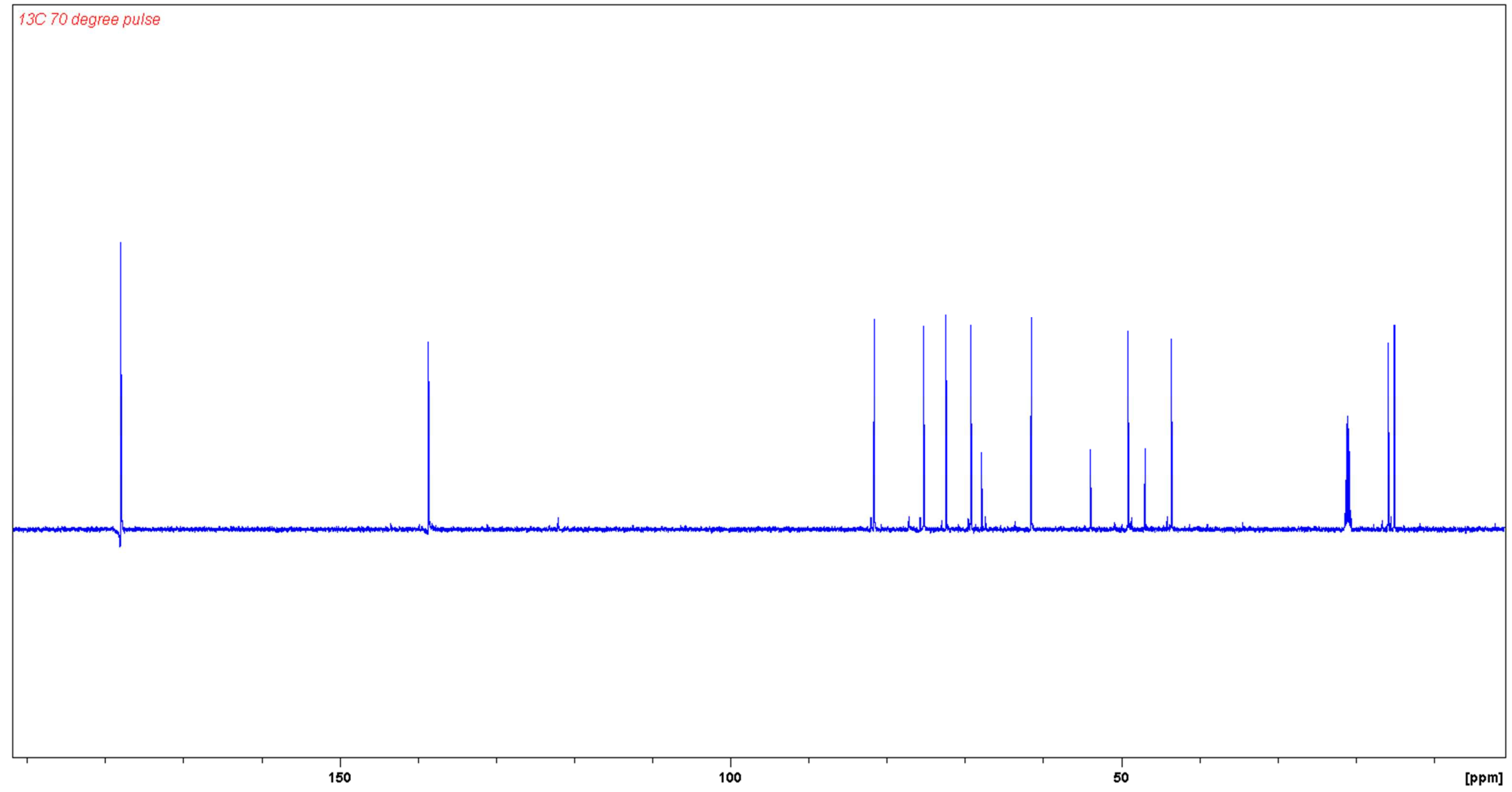

Figure S9. ${ }^{13} \mathrm{C}$ NMR spectrum of $\mathbf{1}(\mathrm{DON})$. 
Supporting Information: Stanic et al., Characterization of deoxynivalenol (DON) and cysteine adducts

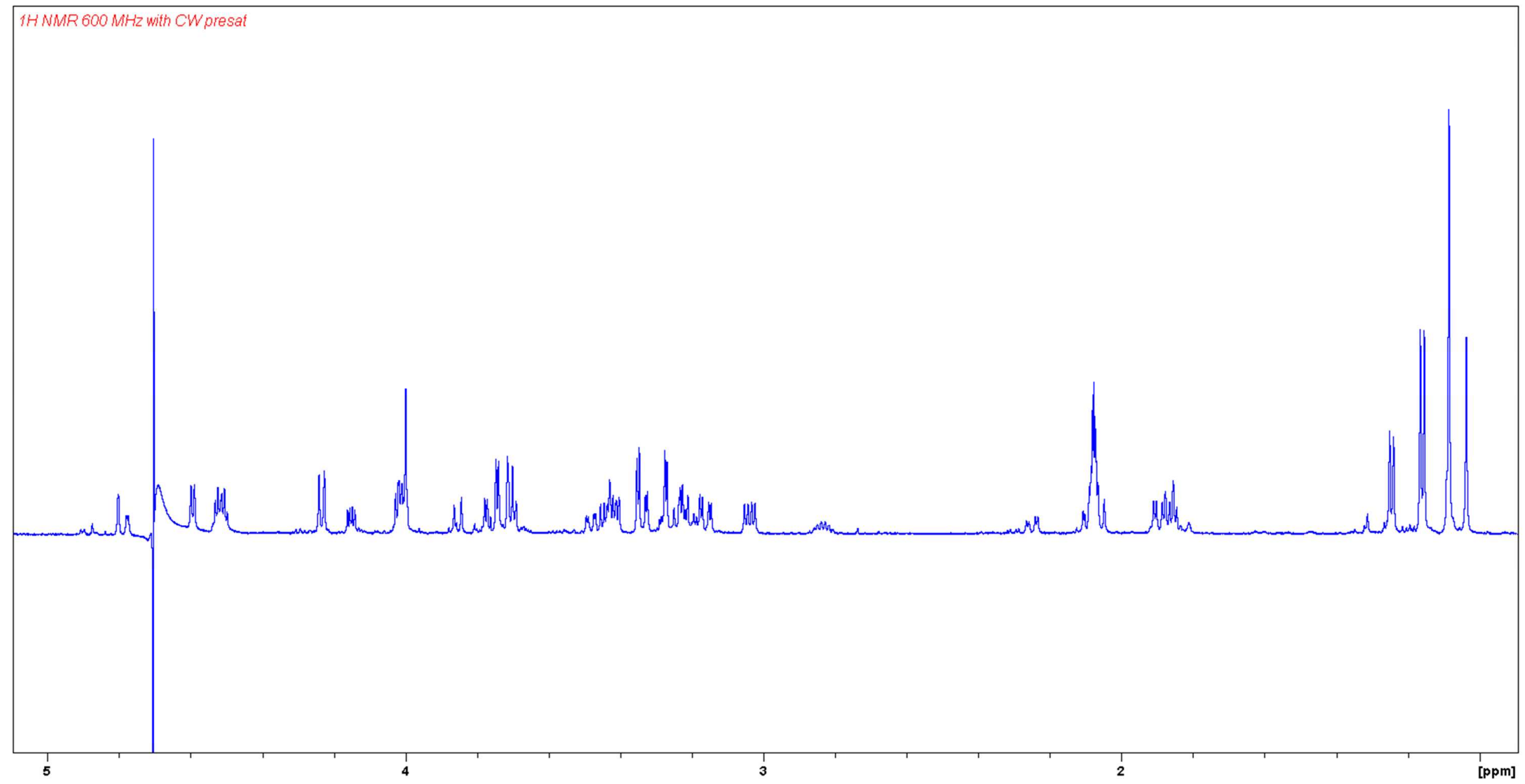

Figure S10. ${ }^{1} \mathrm{H}$ NMR spectrum of $\mathbf{3}$ (DON-Cys Michael adduct). 
Supporting Information: Stanic et al., Characterization of deoxynivalenol (DON) and cysteine adducts

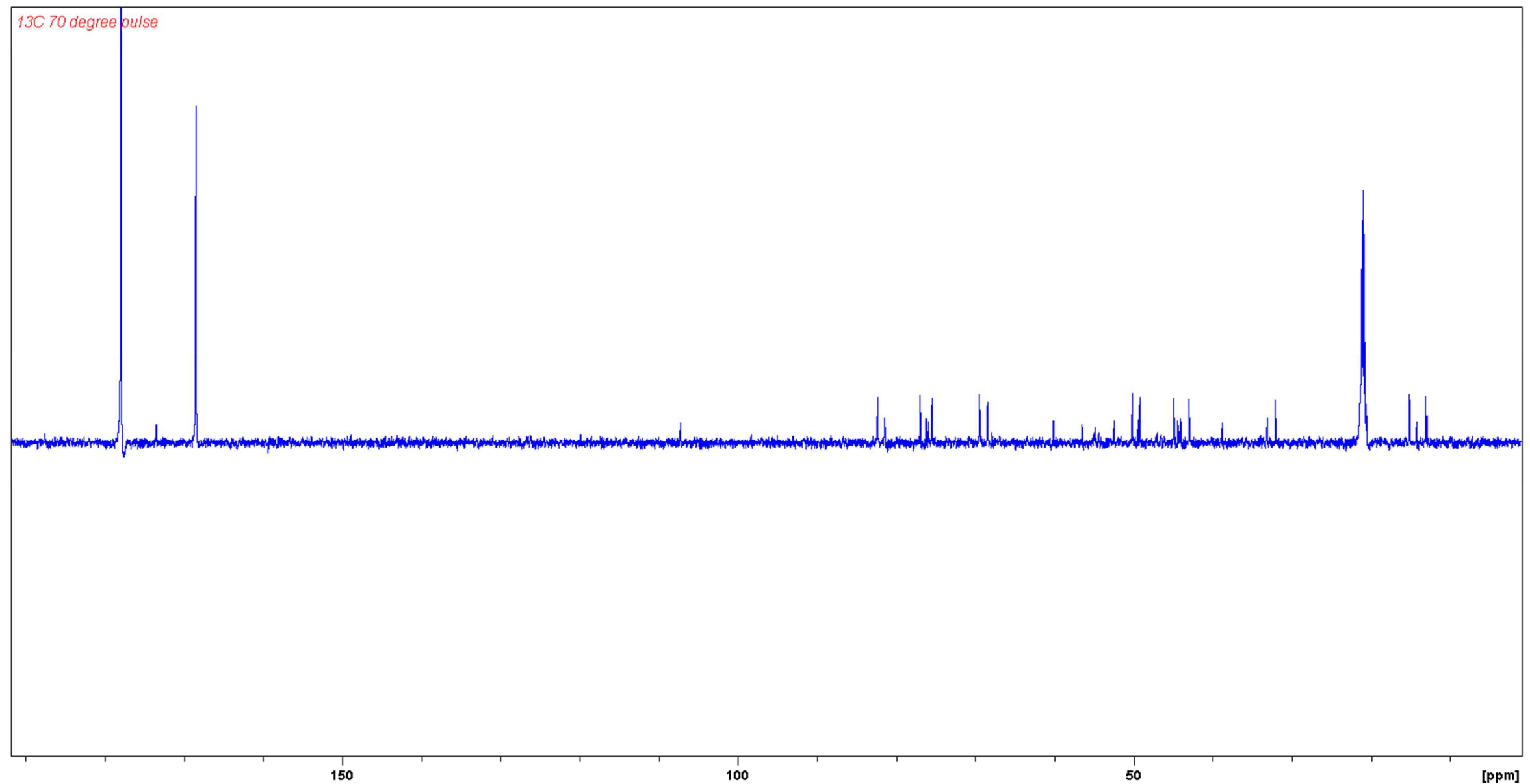

Figure S11. ${ }^{13} \mathrm{C}$ NMR spectrum of $\mathbf{3}$ (DON-Cys Michael adduct). 


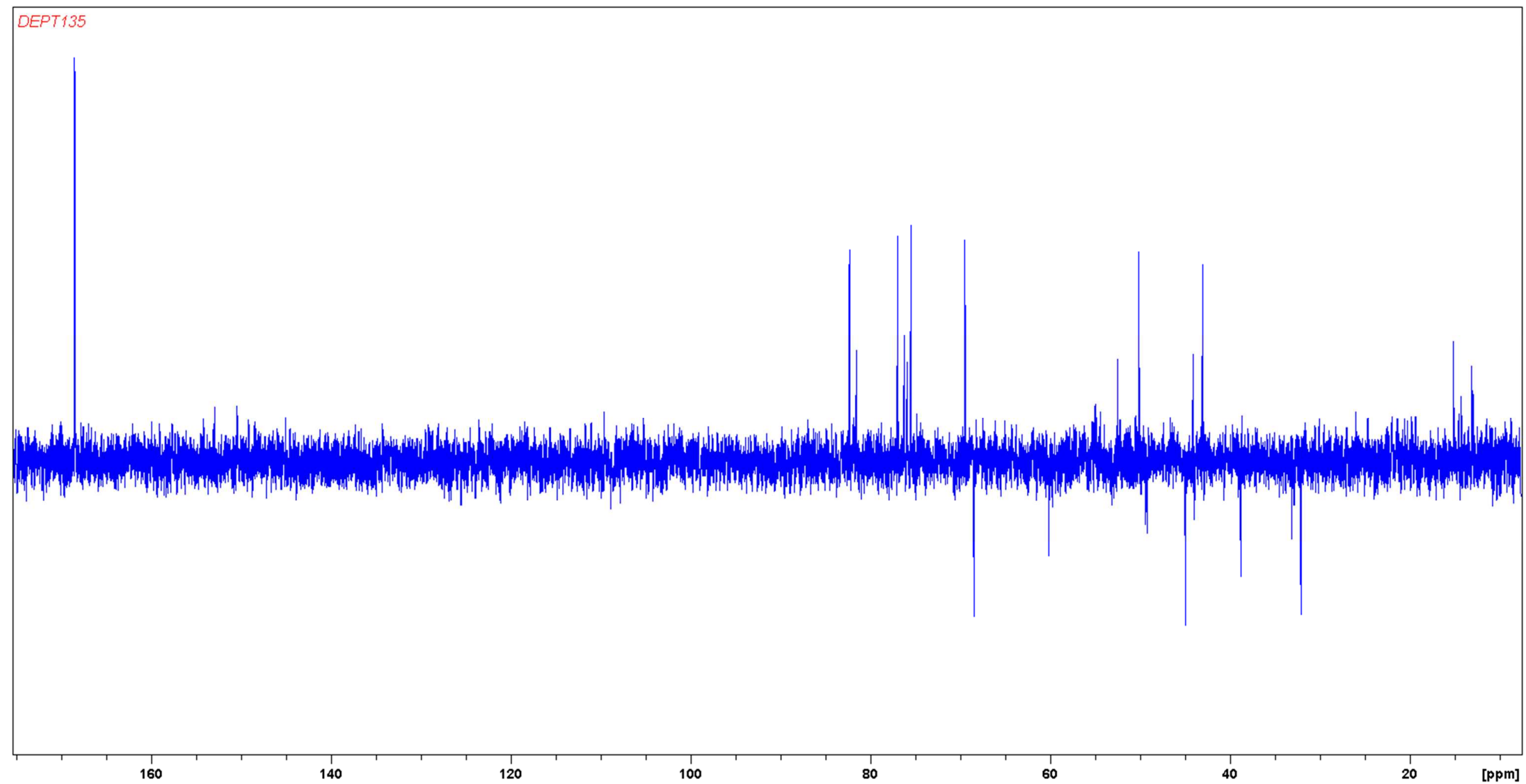

Figure S12. DEPT135 NMR experiment, ${ }^{13} \mathrm{C}$ spectrum of $\mathbf{3}$ (DON-Cys Michael adduct); $\mathrm{CH}_{3}$ and $\mathrm{CH}$ groups are in positive phase and $\mathrm{CH}_{2}$ is in negative phase. 
Supporting Information: Stanic et al., Characterization of deoxynivalenol (DON) and cysteine adducts

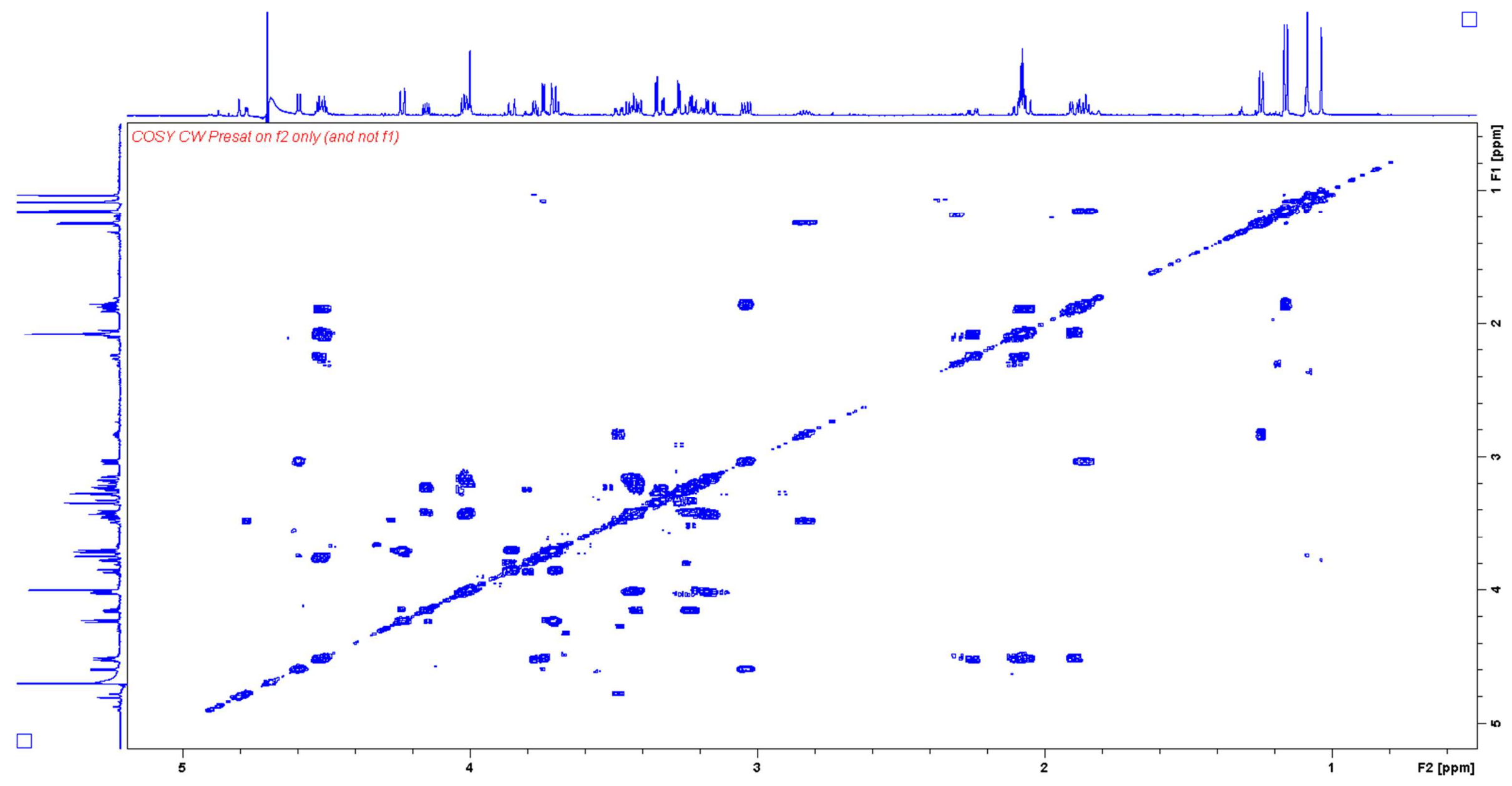

Figure S13. COSY NMR spectrum of 3 (DON-Cys Michael adduct). 
Supporting Information: Stanic et al., Characterization of deoxynivalenol (DON) and cysteine adducts

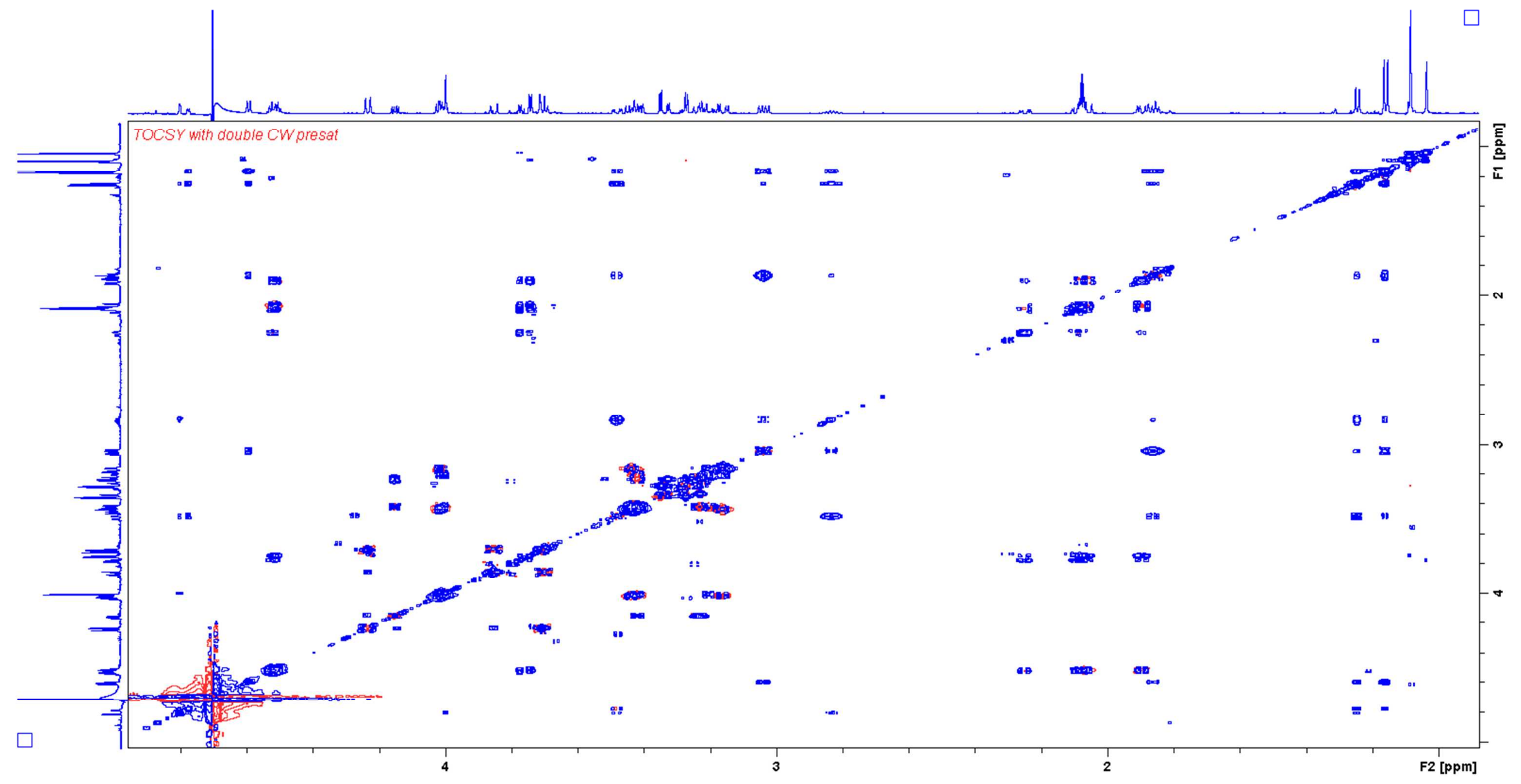

Figure S14. TOCSY NMR spectrum of $\mathbf{3}$ (DON-Cys Michael adduct). 
Supporting Information: Stanic et al., Characterization of deoxynivalenol (DON) and cysteine adducts

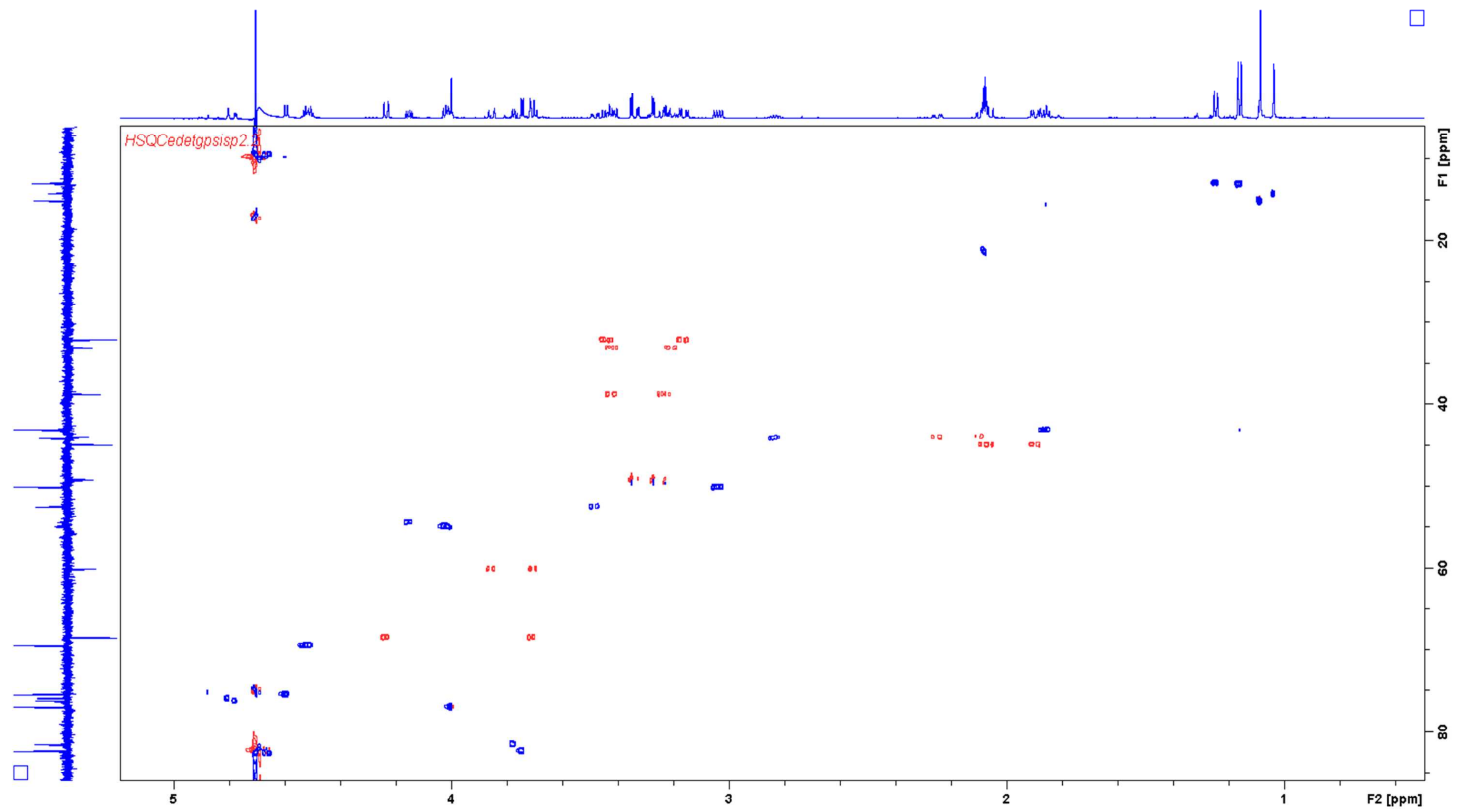

Figure S15. HSQC NMR spectrum of $\mathbf{3}$ (DON-Cys Michael adduct). 
Supporting Information: Stanic et al., Characterization of deoxynivalenol (DON) and cysteine adducts

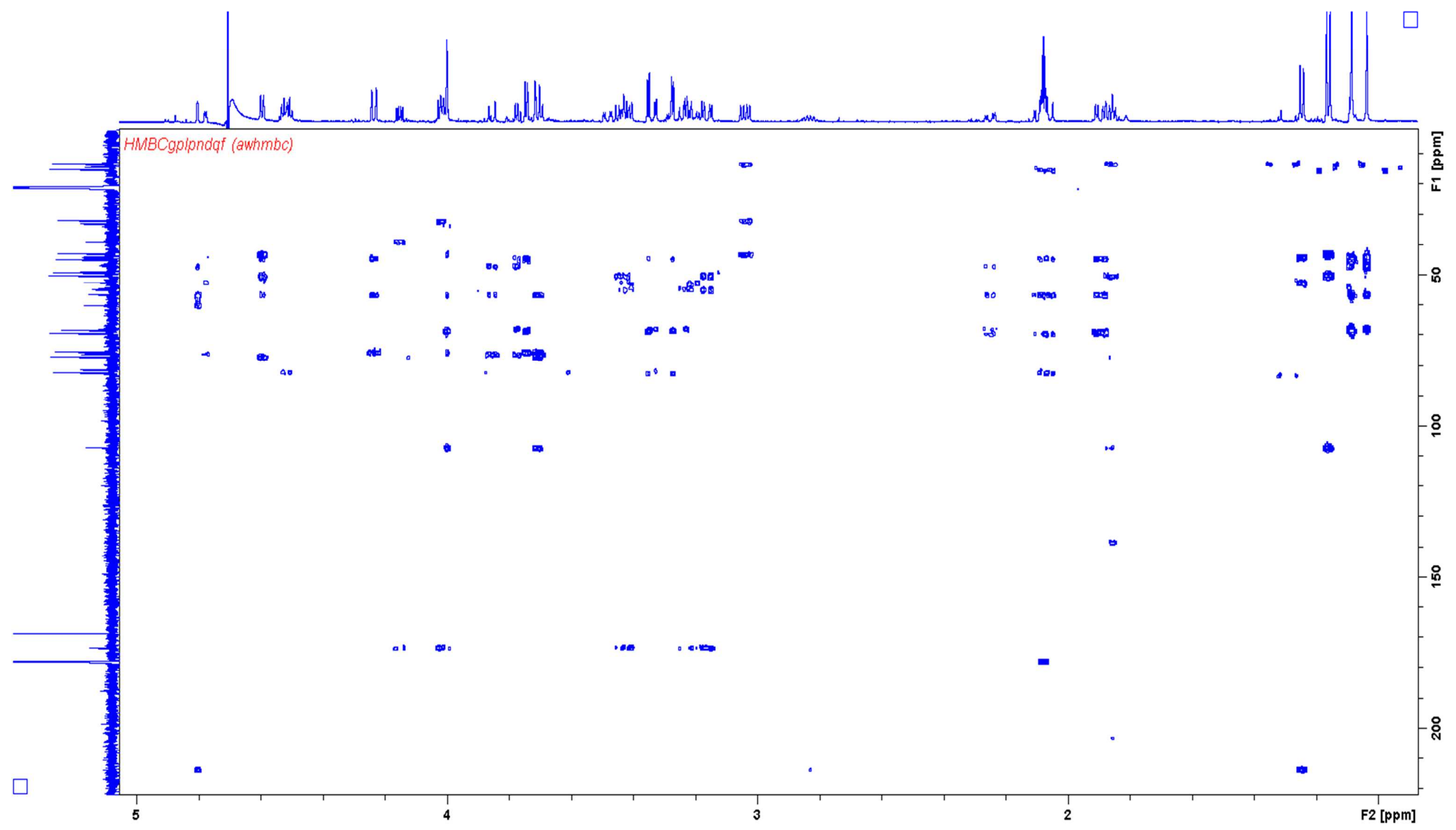

Figure S16. HMBC NMR spectrum of $\mathbf{3}$ (DON-Cys Michael adduct). 
Supporting Information: Stanic et al., Characterization of deoxynivalenol (DON) and cysteine adducts

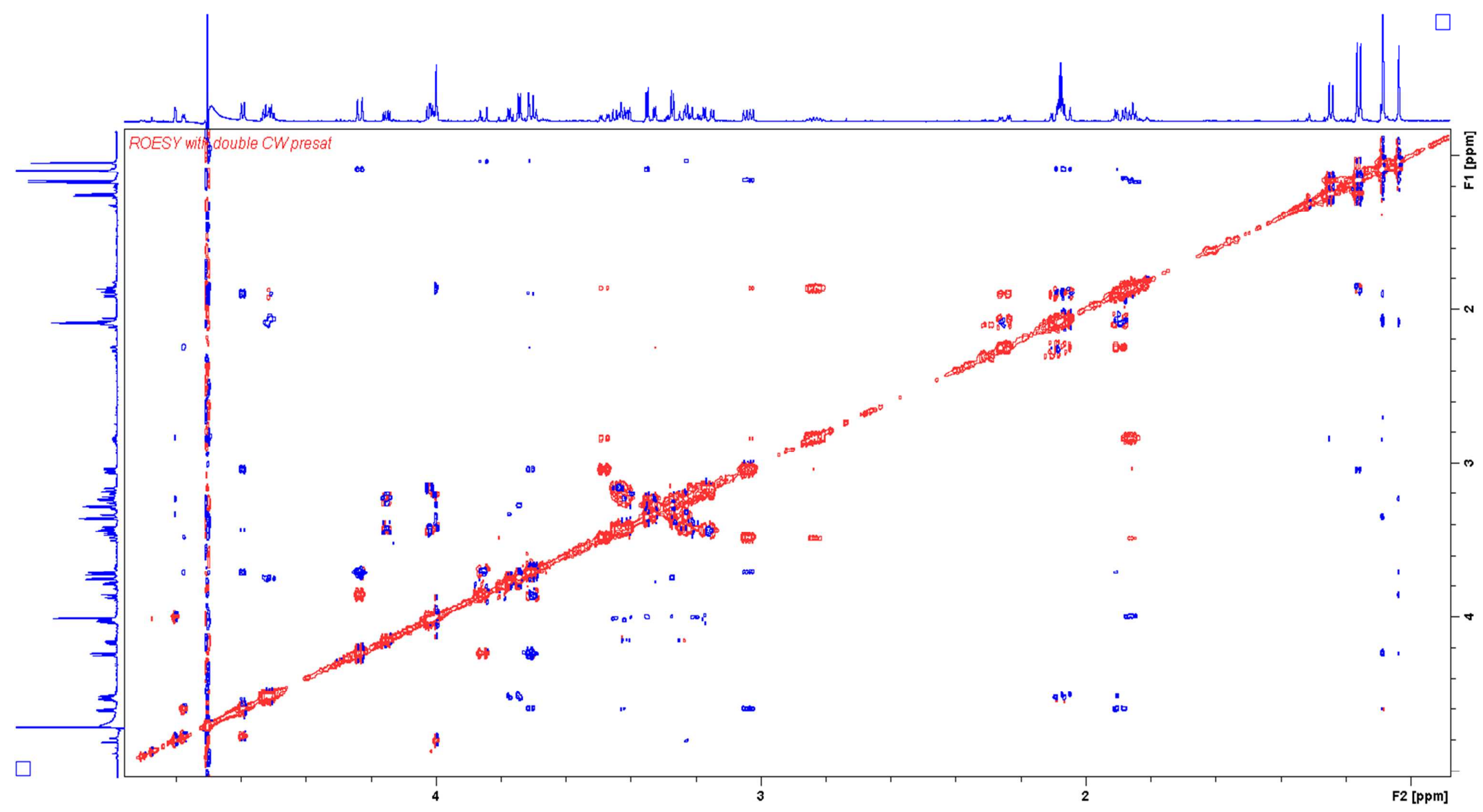

Figure S17. ROESY NMR spectrum of $\mathbf{3}$ (DON-Cys Michael adduct). 
Supporting Information: Stanic et al., Characterization of deoxynivalenol (DON) and cysteine adducts

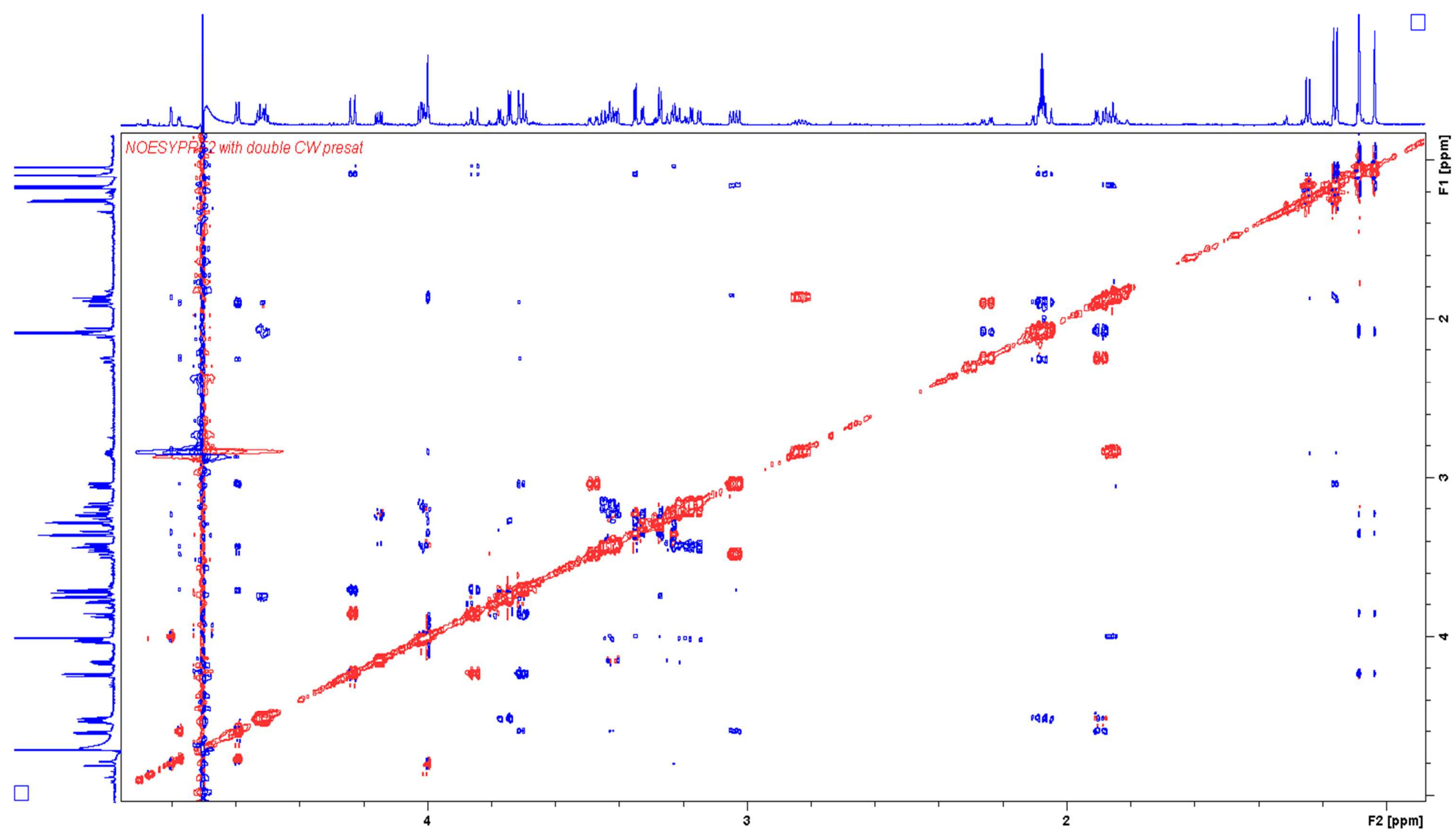

Figure S18. NOESY NMR spectrum of $\mathbf{3}$ (DON-Cys Michael adduct). 
Supporting Information: Stanic et al., Characterization of deoxynivalenol (DON) and cysteine adducts

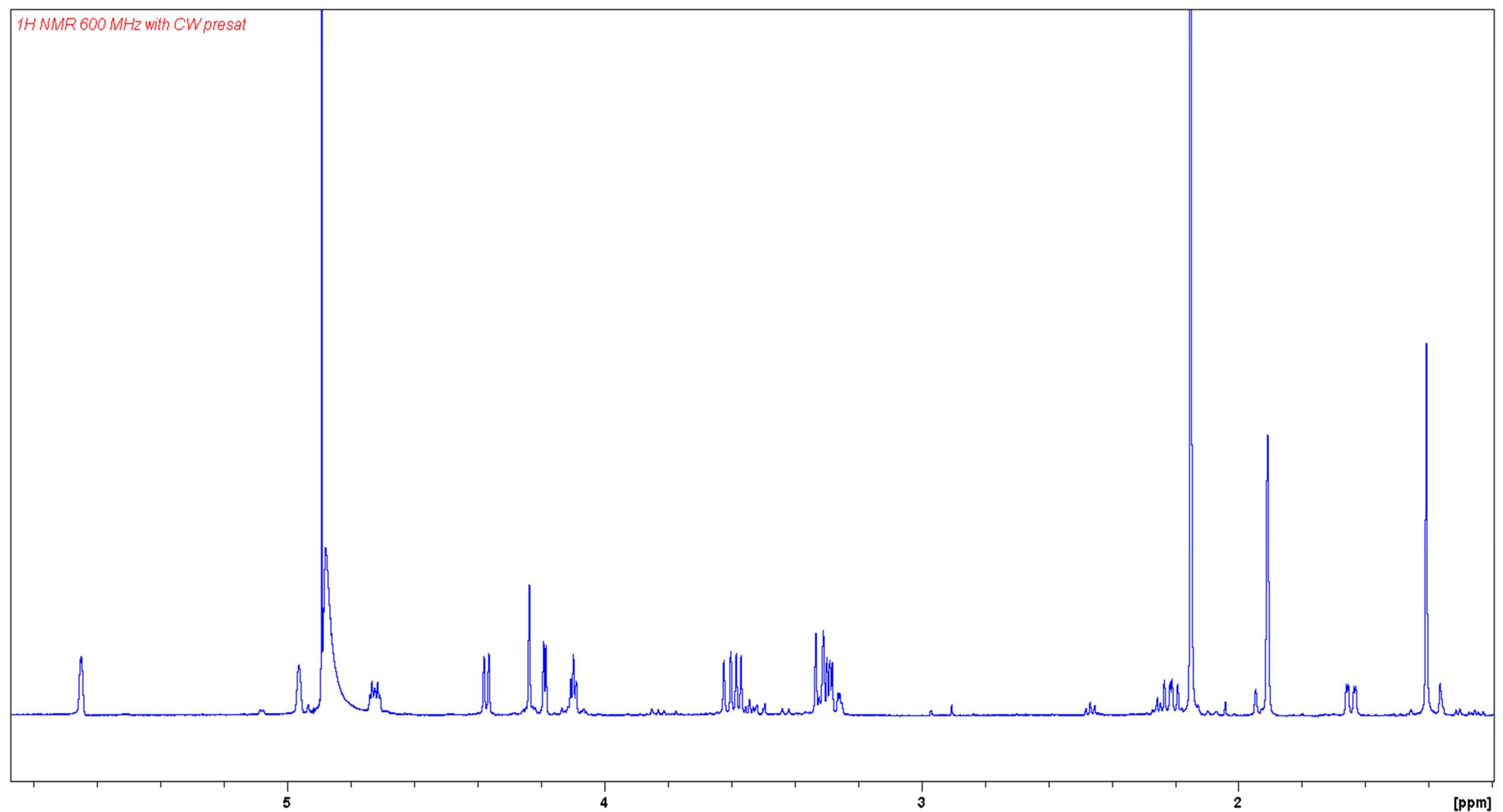

Figure S19. ${ }^{1} \mathrm{H}$ NMR spectrum of 2 (DON-Cys epoxide adduct). 
Supporting Information: Stanic et al., Characterization of deoxynivalenol (DON) and cysteine adducts

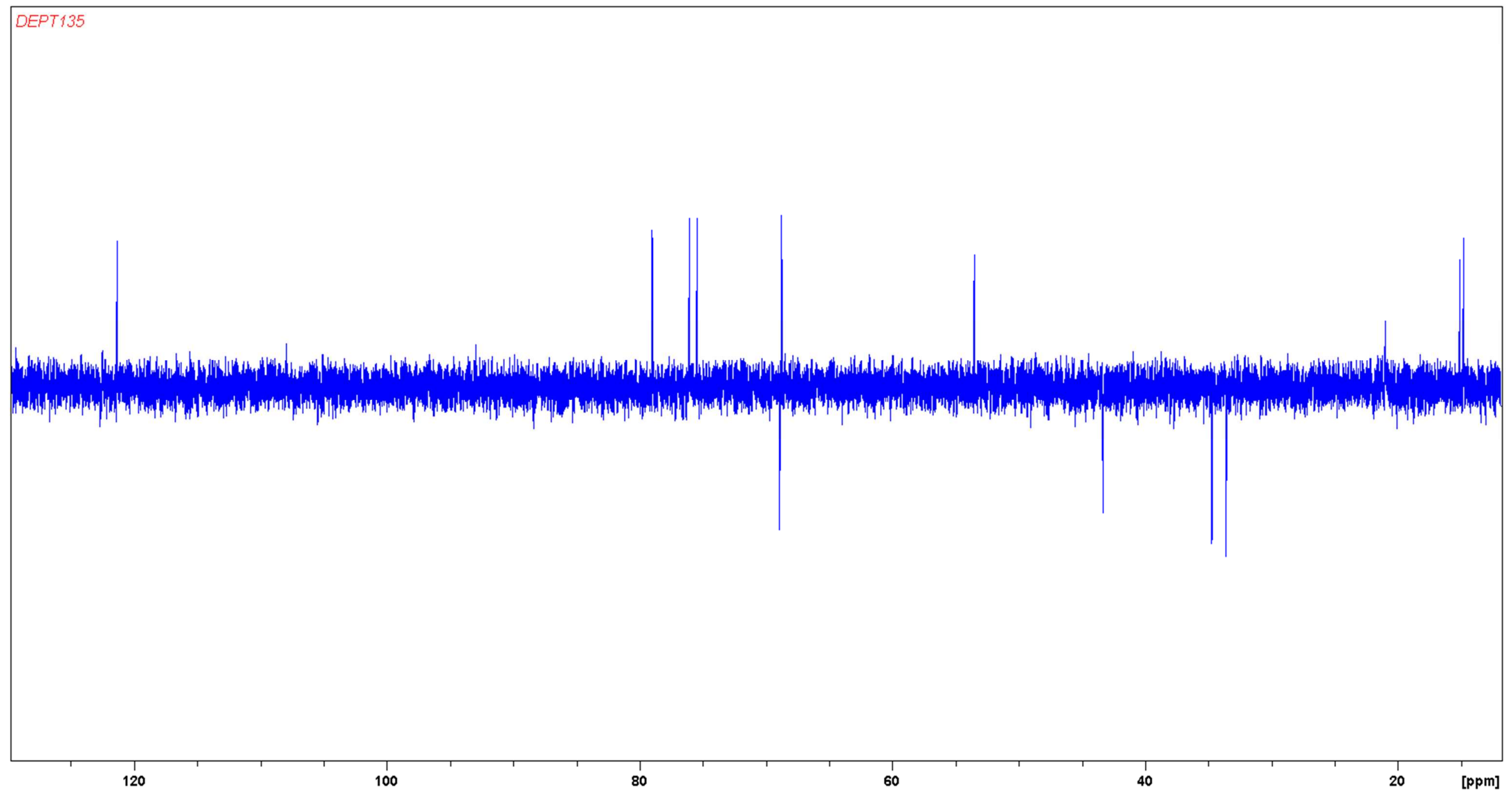

Figure S20. DEPT 135 NMR experiment, carbon spectrum of 2 (DON-Cys epoxide adduct). 
Supporting Information: Stanic et al., Characterization of deoxynivalenol (DON) and cysteine adducts

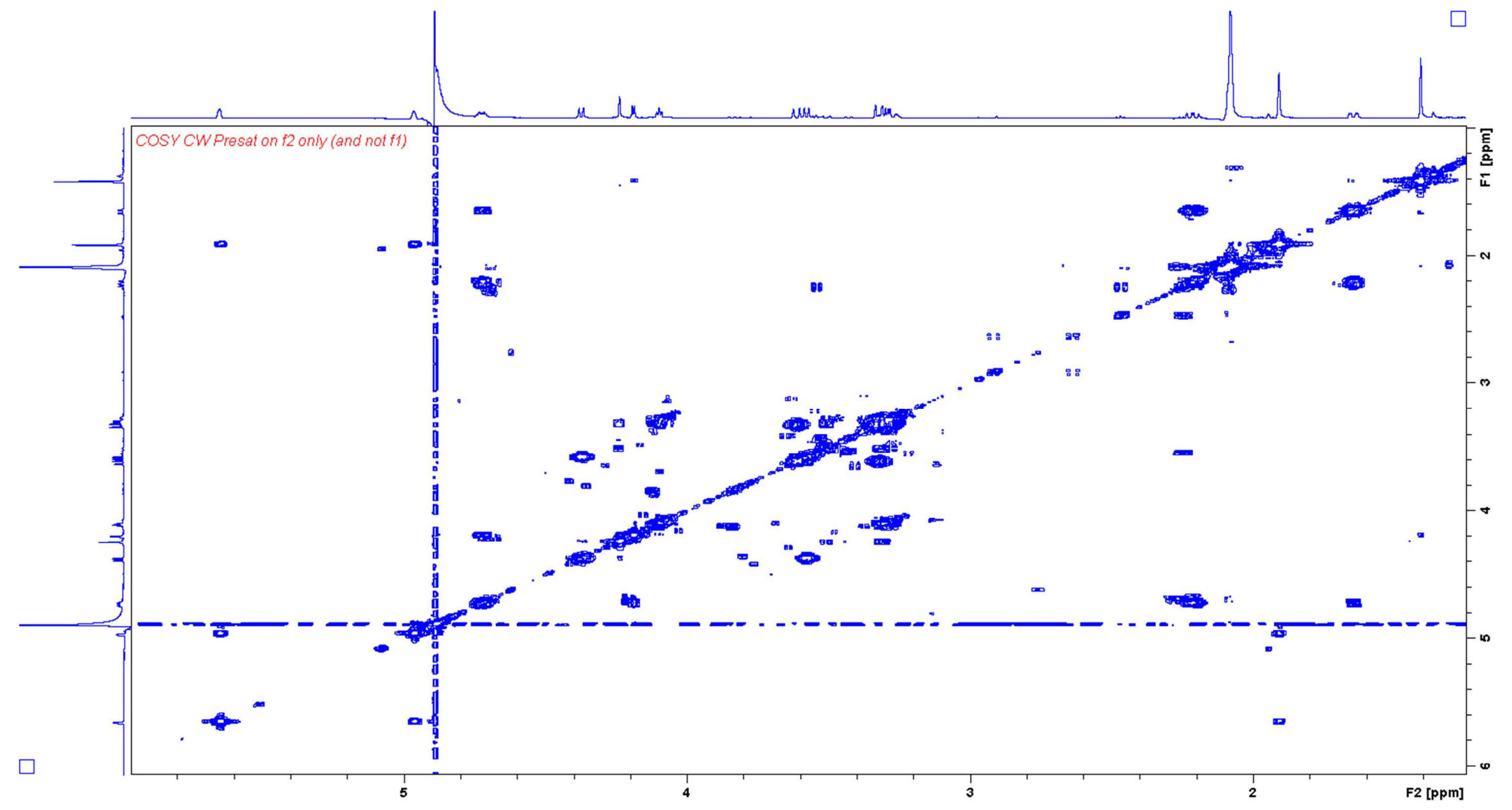

Figure S21. COSY NMR spectrum of 2 (DON-Cys epoxide adduct). 
Supporting Information: Stanic et al., Characterization of deoxynivalenol (DON) and cysteine adducts

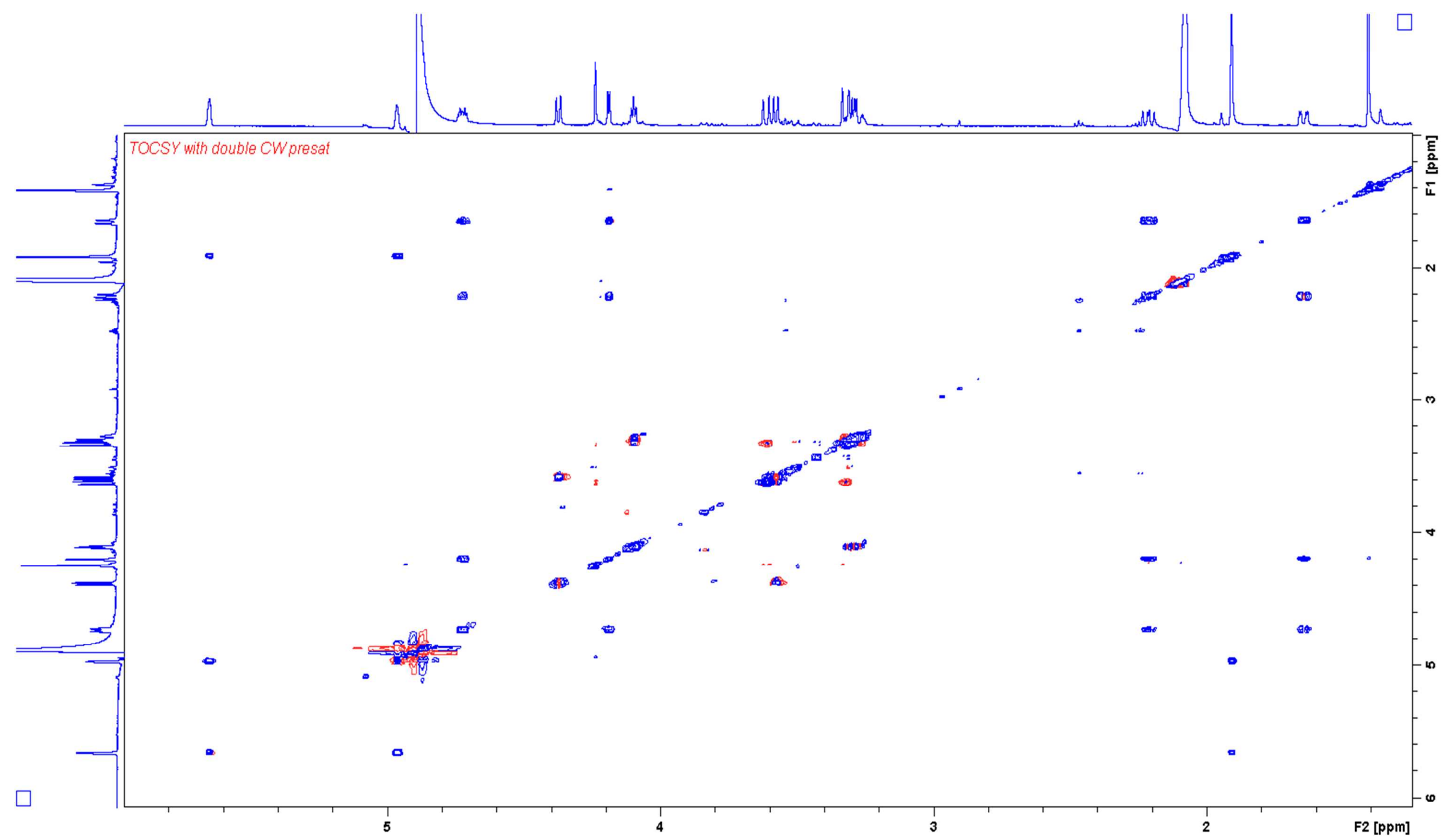

Figure S22. TOCSY NMR spectrum of 2 (DON-Cys epoxide adduct). 
Supporting Information: Stanic et al., Characterization of deoxynivalenol (DON) and cysteine adducts

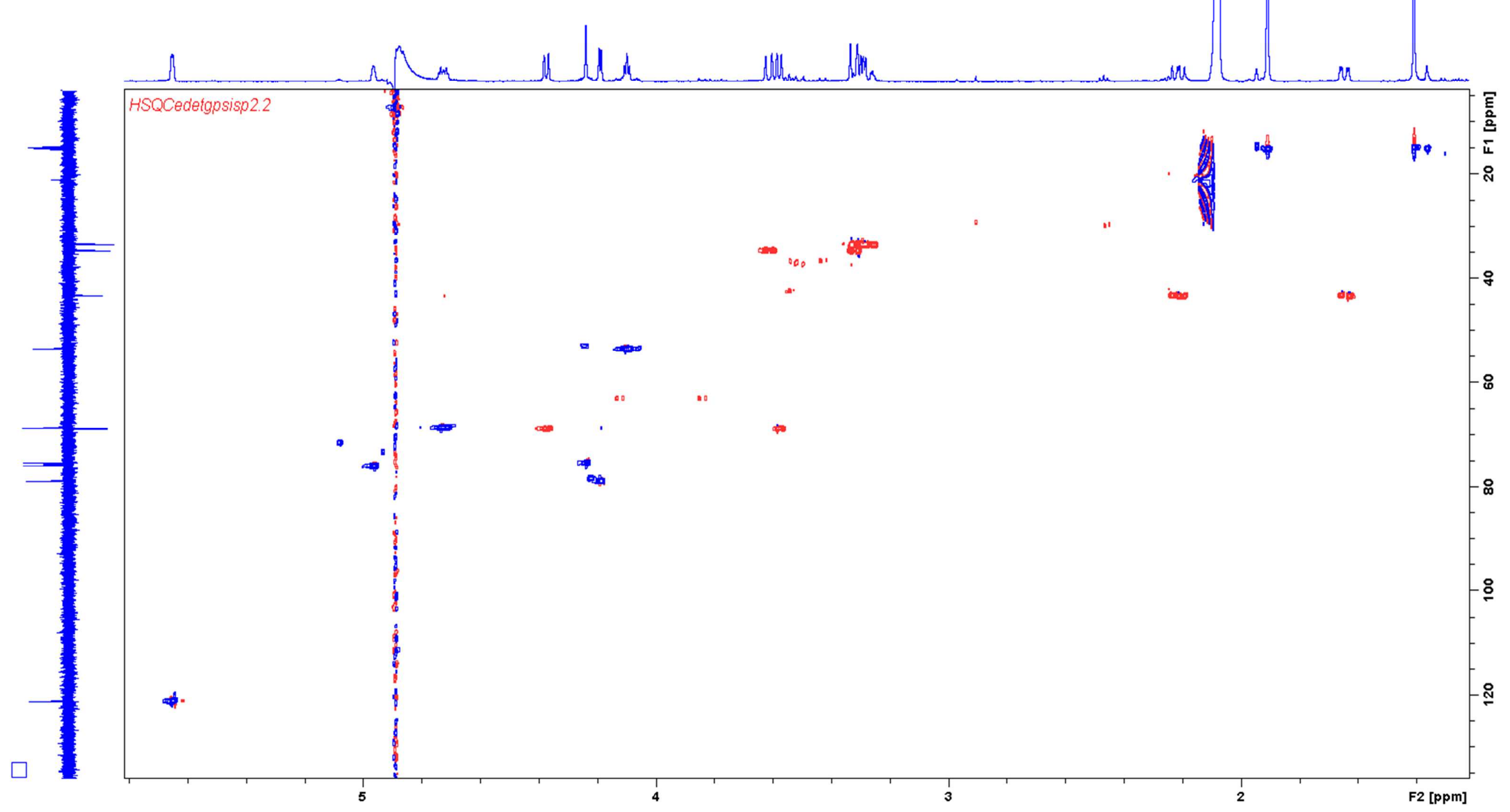

Figure S23. HSQC NMR spectrum of $\mathbf{2}$ (DON-Cys epoxide adduct). 
Supporting Information: Stanic et al., Characterization of deoxynivalenol (DON) and cysteine adducts

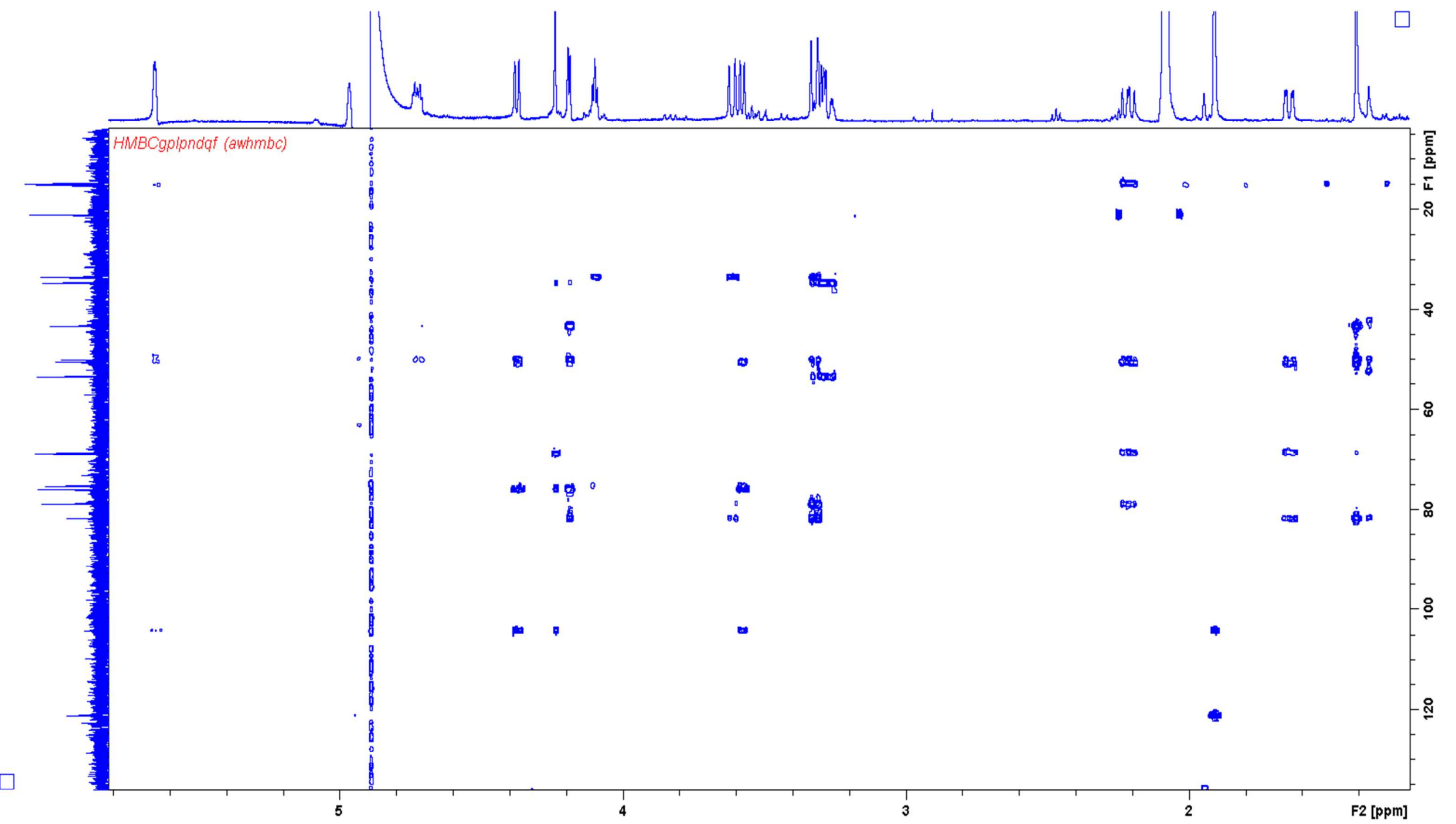

Figure S24. HMBC NMR spectrum of 2 (DON-Cys epoxide adduct). 
Supporting Information: Stanic et al., Characterization of deoxynivalenol (DON) and cysteine adducts

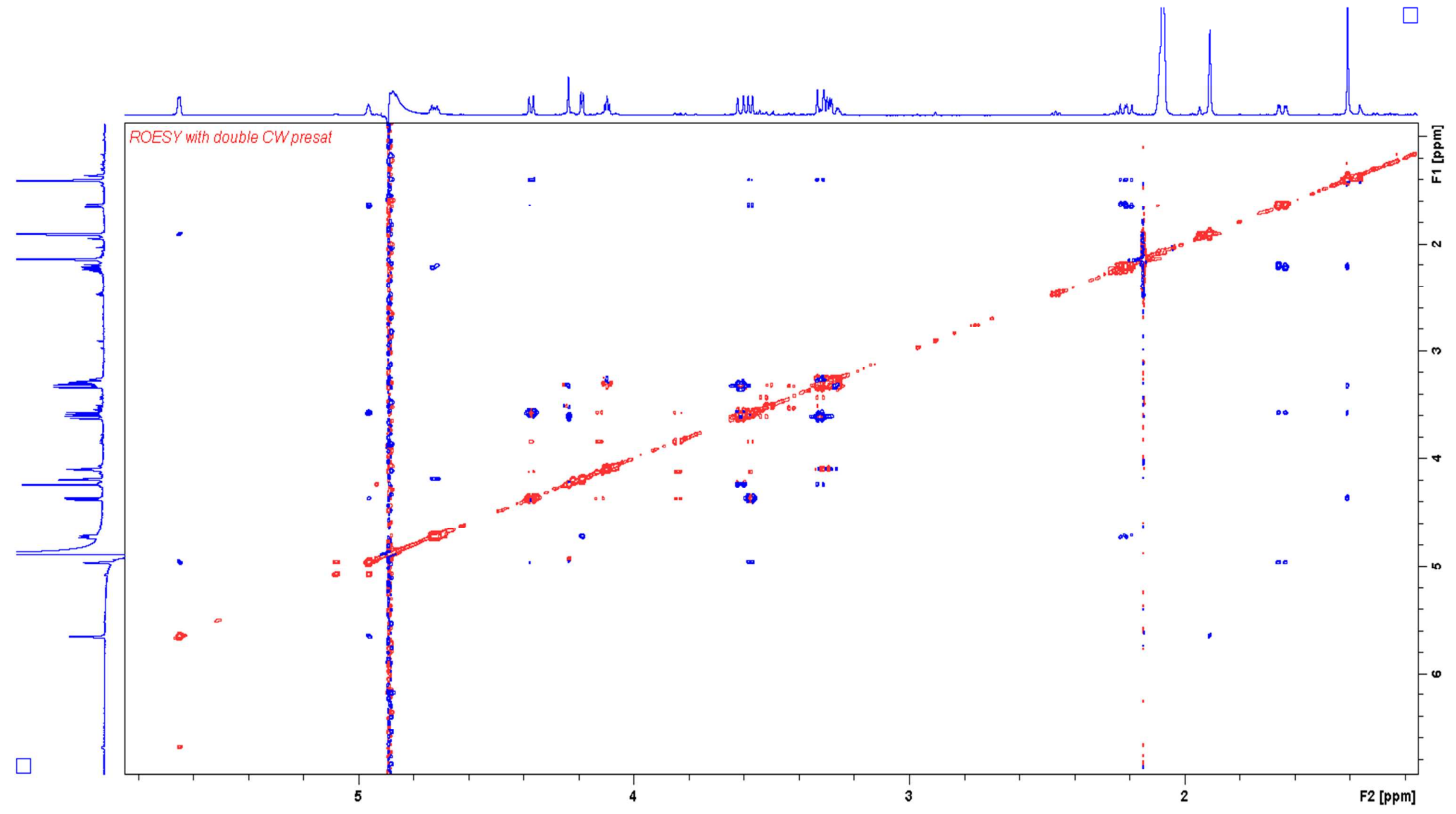

Figure S25. ROESY NMR spectrum of 2 (DON-Cys epoxide adduct). 
Supporting Information: Stanic et al., Characterization of deoxynivalenol (DON) and cysteine adducts

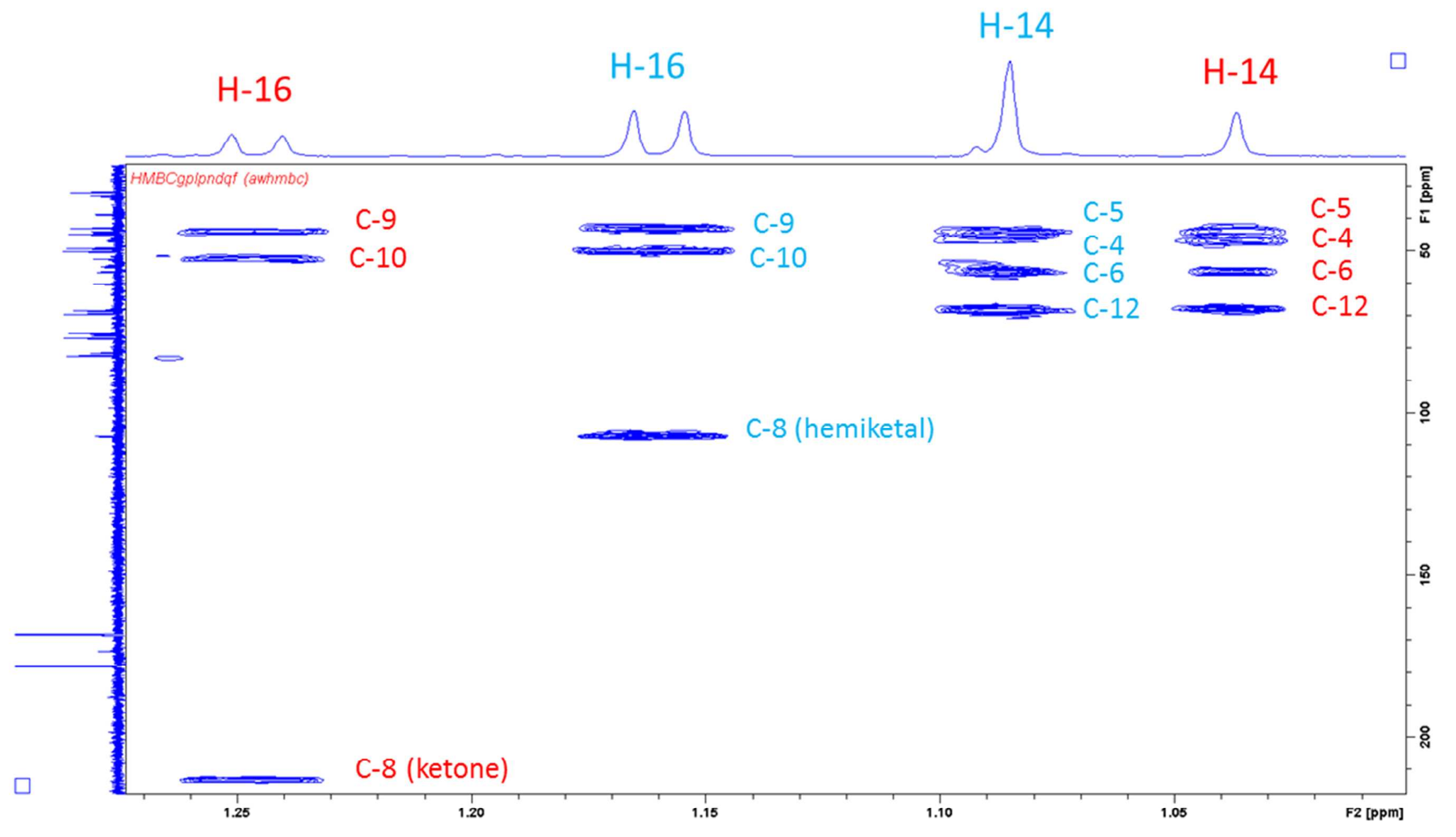

Figure S26. Selected area of HMBC spectrum of 3 showing correlations between H-16 to hemiketal or ketone (C-8) carbon. Red and blue colors are used to help distinguish between minor and major isomer, respectively. 
Supporting Information: Stanic et al., Characterization of deoxynivalenol (DON) and cysteine adducts

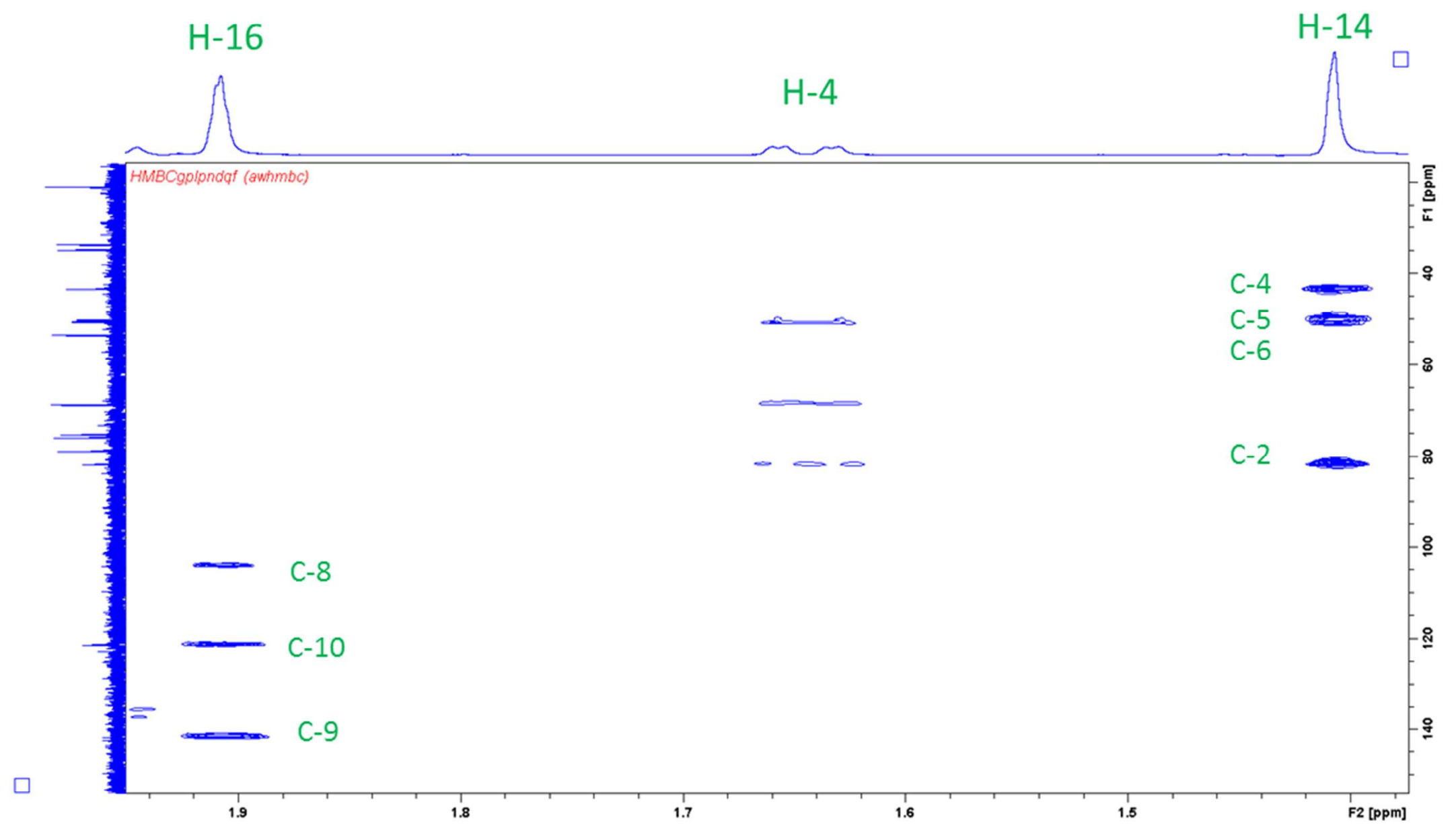

Figure S27. Selected HMBC area of $\mathbf{2}$ (DON-Cys epoxide adduct). Presence of the more downfield chemical shift of H-16 methyl group is the first indicator that the double bond is preserved. 
Supporting Information: Stanic et al., Characterization of deoxynivalenol (DON) and cysteine adducts

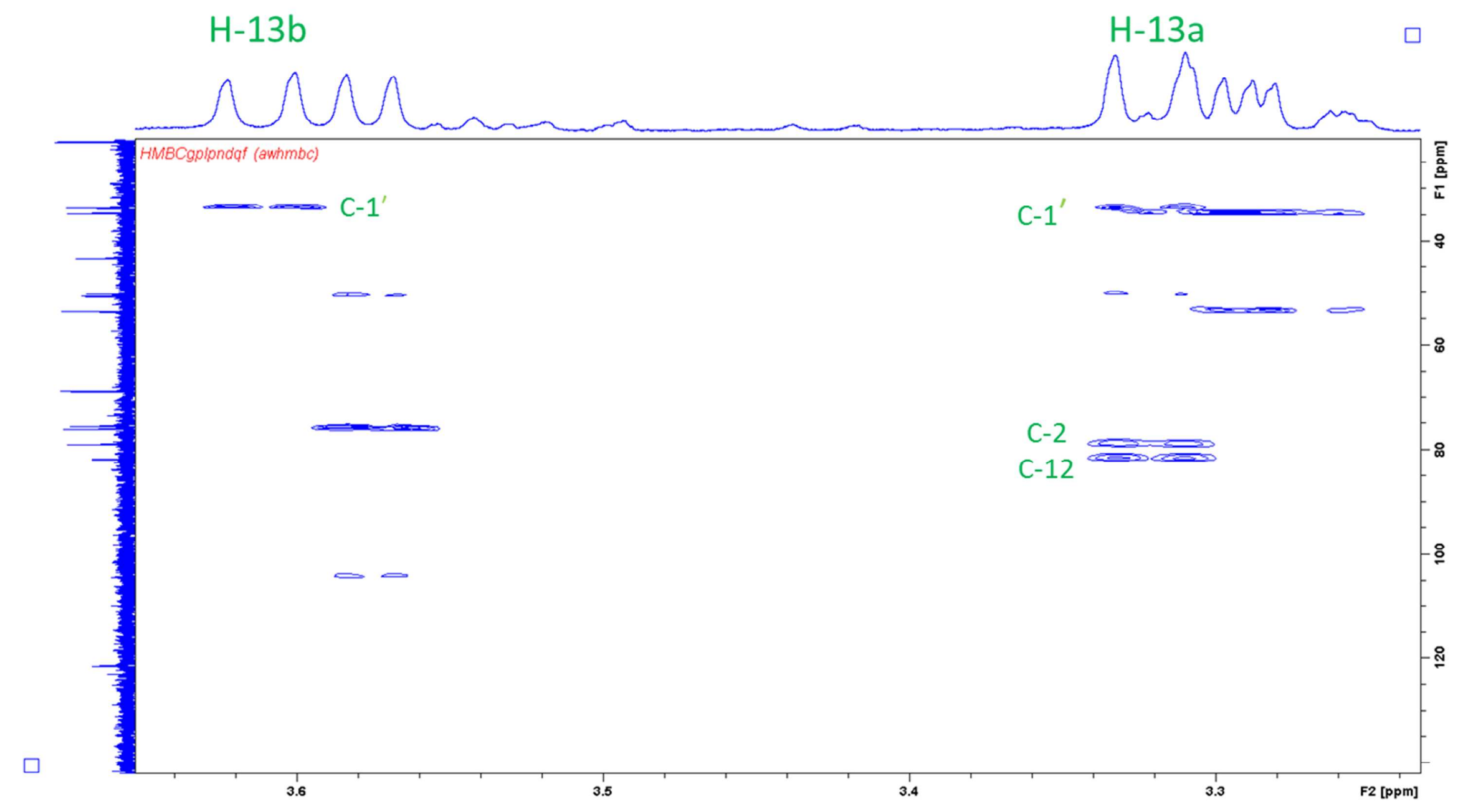

Figure S28. Selected HMBC area of 2 (DON-Cys epoxide adduct) showing correlations between H-13 protons and attached cysteine, C-1' carbon. 


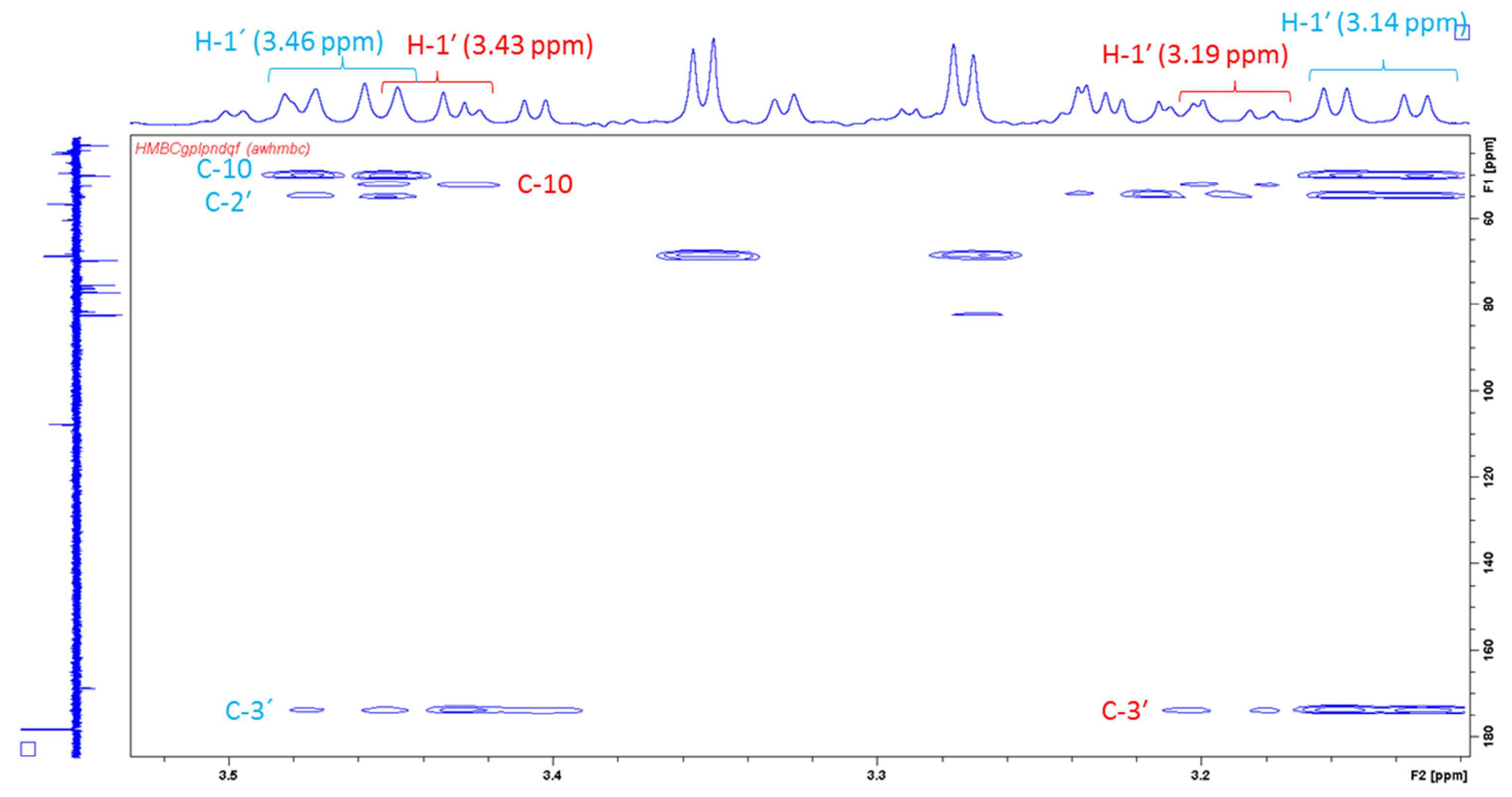

Figure S29. Selected HMBC area of $\mathbf{3}$ (DON-Cys Michael adduct) showing correlations between attached cysteine C-1' atom to C-10 atom of DON and to carboxylic atom C-3', and C-2'. Red and blue colors are used to help distinguish between minor and major isomer, respectively. 
Supporting Information: Stanic et al., Characterization of deoxynivalenol (DON) and cysteine adducts

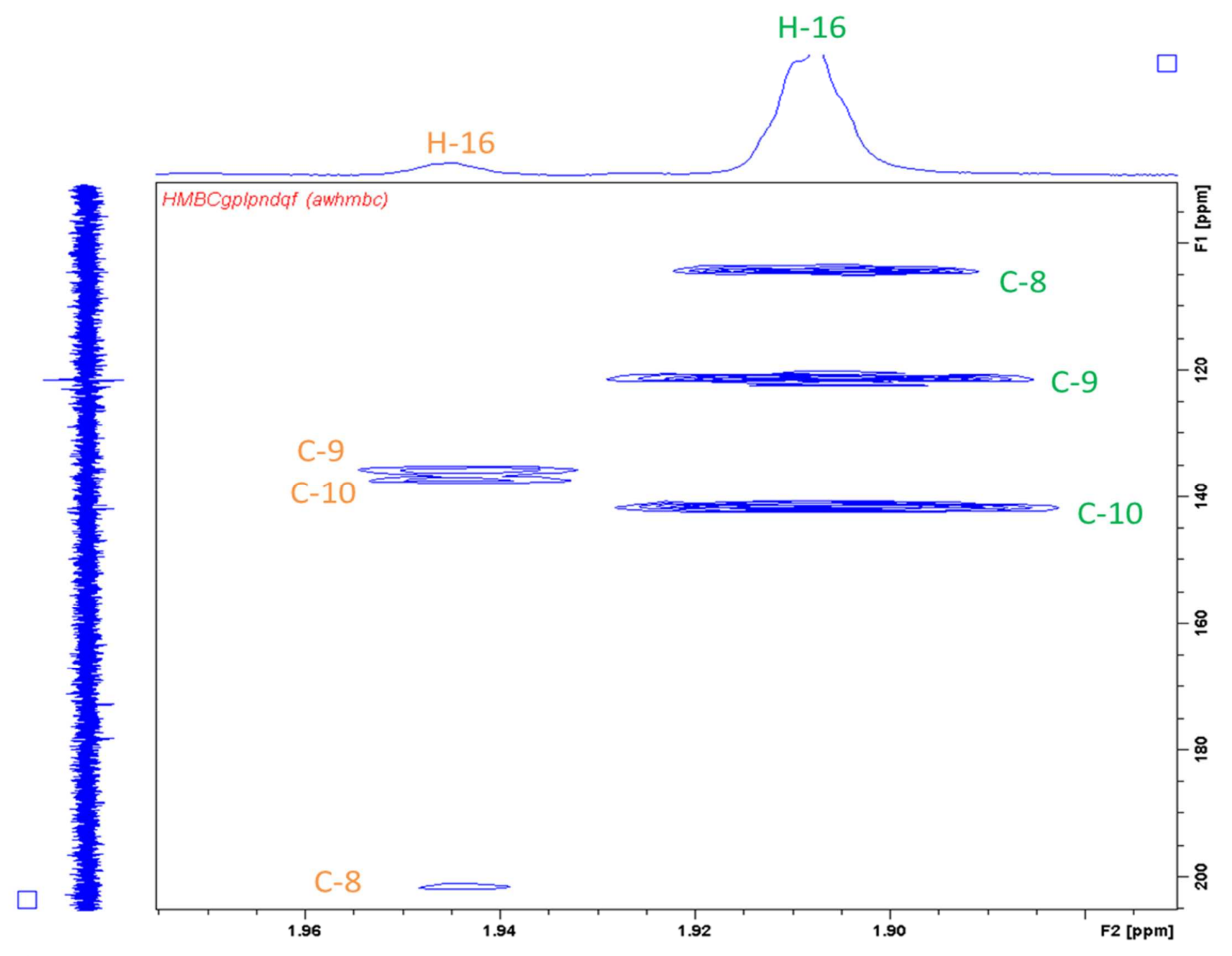

Figure S30. Selected HMBC area of 2 (DON-Cys epoxide adduct) showing correlations from H-16 of a major isomer (green) to a hemiketal carbon C8 (104.2 ppm) and minor isomer (orange) to ketone carbon C-8 (201.4 ppm). 


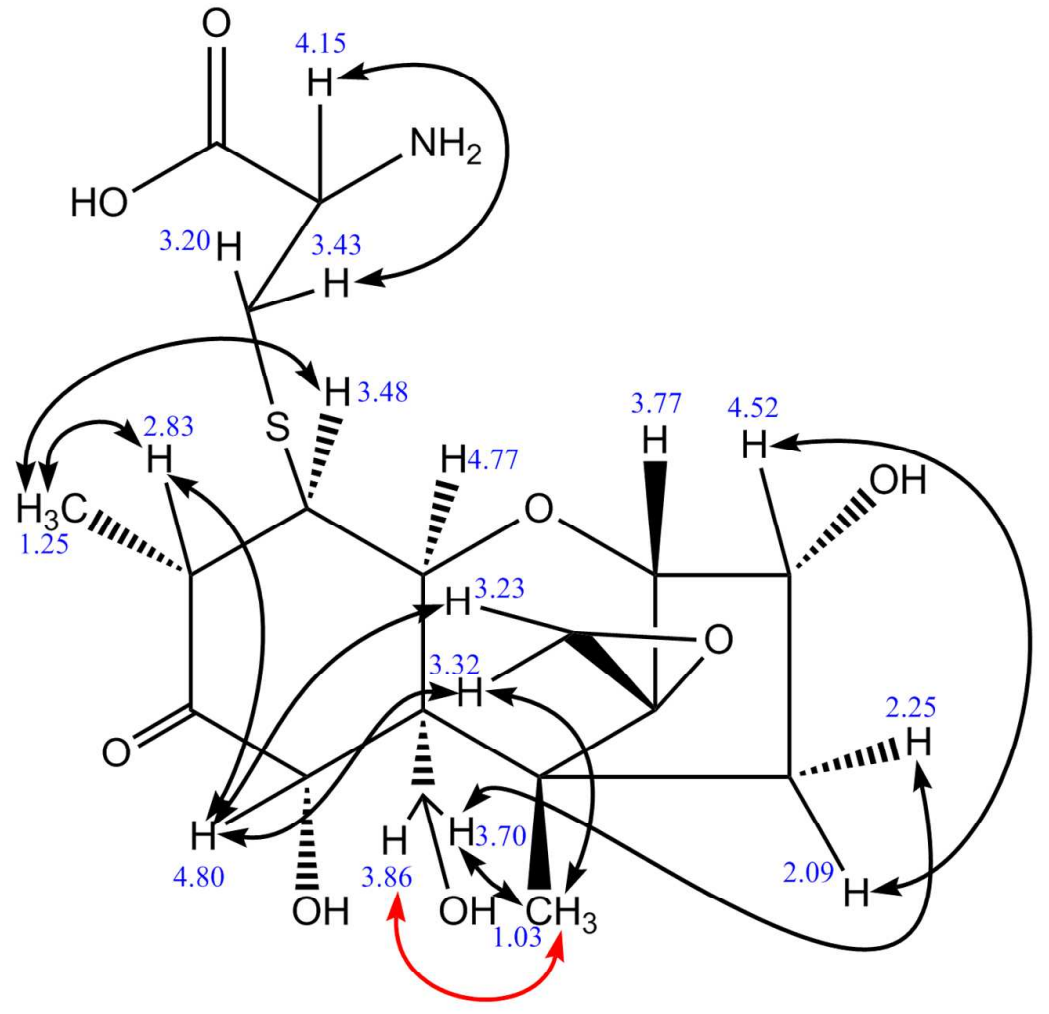

$3 \mathrm{a}$

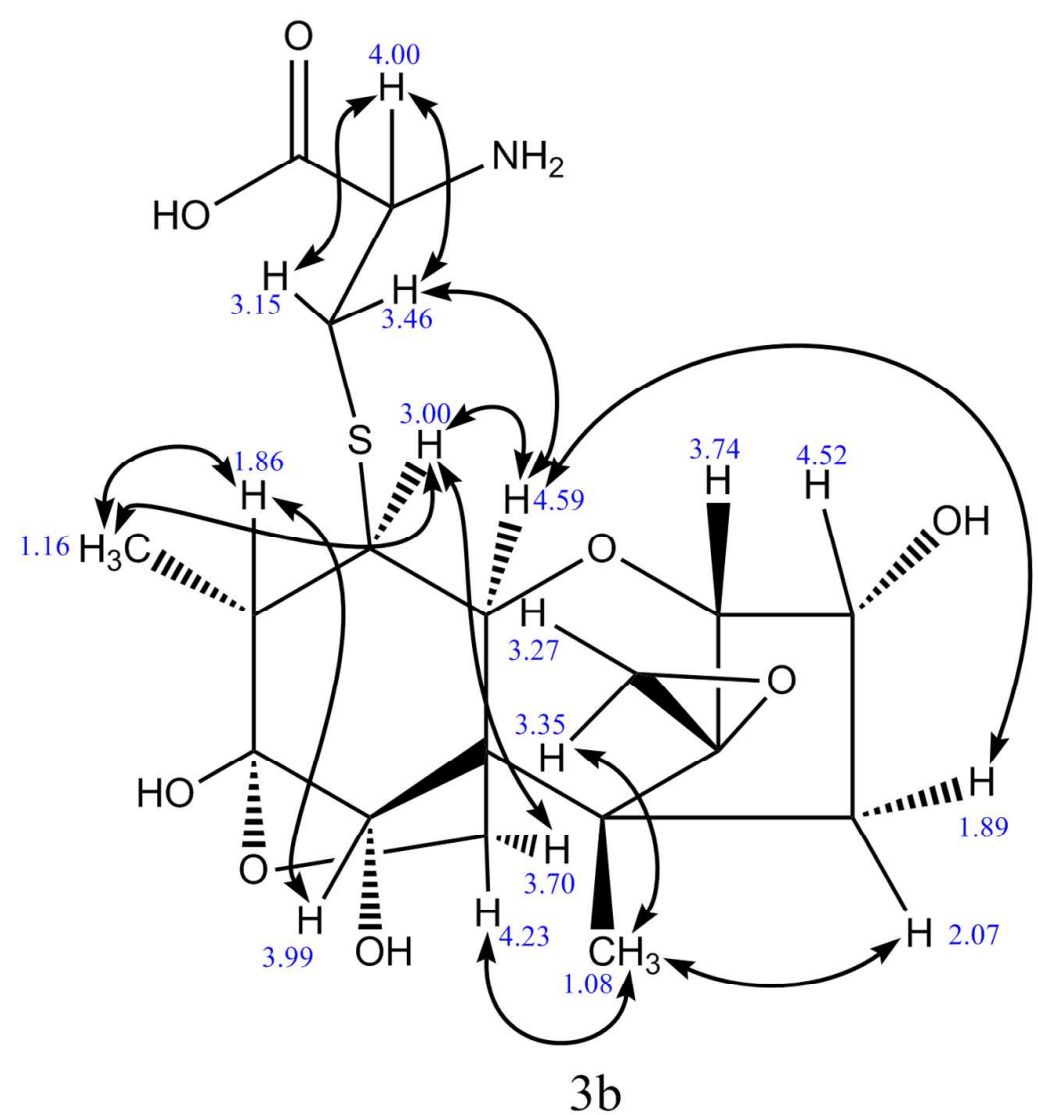

Figure S31. Selected NOE correlations of 3a and 3b (DON-Cys Michael conjugate). Where methylene protons show NOE correlations to the same proton, the red colored arrow denotes the stronger of the two correlations. 


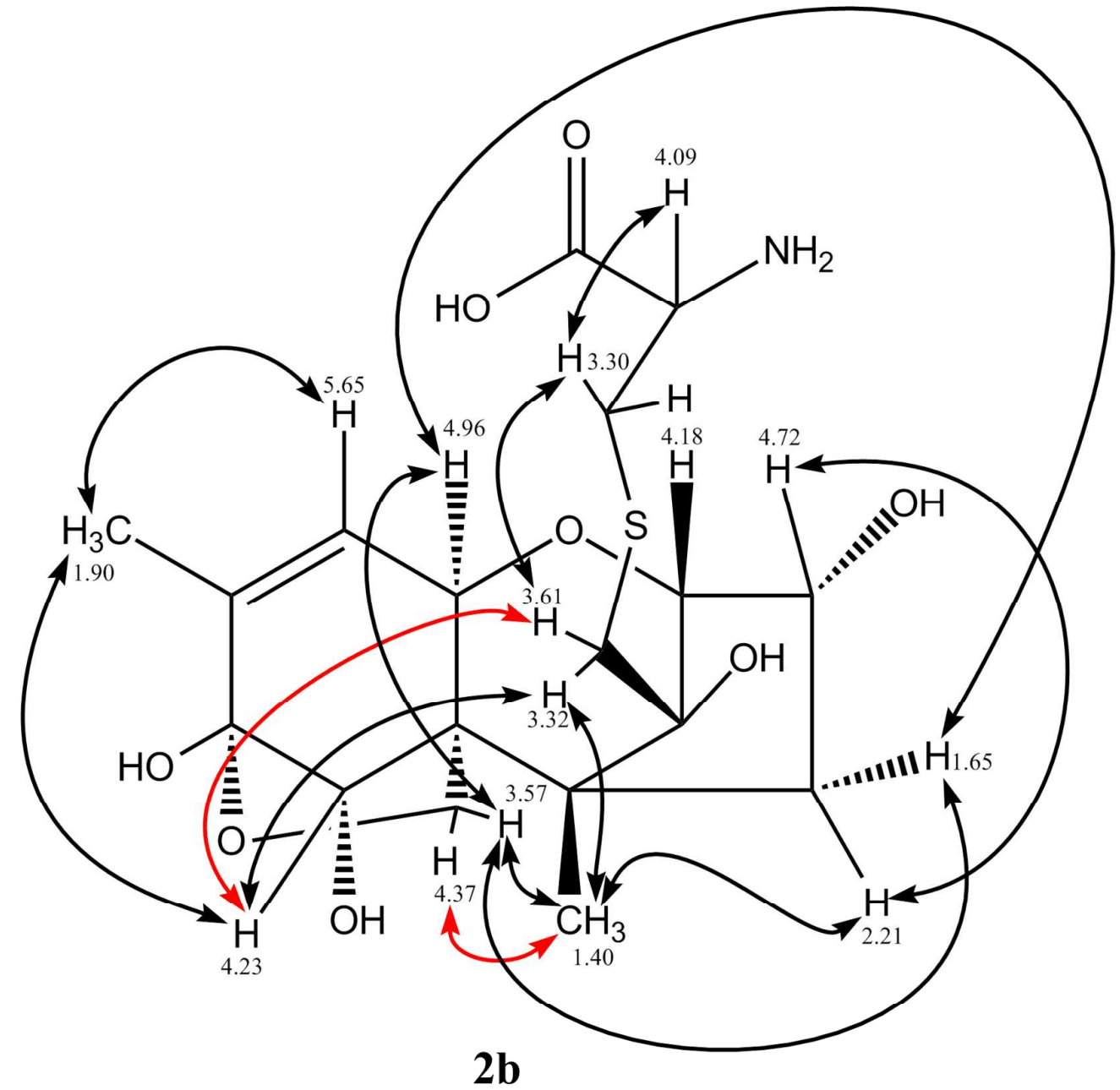

Figure S32. Selected NOE correlations of $\mathbf{2 b}$ (DON-Cys epoxide adduct). Where methylene protons show NOE correlations to the same proton, the red colored arrow denotes the stronger of the two correlations. 


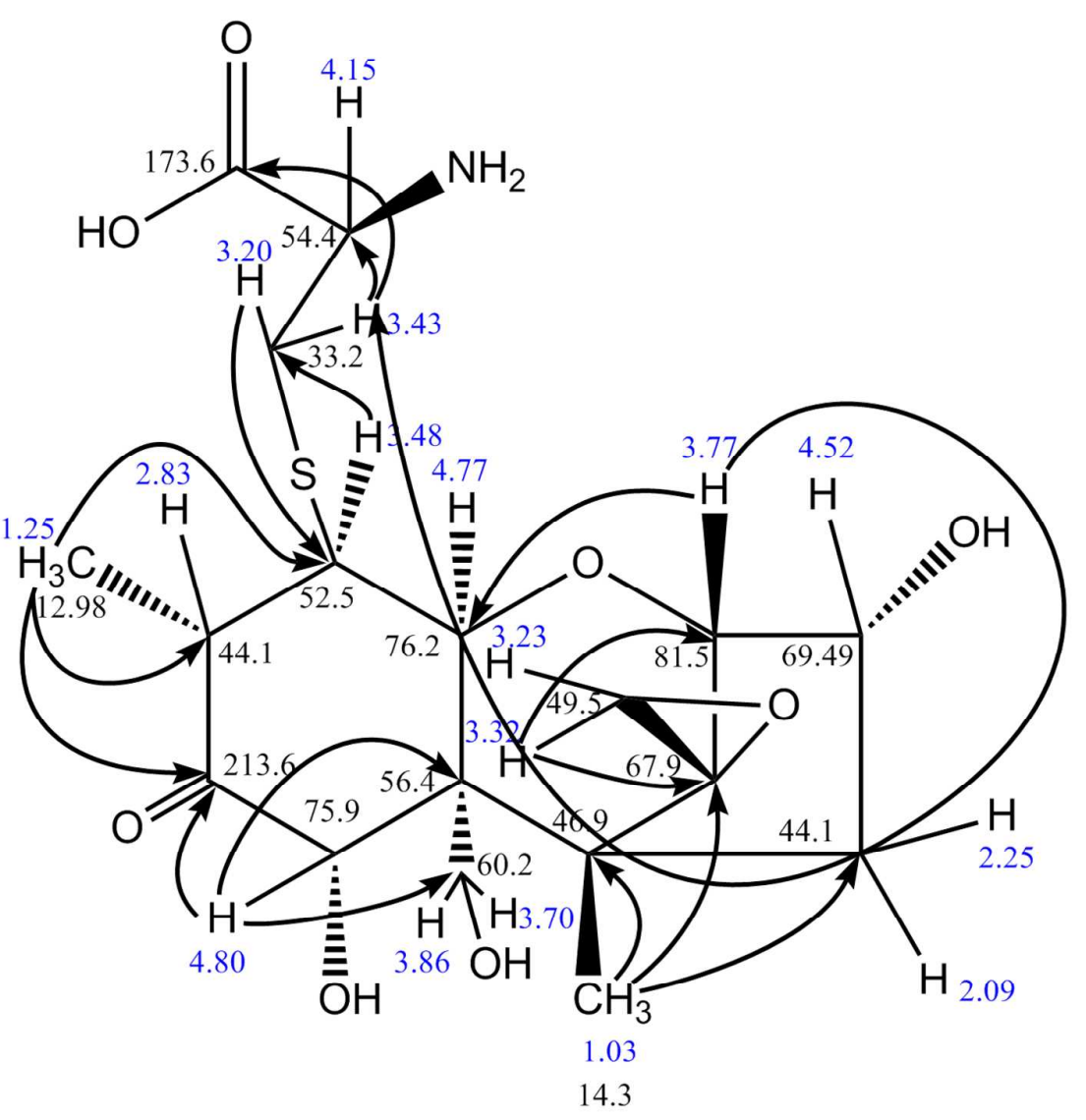

$3 a$

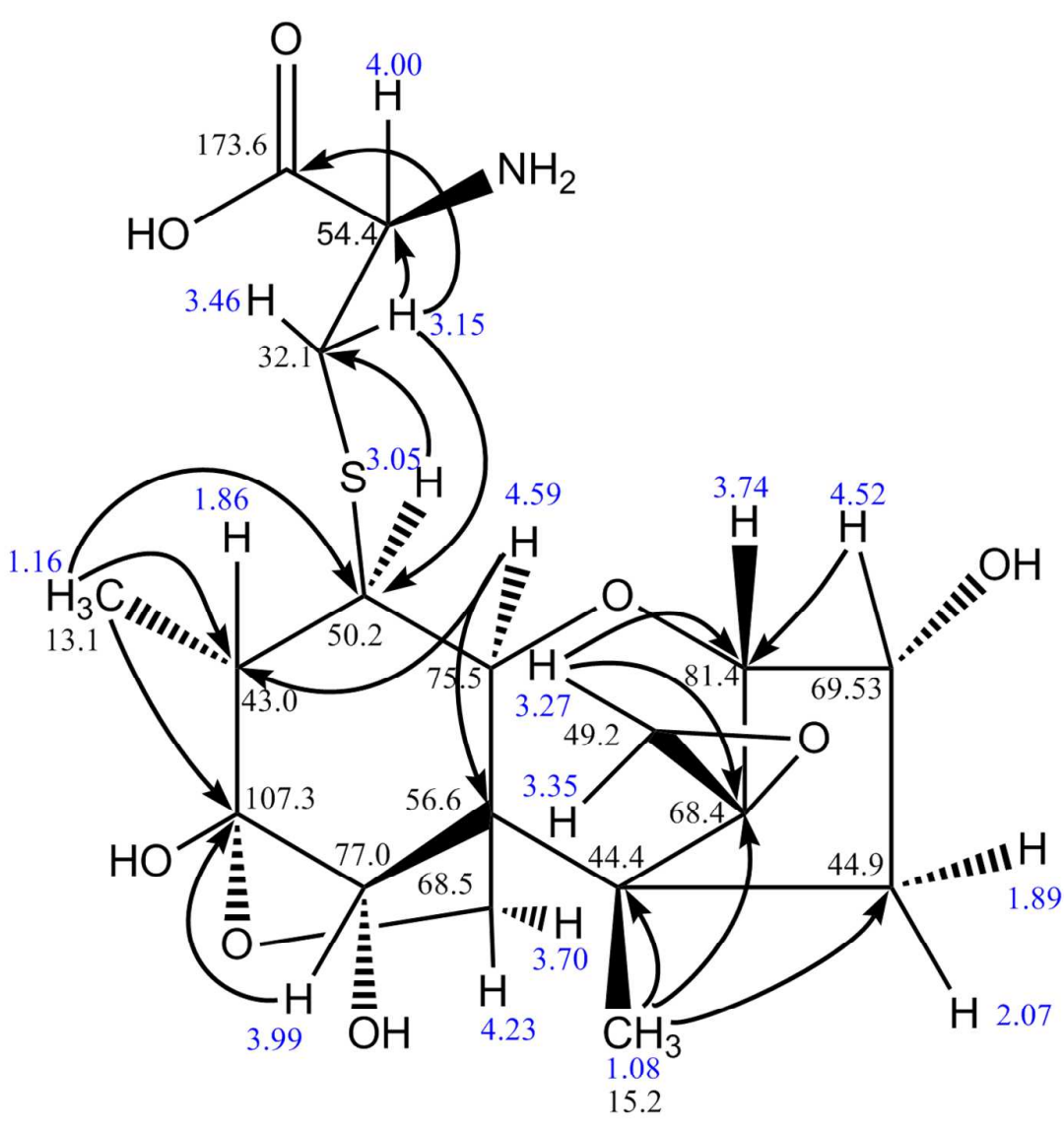

$3 b$

Figure S33. Selected HMBC correlations of 3a and 3b (DON-Cys Michael conjugates). 


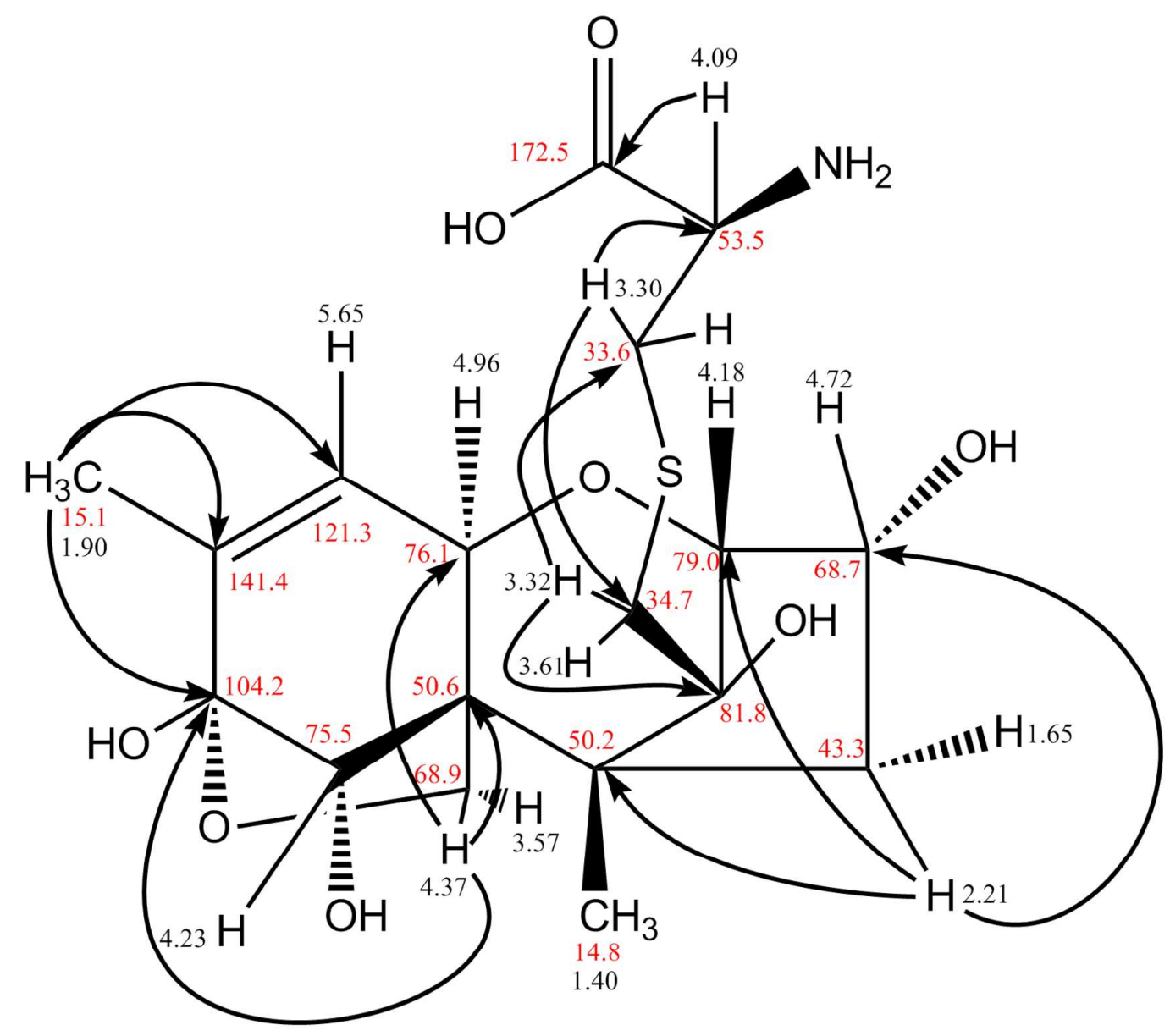

2b

Figure S34. Selected HMBC correlations of $\mathbf{2 b}$ (DON-Cys epoxide adduct). 
Supporting Information: Stanic et al., Characterization of deoxynivalenol (DON) and cysteine adducts

Table S1. HRMS data for DON (1), DON-Cys adducts (2-4), DON-(Cys) $)_{2}$ (7-10), 2-sulfoxide and 3-sulfoxide

\begin{tabular}{|c|c|c|c|c|c|c|c|}
\hline COMPOUND & ION & $\begin{array}{l}\text { ELEMENTAL } \\
\text { COMPOSITION }\end{array}$ & $\begin{array}{l}\text { ACCURATE } \\
\text { (measured) } m / z\end{array}$ & DBE & $\begin{array}{c}\text { EXACT } \\
\text { (theoretical) } \\
\text { MASS }\end{array}$ & $\begin{array}{c}\text { ERROR } \\
(\mathrm{ppm})\end{array}$ & $\begin{array}{c}\text { RETENTION } \\
\text { TIME (min) }\end{array}$ \\
\hline $\mathbf{1}^{a}$ & {$[\mathrm{M}+\mathrm{HCOO}]^{-}$} & $\mathrm{C}_{16} \mathrm{H}_{21} \mathrm{O}_{8}^{-}$ & 341.1244 & 6.5 & 341.1242 & 0.5 & 13.50 \\
\hline \multirow{4}{*}{$\mathbf{2}^{a}$} & {$[\mathrm{M}+\mathrm{H}]^{+}$} & $\mathrm{C}_{18} \mathrm{H}_{28} \mathrm{O}_{8} \mathrm{NS}^{+}$ & 418.1532 & 5.5 & 418.1530 & 0.4 & 6.50 \\
\hline & {$[\mathrm{M}+\mathrm{H}+\mathrm{Na}]^{+}$} & $\mathrm{C}_{18} \mathrm{H}_{27} \mathrm{O}_{8} \mathrm{NNaS}^{+}$ & 440.1350 & 5.5 & 440.1350 & 0.0 & 6.50 \\
\hline & {$[\mathrm{M}+\mathrm{H}+\mathrm{K}]^{+}$} & $\mathrm{C}_{18} \mathrm{H}_{27} \mathrm{O}_{8} \mathrm{NKS}^{+}$ & 456.1089 & 5.5 & 456.1089 & -0.1 & 6.50 \\
\hline & {$[\mathrm{M}-\mathrm{H}]^{-}$} & $\mathrm{C}_{18} \mathrm{H}_{26} \mathrm{O}_{8} \mathrm{NS}^{--}$ & 416.1388 & 6.5 & 416.1385 & 0.8 & 6.48 \\
\hline \multirow{4}{*}{$3^{a}$} & {$[\mathrm{M}+\mathrm{H}]^{+}$} & $\mathrm{C}_{18} \mathrm{H}_{28} \mathrm{O}_{8} \mathrm{NS}^{+}$ & 418.1529 & 5.5 & 418.1530 & 0.4 & 10.55 \\
\hline & {$[\mathrm{M}+\mathrm{Na}]^{+}$} & $\mathrm{C}_{18} \mathrm{H}_{27} \mathrm{O}_{8} \mathrm{NNaS}^{+}$ & 440.1346 & 5.5 & 440.1350 & -0.8 & 10.55 \\
\hline & {$[\mathrm{M}+2 \mathrm{Na}]^{+}$} & $\mathrm{C}_{18} \mathrm{H}_{26} \mathrm{O}_{8} \mathrm{NNa}_{2} \mathrm{~S}^{+}$ & 462.1163 & 5.5 & 462.1169 & -1.2 & 10.55 \\
\hline & {$[\mathrm{M}+\mathrm{H}]^{-}$} & $\mathrm{C}_{18} \mathrm{H}_{26} \mathrm{O}_{8} \mathrm{NS}^{-}$ & 416.1389 & 6.5 & 416.1385 & 1.1 & 10.54 \\
\hline \multirow{2}{*}{4} & {$[\mathrm{M}+\mathrm{H}]^{+}$} & $\mathrm{C}_{18} \mathrm{H}_{28} \mathrm{O}_{8} \mathrm{NS}^{+}$ & 418.1530 & 5.5 & 418.1530 & -0.1 & 9.45 \\
\hline & {$[\mathrm{M}+\mathrm{H}]^{-}$} & $\mathrm{C}_{18} \mathrm{H}_{26} \mathrm{O}_{8} \mathrm{NS}^{-}$ & 416.1393 & 6.5 & 416.1385 & 1.9 & 9.45 \\
\hline \multirow{3}{*}{7} & {$[\mathrm{M}+\mathrm{H}]^{+}$} & $\mathrm{C}_{21} \mathrm{H}_{35} \mathrm{O}_{10} \mathrm{~N}_{2} \mathrm{~S}_{2}^{+}$ & 539.1729 & 5.5 & 539.1728 & 0.2 & 4.18 \\
\hline & {$[\mathrm{M}+\mathrm{Na}]^{+}$} & $\mathrm{C}_{21} \mathrm{H}_{34} \mathrm{O}_{13} \mathrm{~N}_{2} \mathrm{NaS}_{2}^{+}$ & 561.1543 & 5.5 & 561.1547 & -0.6 & 4.18 \\
\hline & {$[\mathrm{M}+\mathrm{H}]^{-}$} & $\mathrm{C}_{21} \mathrm{H}_{33} \mathrm{O}_{10} \mathrm{~N}_{2} \mathrm{~S}_{2}^{--}$ & 537.1587 & 6.5 & 537.1582 & 0.9 & 4.19 \\
\hline \multirow{2}{*}{8} & {$[\mathrm{M}+\mathrm{H}]^{+}$} & $\mathrm{C}_{21} \mathrm{H}_{35} \mathrm{O}_{10} \mathrm{~N}_{2} \mathrm{~S}_{2}{ }^{+}$ & 539.1729 & 5.5 & 539.1728 & 0.2 & 4.62 \\
\hline & {$[\mathrm{M}+\mathrm{H}]^{-}$} & $\mathrm{C}_{21} \mathrm{H}_{33} \mathrm{O}_{10} \mathrm{~N}_{2} \mathrm{~S}_{2}^{-}$ & 537.1587 & 6.5 & 537.1582 & 0.9 & 4.64 \\
\hline \multirow{2}{*}{9} & {$[\mathrm{M}+\mathrm{H}]^{+}$} & $\mathrm{C}_{21} \mathrm{H}_{35} \mathrm{O}_{10} \mathrm{~N}_{2} \mathrm{~S}_{2}^{+}$ & 539.1728 & 5.5 & 539.1728 & 0.1 & 5.02 \\
\hline & {$[\mathrm{M}+\mathrm{H}]^{-}$} & $\mathrm{C}_{21} \mathrm{H}_{33} \mathrm{O}_{10} \mathrm{~N}_{2} \mathrm{~S}_{2}^{--}$ & 537.1588 & 6.5 & 537.1582 & 1.1 & 5.02 \\
\hline \multirow{2}{*}{10} & {$[\mathrm{M}+\mathrm{H}]^{+}$} & $\mathrm{C}_{21} \mathrm{H}_{35} \mathrm{O}_{10} \mathrm{~N}_{2} \mathrm{~S}_{2}^{+}$ & 539.1728 & 5.5 & 539.1728 & 0.0 & 6.13 \\
\hline & {$[\mathrm{M}+\mathrm{H}]^{-}$} & $\mathrm{C}_{21} \mathrm{H}_{33} \mathrm{O}_{10} \mathrm{~N}_{2} \mathrm{~S}_{2}^{--}$ & 537.1586 & 6.5 & 537.1582 & 0.7 & 6.13 \\
\hline
\end{tabular}


Supporting Information: Stanic et al., Characterization of deoxynivalenol (DON) and cysteine adducts

\begin{tabular}{|c|c|c|c|c|c|c|c|}
\hline \multirow{4}{*}{ 2-sulfoxide ${ }^{b}$} & {$[\mathrm{M}+\mathrm{H}]^{+}$} & $\mathrm{C}_{18} \mathrm{H}_{28} \mathrm{O}_{9} \mathrm{NS}^{+}$ & 434.1473 & 5.5 & 434.1479 & 1.4 & 5.91 \\
\hline & {$[\mathrm{M}+\mathrm{H}]^{-}$} & $\mathrm{C}_{18} \mathrm{H}_{28} \mathrm{O}_{9} \mathrm{NS}^{-}$ & 432.1324 & 6.5 & 432.1334 & 1.9 & 5.91 \\
\hline & {$[\mathrm{M}+\mathrm{H}]^{+}$} & $\mathrm{C}_{18} \mathrm{H}_{28} \mathrm{O}_{9} \mathrm{NS}^{+}$ & 434.1471 & 5.5 & 434.1479 & 2.2 & 6.01 \\
\hline & {$[\mathrm{M}+\mathrm{H}]^{-}$} & $\mathrm{C}_{18} \mathrm{H}_{28} \mathrm{O}_{9} \mathrm{NS}^{-}$ & 432.1325 & 6.5 & 432.1334 & 2.1 & 6.01 \\
\hline \multirow{6}{*}{ 3-sulfoxide ${ }^{b}$} & {$[\mathrm{M}+\mathrm{H}]^{+}$} & $\mathrm{C}_{18} \mathrm{H}_{28} \mathrm{O}_{9} \mathrm{NS}^{+}$ & 434.1473 & 5.5 & 434.1479 & 1.2 & 8.51 \\
\hline & {$[\mathrm{M}+\mathrm{H}]^{-}$} & $\mathrm{C}_{18} \mathrm{H}_{28} \mathrm{O}_{9} \mathrm{NS}^{-}$ & 432.1326 & 6.5 & 432.1334 & 1.8 & 8.51 \\
\hline & {$[\mathrm{M}+\mathrm{H}]^{+}$} & $\mathrm{C}_{18} \mathrm{H}_{28} \mathrm{O}_{9} \mathrm{NS}^{+}$ & 434.1473 & 5.5 & 434.1479 & 1.4 & 8.89 \\
\hline & {$[\mathrm{M}+\mathrm{H}]^{-}$} & $\mathrm{C}_{18} \mathrm{H}_{28} \mathrm{O}_{9} \mathrm{NS}^{-}$ & 432.1325 & 6.5 & 432.1334 & 2.0 & 8.89 \\
\hline & {$[\mathrm{M}+\mathrm{H}]^{+}$} & $\mathrm{C}_{18} \mathrm{H}_{28} \mathrm{O}_{9} \mathrm{NS}^{+}$ & 434.1474 & 5.5 & 434.1479 & 1.17 & 9.32 \\
\hline & {$[\mathrm{M}+\mathrm{H}]^{-}$} & $\mathrm{C}_{18} \mathrm{H}_{28} \mathrm{O}_{9} \mathrm{NS}^{-}$ & 432.1325 & 6.5 & 432.1334 & 2.0 & 9.32 \\
\hline
\end{tabular}

${ }^{a} \mathbf{2}$ and $\mathbf{3}$ are equilibrating mixtures of the ketone-hemiketal. ${ }^{b} \mathrm{NB}$ compound $\mathbf{2}$-sulfoxide consist of 2 stereoisomers (Figure S35); compound 3-sulfoxide consist from 3 stereoisomers (Figure S36). DBE, double bond equivalents 
Supporting Information: Stanic et al., Characterization of deoxynivalenol (DON) and cysteine adducts
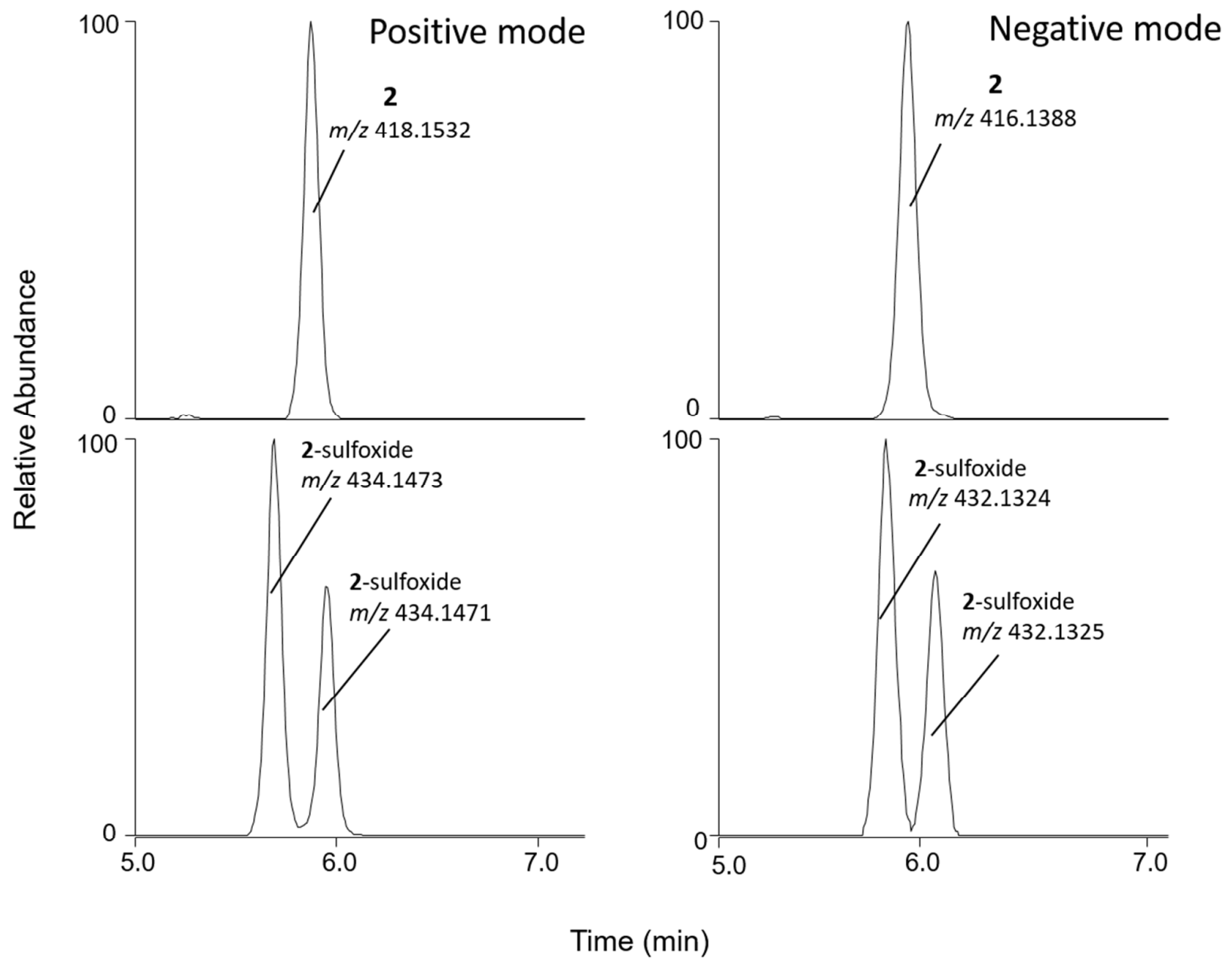

Figure S35. Extracted ion LC-HRMS chromatograms of exact masses corresponding to 2 (top) and 2-sulfoxides (bottom) in positive (left) and negative (right) mode. 
Supporting Information: Stanic et al., Characterization of deoxynivalenol (DON) and cysteine adducts
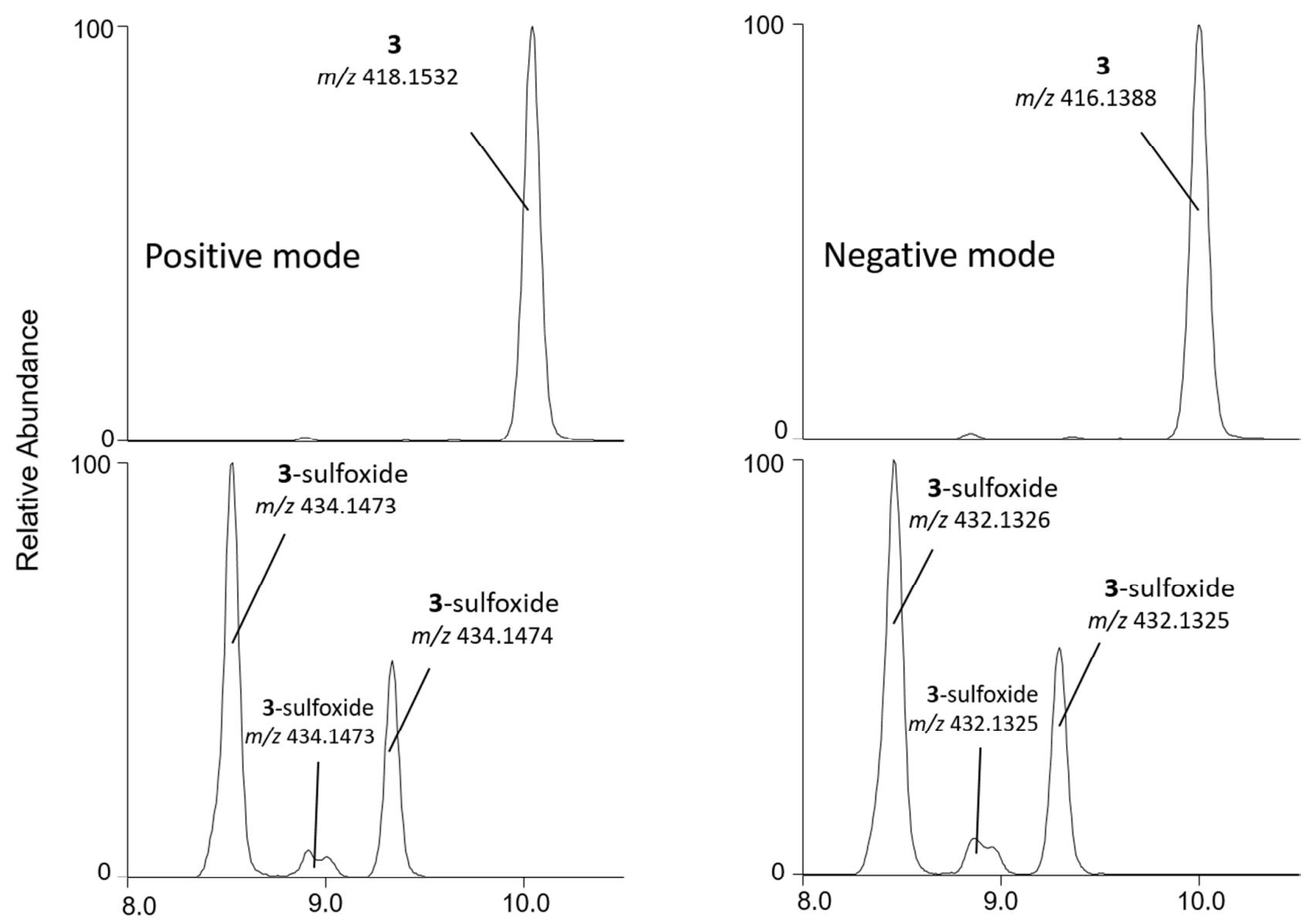

Time (min)

Figure S36. Extracted ion LC-HRMS chromatograms of exact masses corresponding to 3 (top) and $\mathbf{3}$-sulfoxides (bottom) in positive (left) and negative (right) mode 
Supporting Information: Stanic et al., Characterization of deoxynivalenol (DON) and cysteine adducts

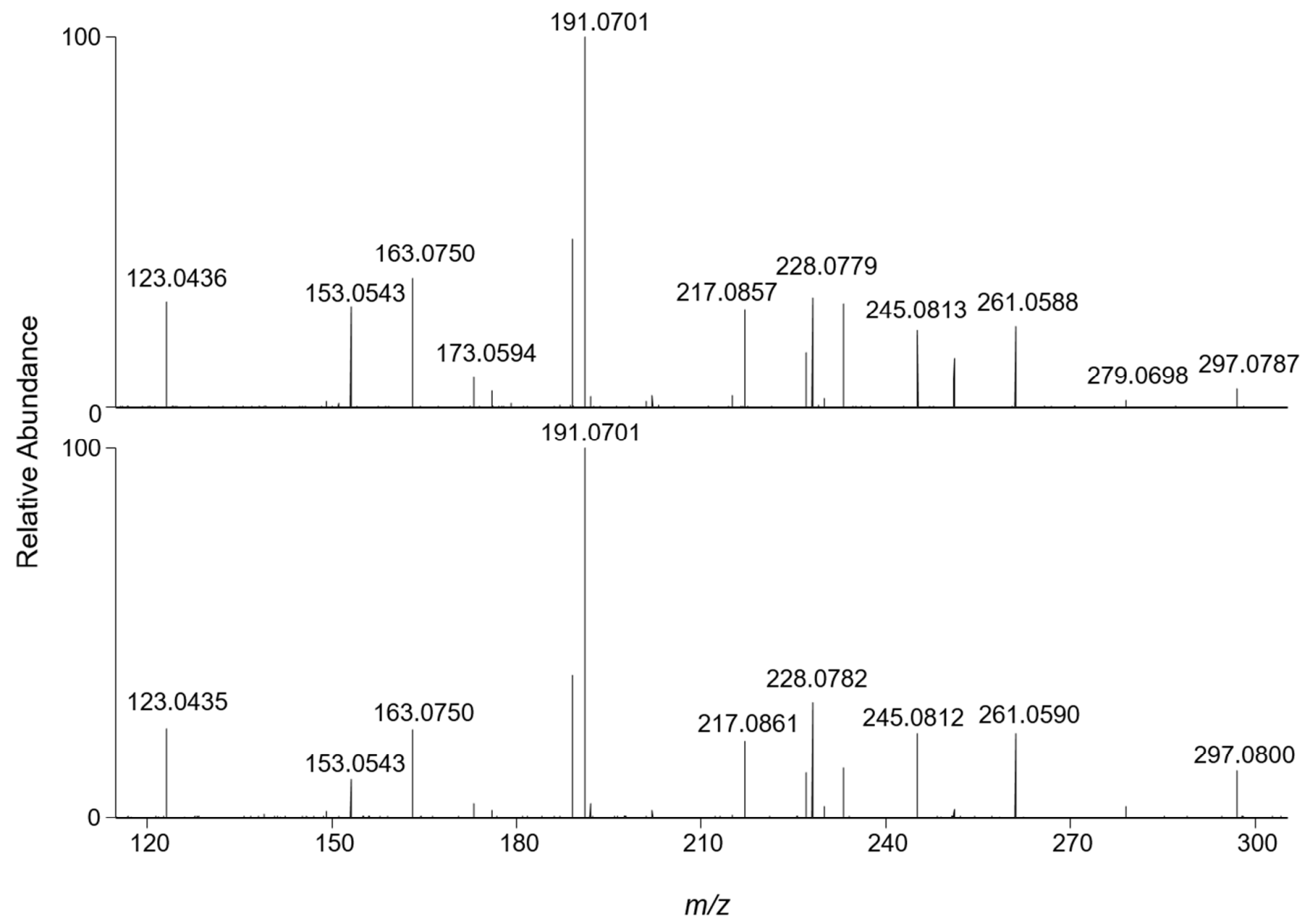

Figure S37. HRMS/MS of 2-sulfoxides in negative mode. The chromatogram on the top belongs to the fragmentation of the earlier eluting 2-sulfoxide, and the bottom chromatogram belongs to later eluting 2-sulfoxide (see Table S1, Figure S35). 
Supporting Information: Stanic et al., Characterization of deoxynivalenol (DON) and cysteine adducts

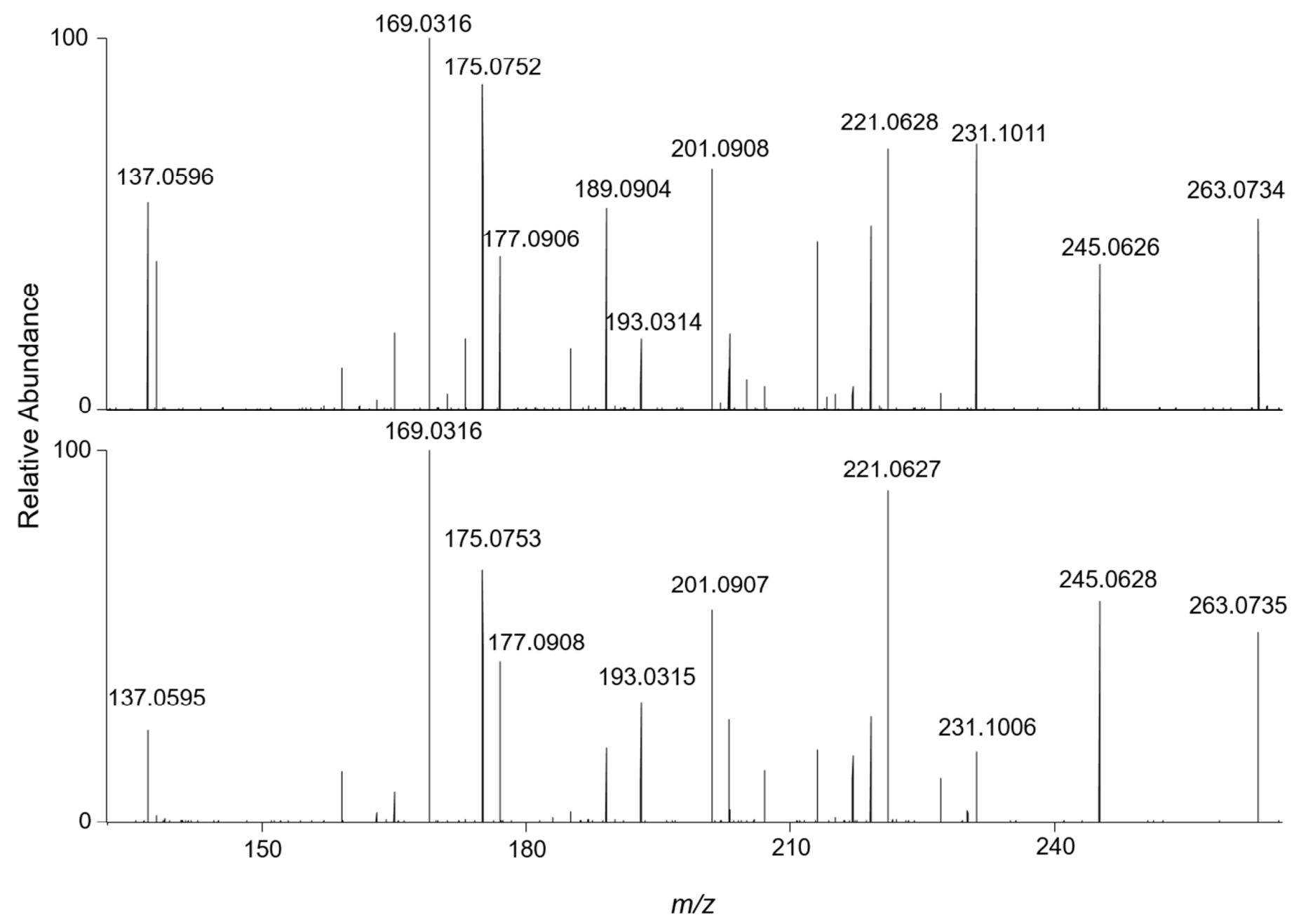

Figure S38. HRMS/MS of sulfoxides-2 in positive mode. The chromatogram at the top belongs to the fragmentation of the earlier eluting 2 -sulfoxide, and the chromatogram at the bottom belongs to the later eluting $\mathbf{2}$-sulfoxide (see Table S1, Figure S35). 
Supporting Information: Stanic et al., Characterization of deoxynivalenol (DON) and cysteine adducts

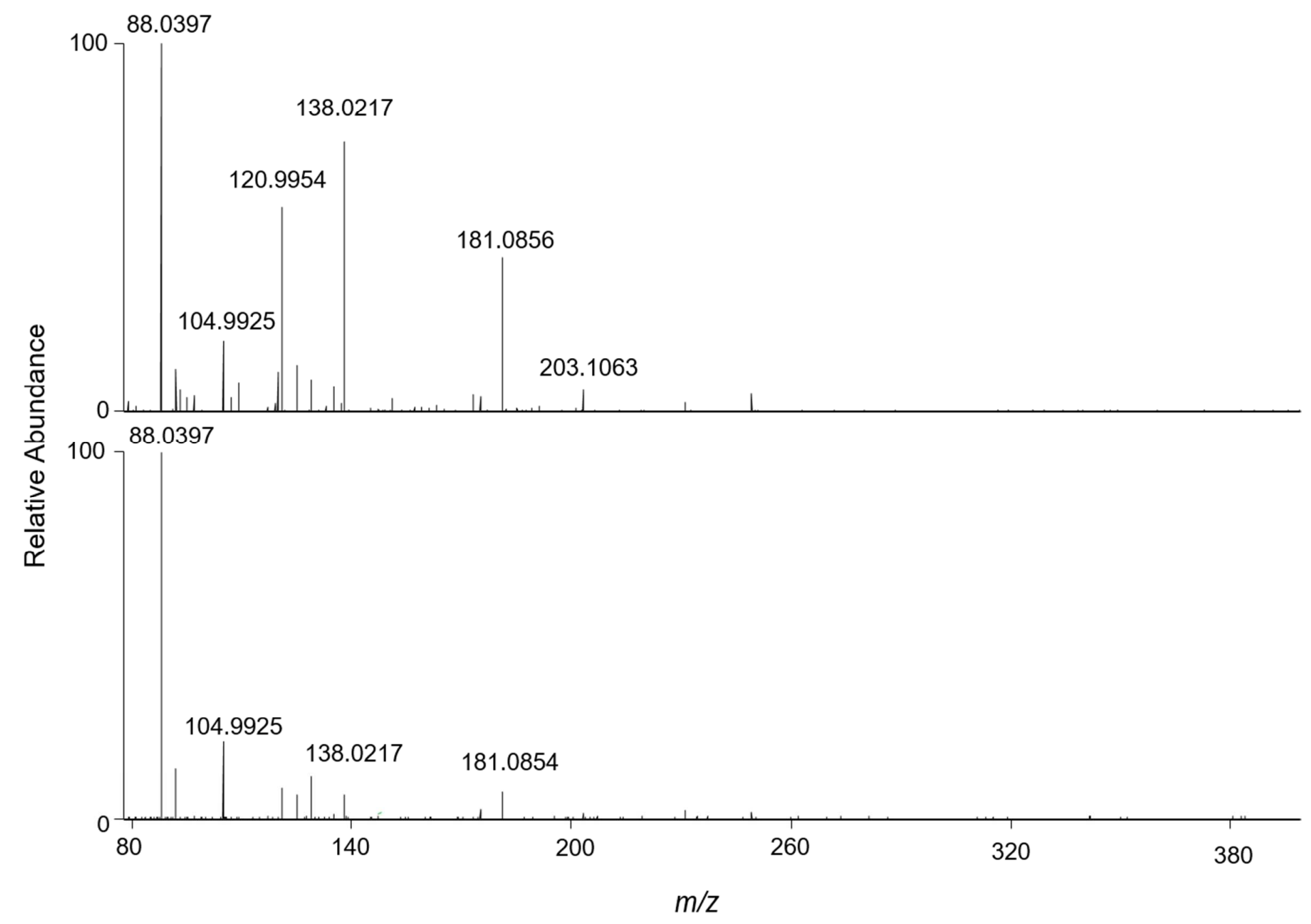

Figure S39. HRMS/MS of 3-sulfoxides in positive mode. The chromatogram at the top belongs to the fragmentation of the earlier eluting 3-sulfoxide, and the chromatogram at the bottom belongs to the later eluting 3 -sulfoxide (see Table S1, Figure S36). 
Supporting Information: Stanic et al., Characterization of deoxynivalenol (DON) and cysteine adducts

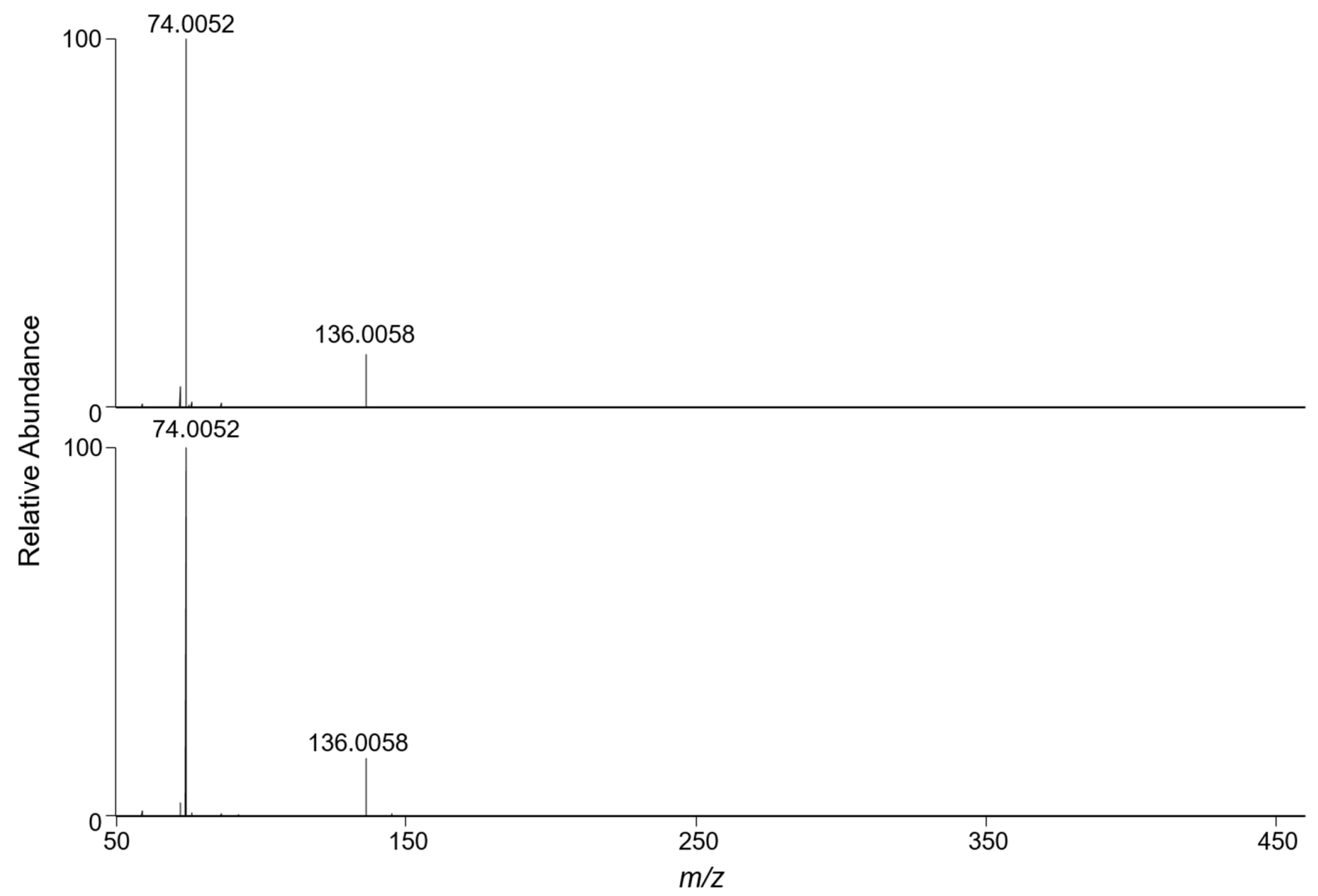

Figure S40. HRMS/MS of 3-sulfoxides in negative mode. The chromatogram at the top belongs to the fragmentation of the earliest eluting 3sulfoxide, and the chromatogram at the bottom belongs to the later eluting 3 -sulfoxide (see Table S1, Figure S36). 
Supporting Information: Stanic et al., Characterization of deoxynivalenol (DON) and cysteine adducts
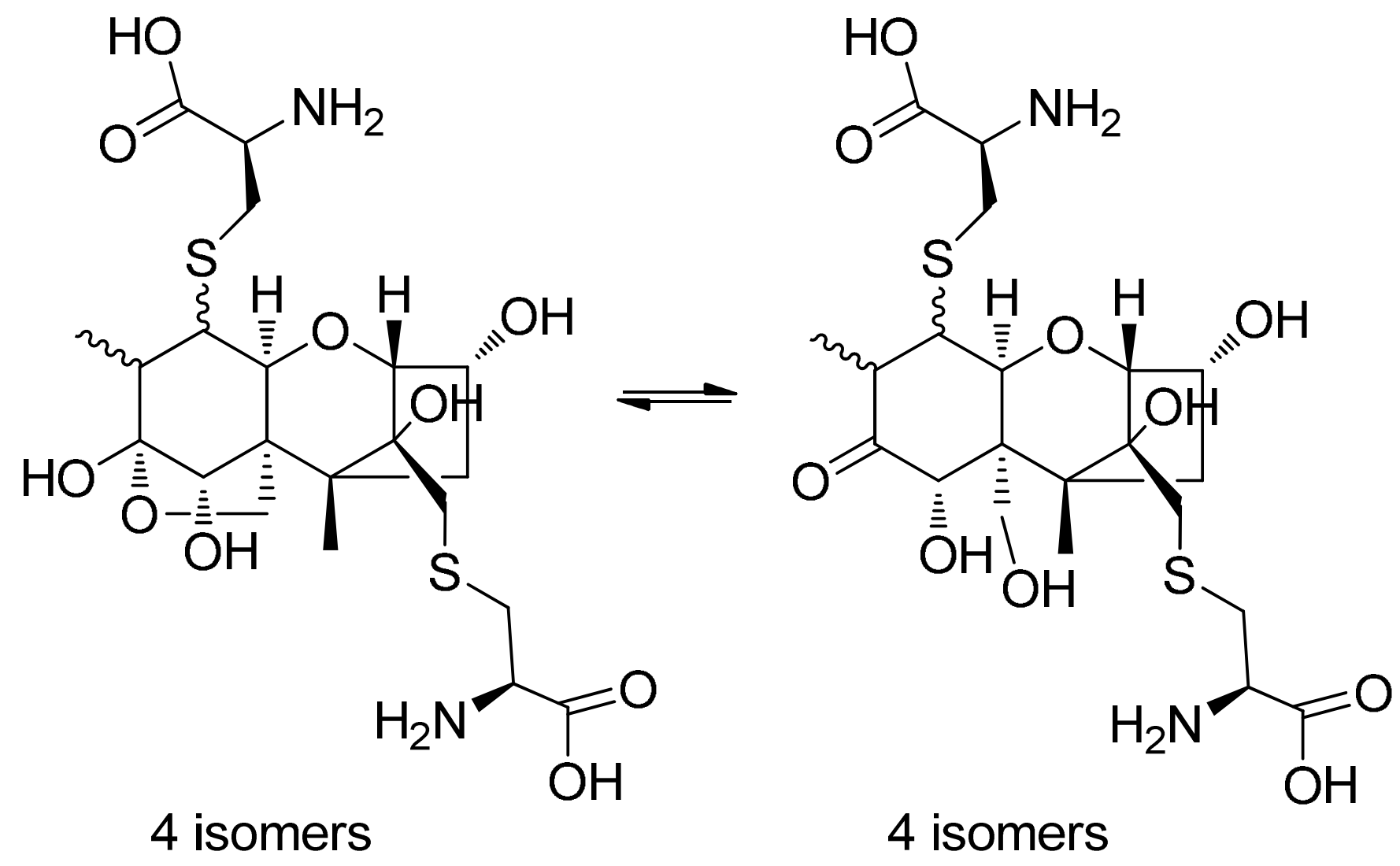

Figure S41.Chemical structures of the double adducts of DON-Cys (7-10). 
Supporting Information: Stanic et al., Characterization of deoxynivalenol (DON) and cysteine adducts

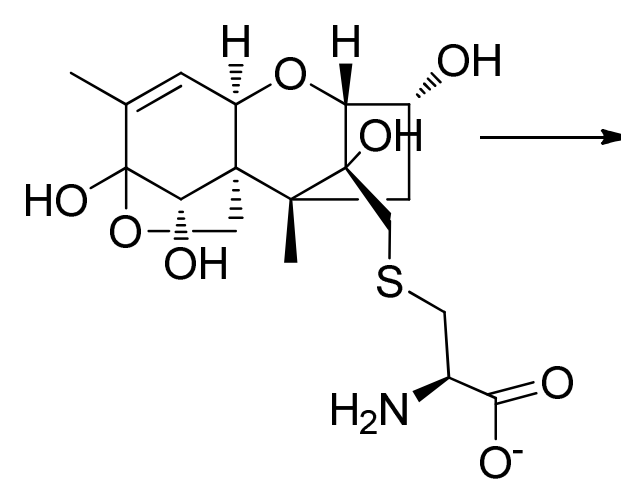

Chemical Formula: $\mathrm{C}_{18} \mathrm{H}_{26} \mathrm{NO}_{8} \mathrm{~S}^{-}$ Accuratet Mass: 416.1385 $\Delta 2.5 \mathrm{ppm}$<smiles>CC1=C[C@H]2O[C@H](O)[C@H](O)[C@@]2(C)[C@H](SCC[C@H](N)C(=O)[O-])[C@@H]1O</smiles>

Chemical Formula: $\mathrm{C}_{17} \mathrm{H}_{24} \mathrm{NO}_{7} \mathrm{~S}^{-}$ Accurate Mass: 386.1279

$\triangle 1.6 \mathrm{ppm}$

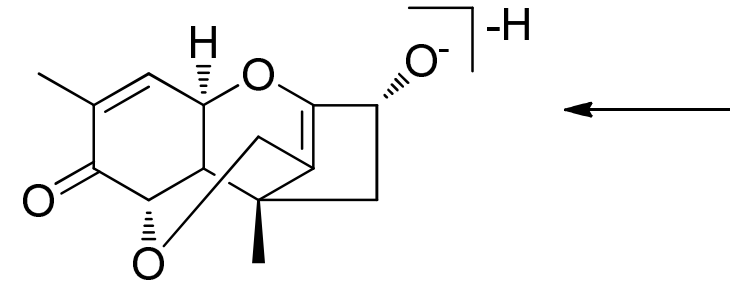

Chemical Formula: $\mathrm{C}_{14} \mathrm{H}_{15} \mathrm{O}_{4}{ }^{-}$ Accurate Mass: 247.0976 $\Delta 0.0 \mathrm{ppm}$

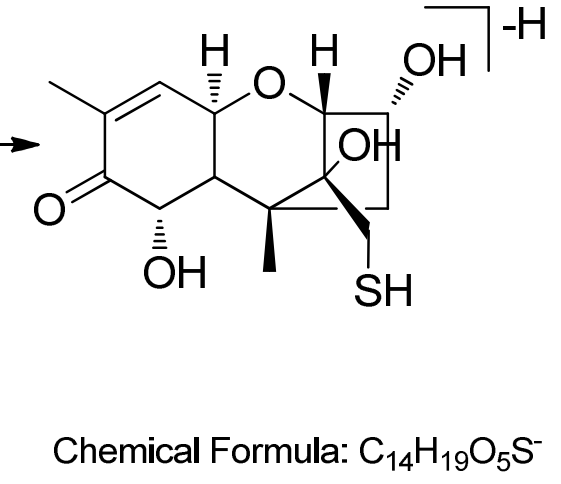
Accurate Mass: 299.0964

$$
\Delta 1.9 \mathrm{ppm}
$$
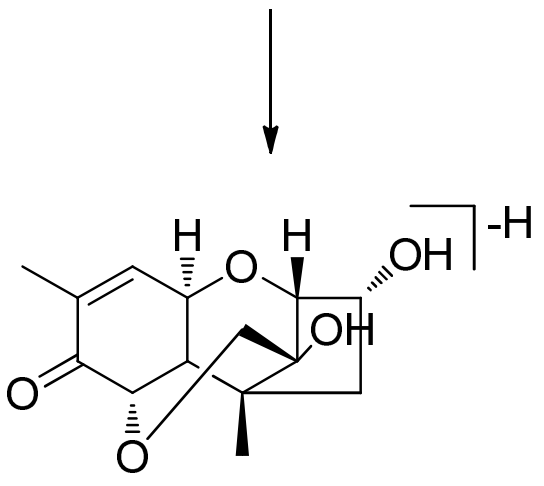

Chemical Formula: $\mathrm{C}_{14} \mathrm{H}_{17} \mathrm{O}_{5}$ Accurate Mass: 265.1088
$\Delta-0.6 \mathrm{ppm}$

Figure S42. Proposed fragmentation in negative mode of 2. Accurate masses were measured using LC-HRMS/MS (Method 2A and Gradient 1). 
Supporting Information: Stanic et al., Characterization of deoxynivalenol (DON) and cysteine adducts

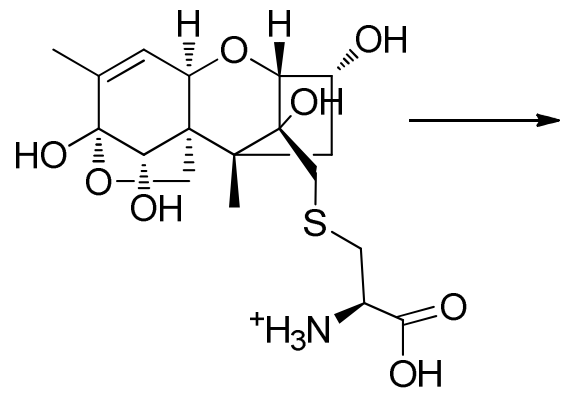

Chemical Formula: $\mathrm{C}_{18} \mathrm{H}_{28} \mathrm{NO}_{8} \mathrm{~S}^{+}$

Accurate Mass: 418.1529

$\Delta-0.3 \mathrm{ppm}$

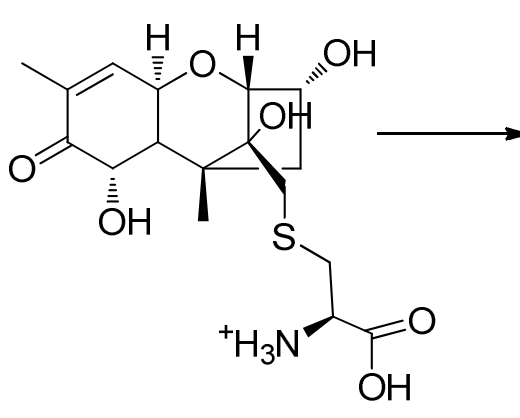

Chemical Formula: $\mathrm{C}_{17} \mathrm{H}_{26} \mathrm{NO}_{7} \mathrm{~S}^{+}$ Accurate Mass: 388.1427

$$
\Delta 0.6 \mathrm{ppm}
$$

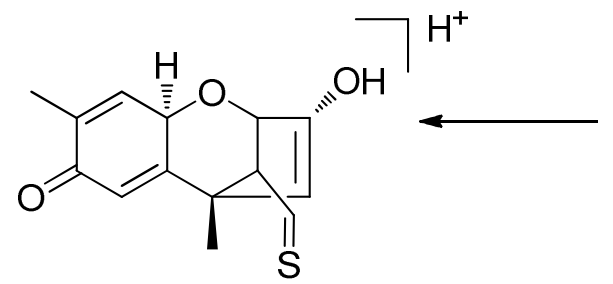

Chemical Formula: $\mathrm{C}_{14} \mathrm{H}_{15} \mathrm{O}_{3} \mathrm{~S}^{+}$ Accurate Mass: 263.0739

$\Delta 0.9 \mathrm{ppm}$

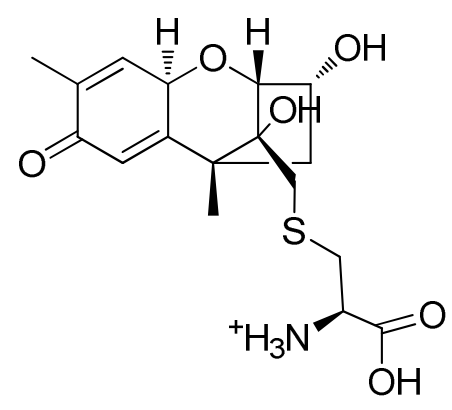

Chemical Formula: $\mathrm{C}_{17} \mathrm{H}_{24} \mathrm{NO}_{6} \mathrm{~S}^{+}$ Accurate Mass: 370.1323

$\Delta 0.9 \mathrm{ppm}$

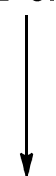<smiles>C[CH+]C[PH3+]</smiles>

Chemical Formula: $\mathrm{C}_{14} \mathrm{H}_{17} \mathrm{O}_{4} \mathrm{~S}^{+}$ Accurate Mass: 281.0846

$\Delta 1.1 \mathrm{ppm}$

Figure S43. Proposed fragmentation of 2 in positive mode. Accurate mass was measured using LC-HRMS/MS (Method 2A and Gradient 1). 
Supporting Information: Stanic et al., Characterization of deoxynivalenol (DON) and cysteine adducts

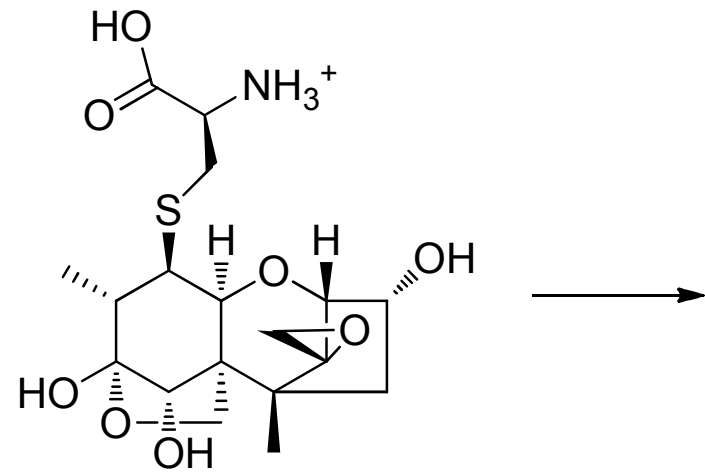

Chemical Formula: $\mathrm{C}_{18} \mathrm{H}_{28} \mathrm{NO}_{8} \mathrm{~S}^{+}$

Accurate Mass: 418.1531

$\Delta 0.2 \mathrm{ppm}$

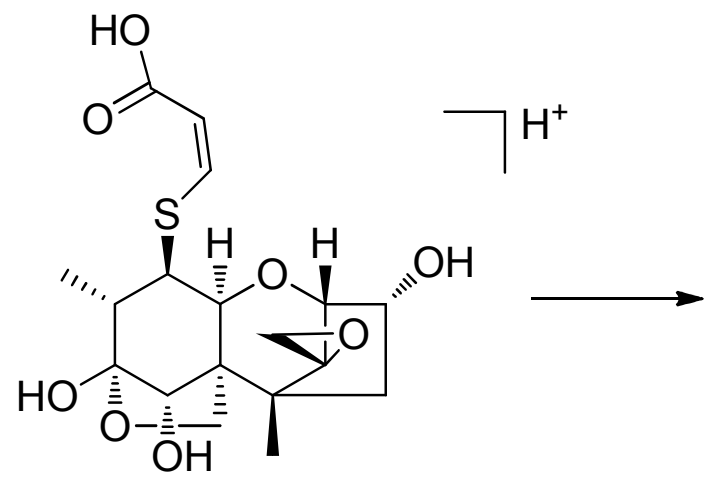

Chemical Formula: $\mathrm{C}_{18} \mathrm{H}_{25} \mathrm{O}_{8} \mathrm{~S}^{+}$

Accurate Mass: 401.1268

$\Delta 0.8 \mathrm{ppm}$

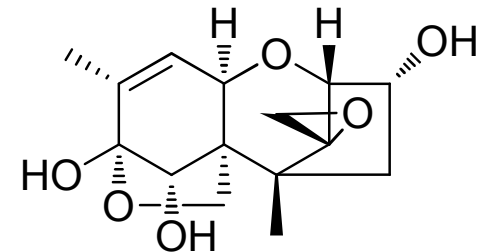

Chemical Formula: $\mathrm{C}_{15} \mathrm{H}_{21} \mathrm{O}_{6}{ }^{+}$ Accurate Mass: 297.1332

$\Delta 0.2 \mathrm{ppm}$

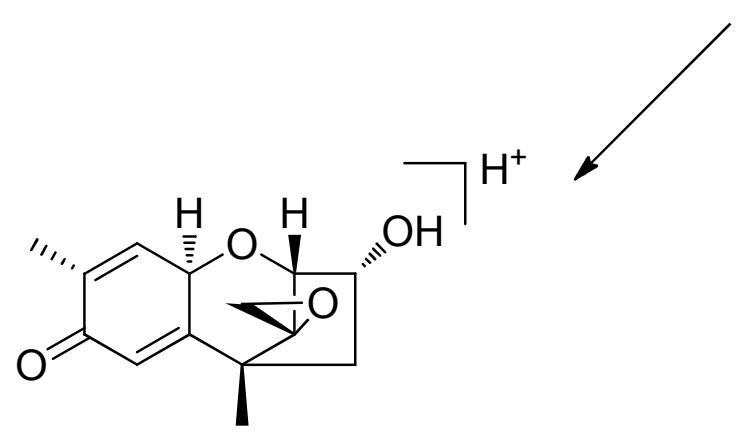

Chemical Formula: $\mathrm{C}_{14} \mathrm{H}_{17} \mathrm{O}_{4}{ }^{+}$

Accurate Mass: 249.1122

$\Delta 0.3 \mathrm{ppm}$

Figure S44. Proposed fragmentation pathway of $\mathbf{3}$ in positive mode. Accurate mass was measured using LC-HRMS/MS (Method 2A and Gradient 1). 


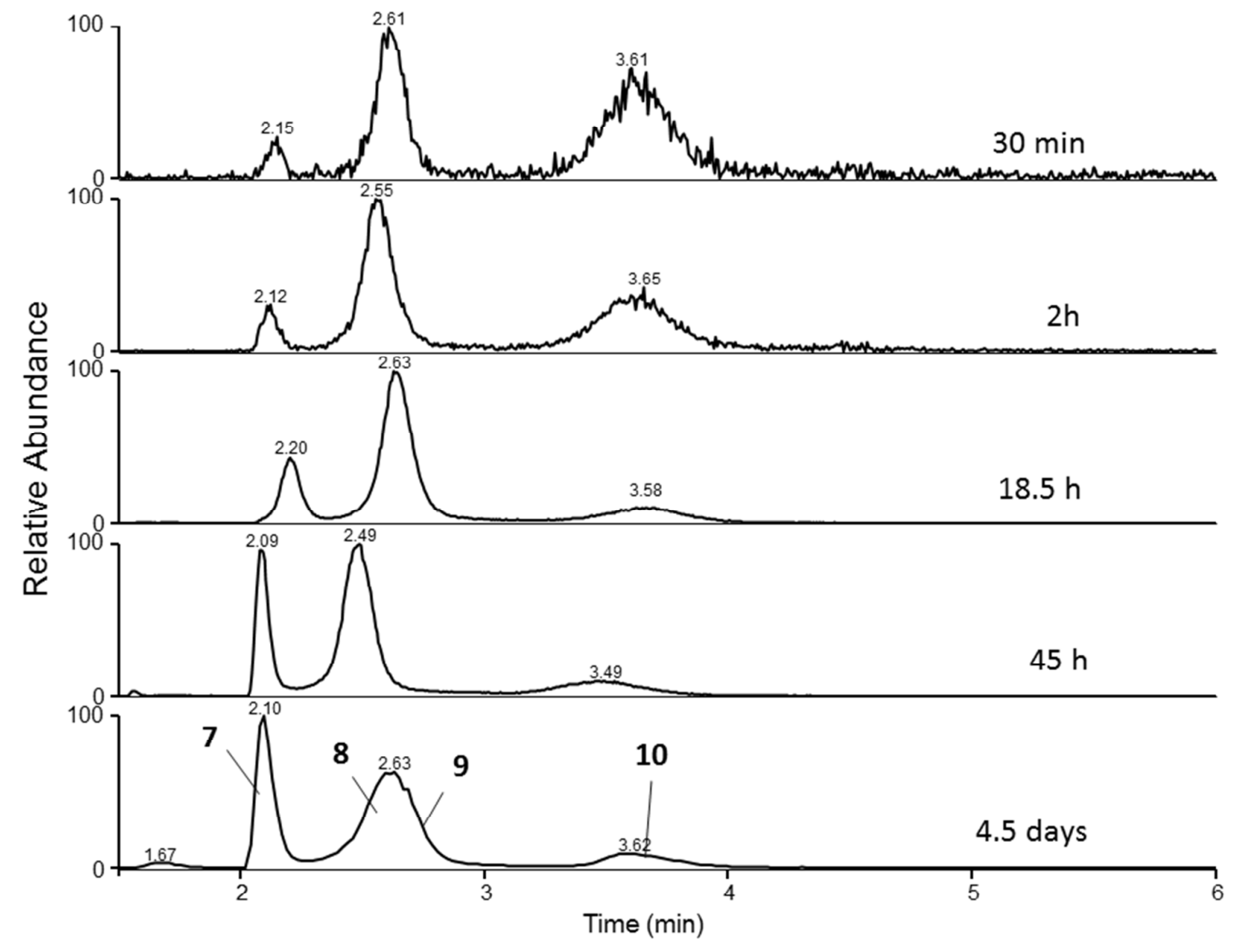

Figure S45. LC-MS extracted ion chromatograms (positive mode, $m / z 539$ ) at the specified values of $\mathrm{m} / \mathrm{z}$ for double-adducts of DON after reaction with cysteine at $\mathrm{pH} 10.7$. 
Supporting Information: Stanic et al., Characterization of deoxynivalenol (DON) and cysteine adducts

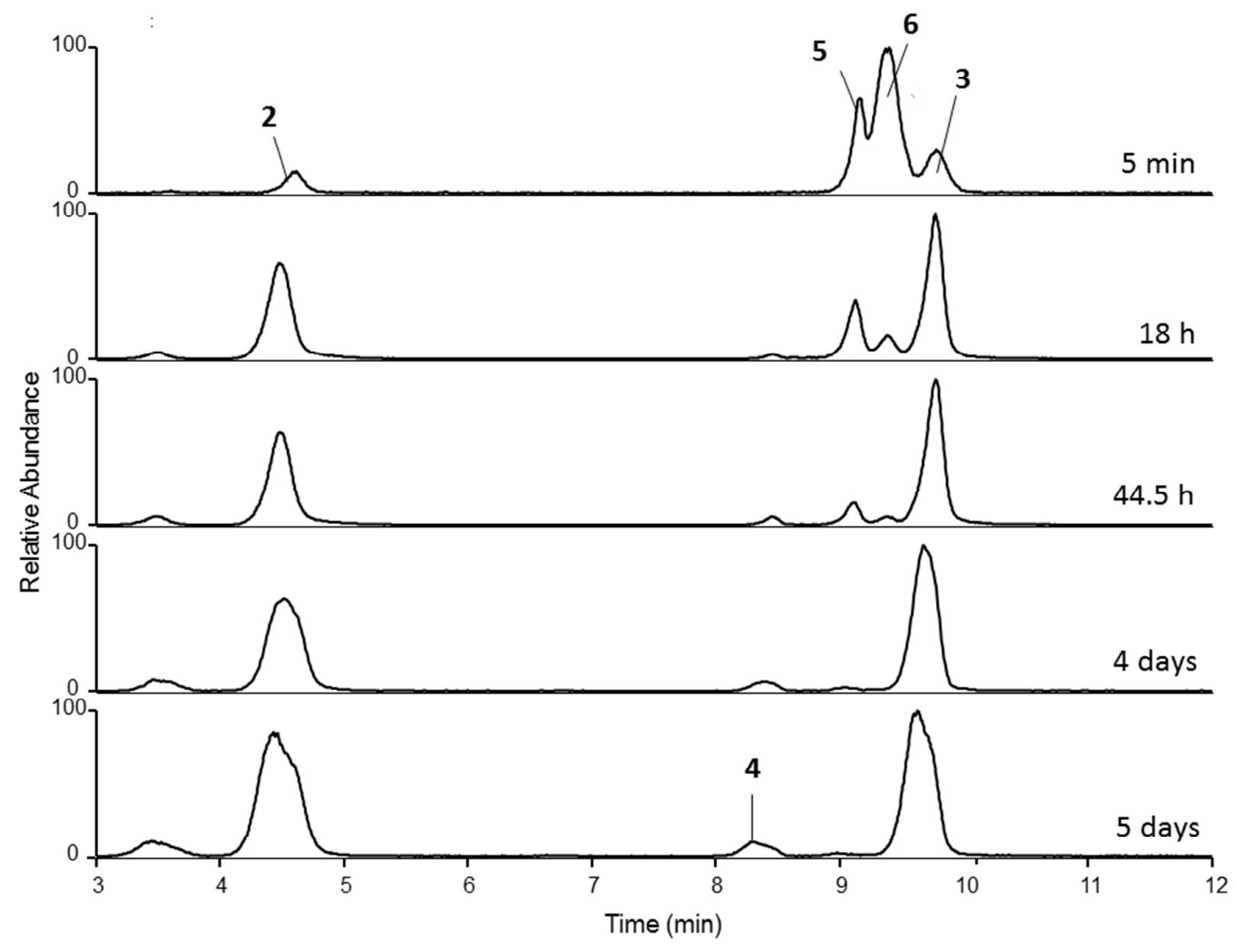

Figure S46. LC-MS (Method 1A, Gradient 1) extracted ion chromatograms (negative mode, $\mathrm{m} / \mathrm{z}$ 416 ) at the specified values of $\mathrm{m} / z$ for single adducts of DON after reaction with cysteine at $\mathrm{pH}$ 10.7 . 


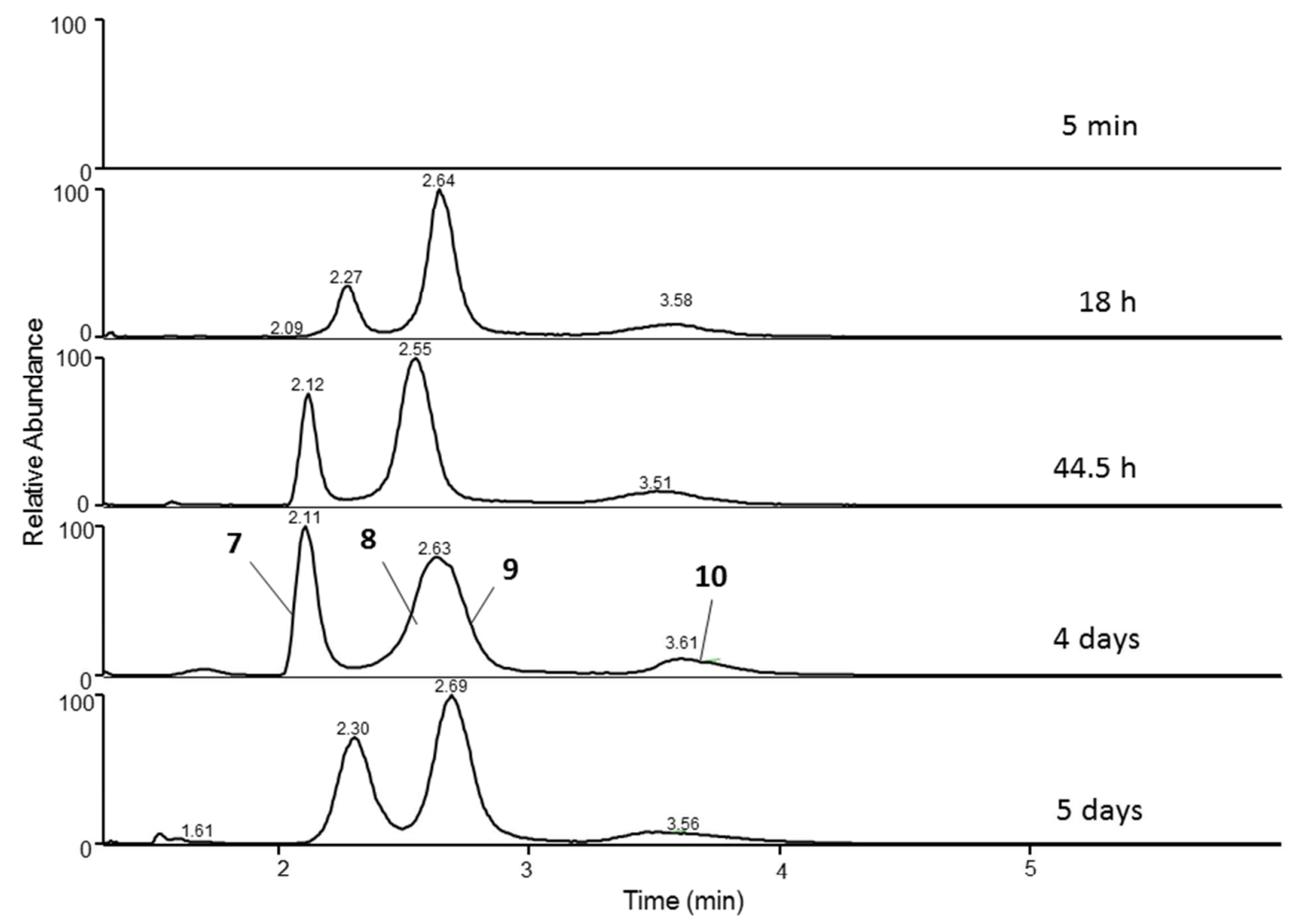

Figure S47. LC-MS (Method 1A, Gradient 1) extracted ion chromatograms (negative mode, $\mathrm{m} / z$ 537 ) at the specified values of $\mathrm{m} / \mathrm{z}$ for double adducts of DON after reaction with cysteine at $\mathrm{pH}$ 10.7 . 


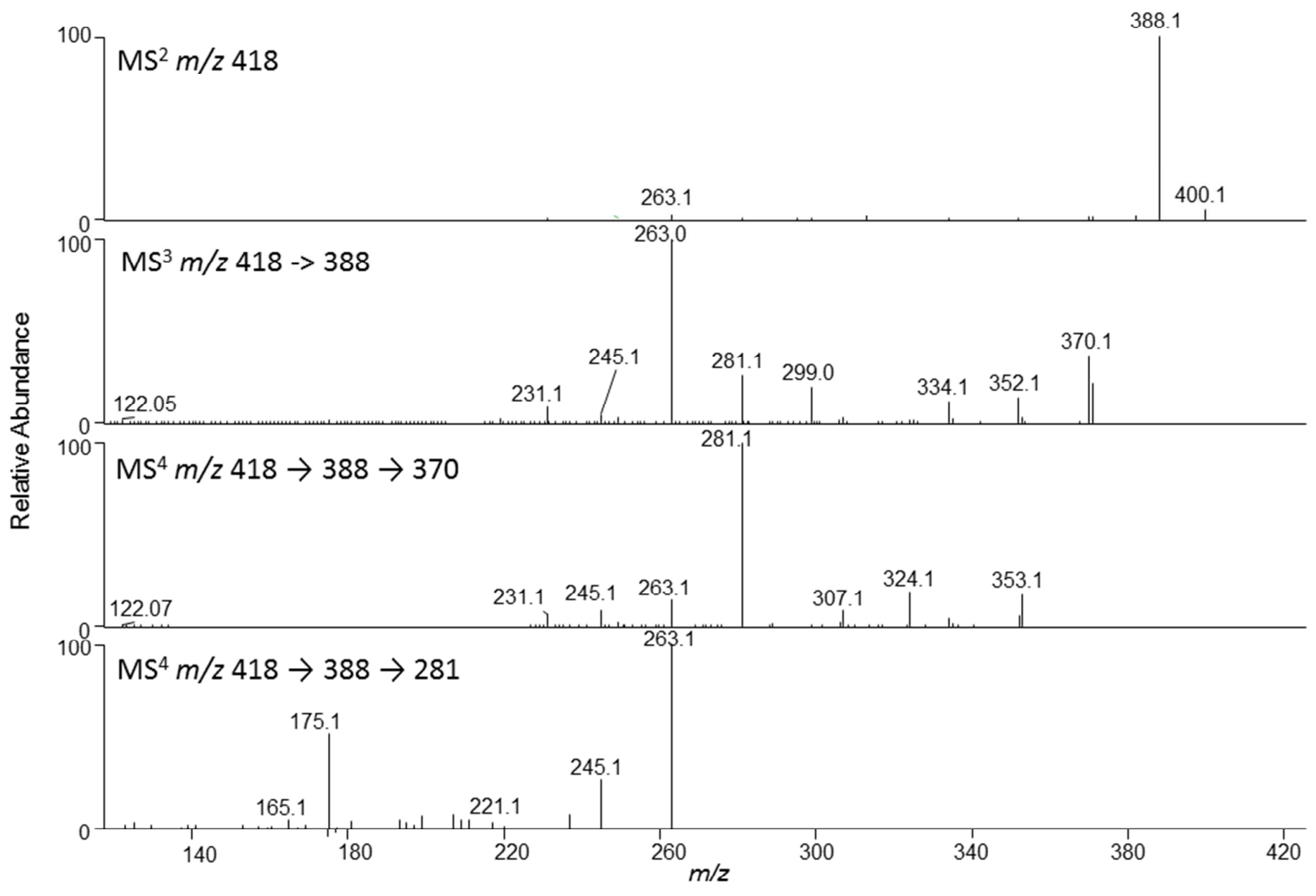

Figure S48. $\mathrm{MS}^{\mathrm{n}}(\mathrm{n}=2-4)$ of $\mathbf{2}$ in positive mode (Method 1, Gradient 1). 
Supporting Information: Stanic et al., Characterization of deoxynivalenol (DON) and cysteine adducts

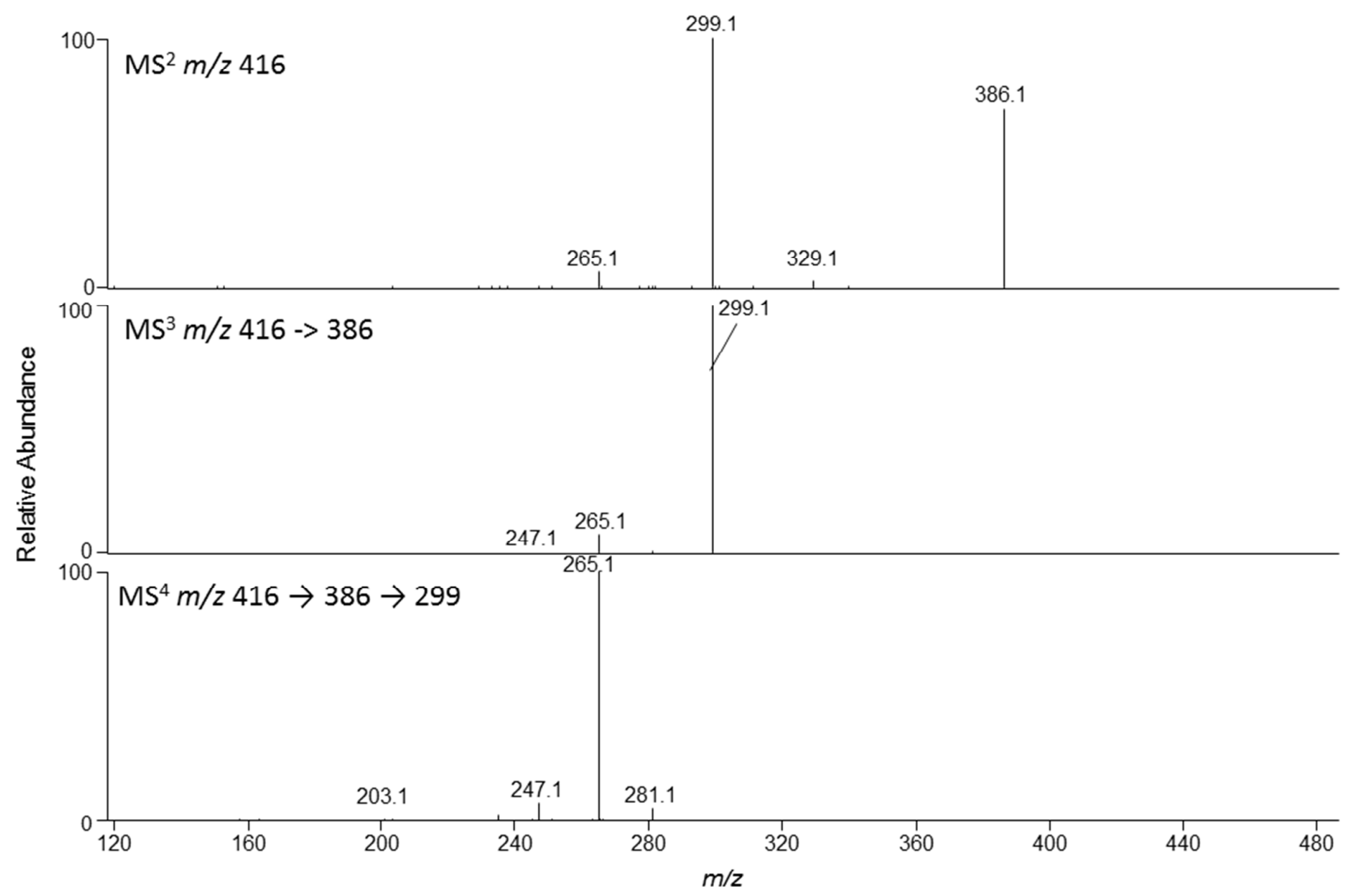

Figure S49. $\mathrm{MS}^{\mathrm{n}}(\mathrm{n}=2-4)$ of 2 in negative mode (Method 1, Gradient 1). 
Supporting Information: Stanic et al., Characterization of deoxynivalenol (DON) and cysteine adducts
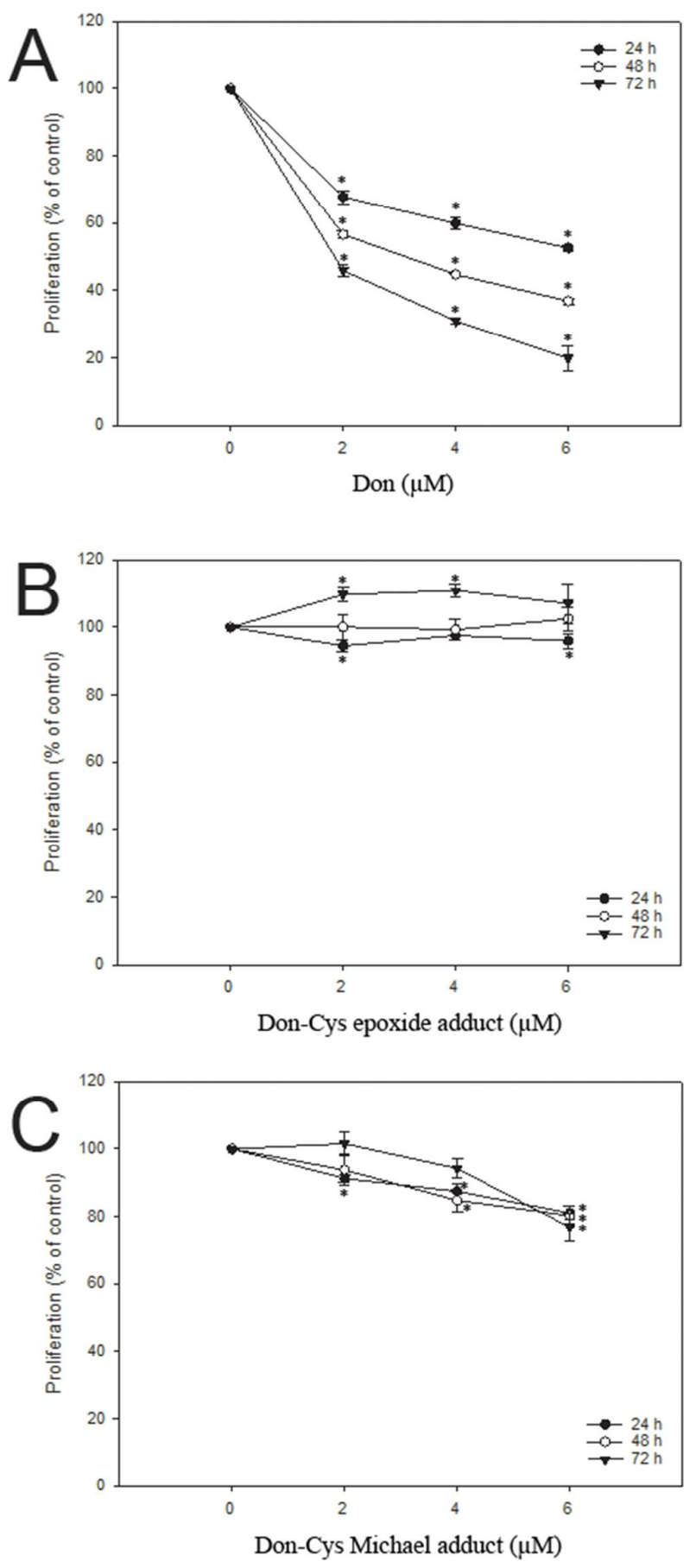

Figure S50. Proliferation of THP-1 monocytes after treatment with 2, 4 and $6 \mu \mathrm{M}$ DON (A) or 2, DON-Cys epoxide adduct (B) and 3, DON-Cys Michael adduct (C) for 24, 48 and 72 hours measured by Alamar Blue. Data represent the arithmetic mean \pm SD of 3 independent incubations. The asterisk indicates measurements that were significantly different from the control (1-wayANOVA with Dunnett's post-test, $\mathrm{p}<0.05$ ). 
Supporting Information: Stanic et al., Characterization of deoxynivalenol (DON) and cysteine adducts

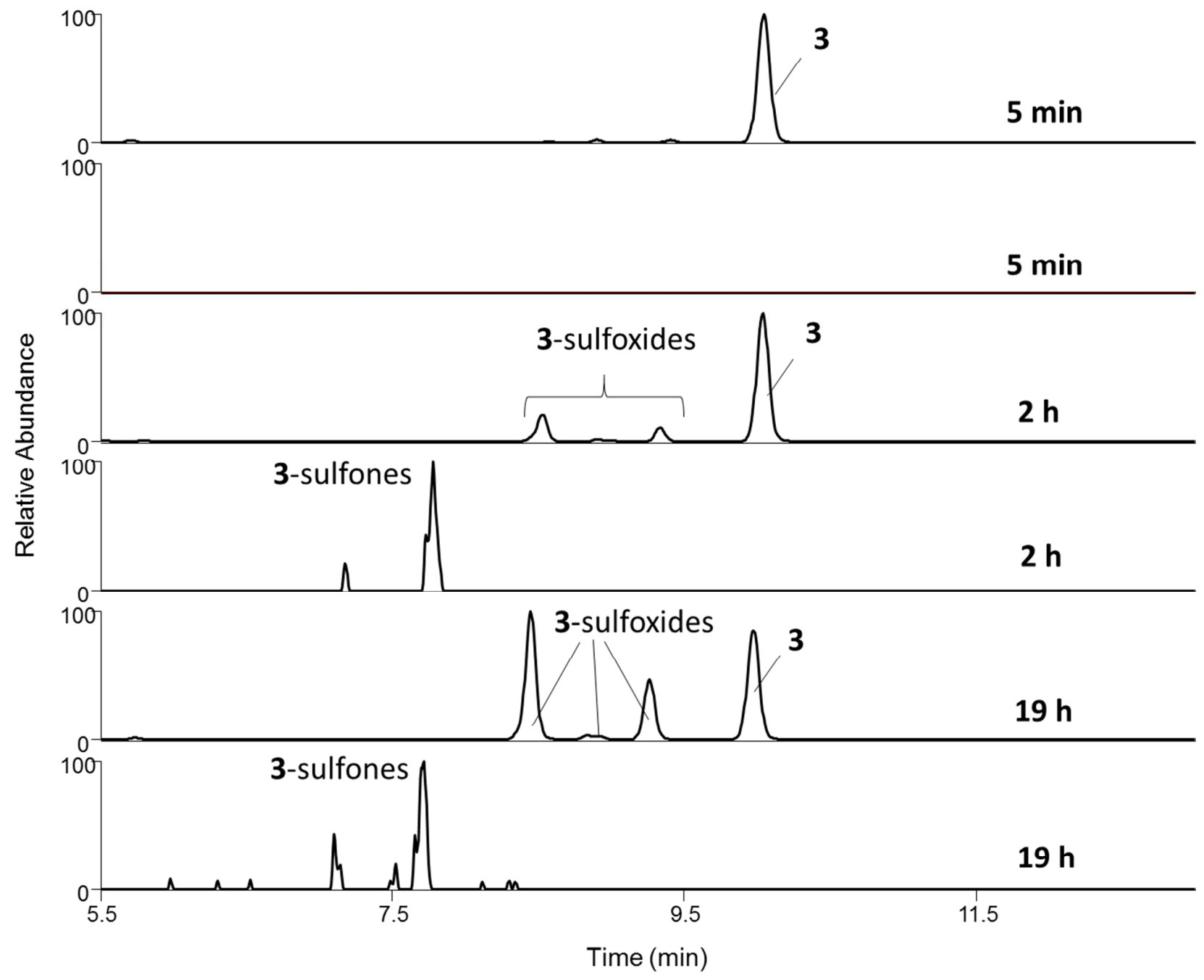

Figure S51. LC-MS extracted ion chromatograms showing DON-Cys Michael adduct $3(\mathrm{~m} / z$ 418.1524, $\left.\mathrm{C}_{18} \mathrm{H}_{28} \mathrm{O}_{8} \mathrm{NS}^{+}, \Delta 1.5 \mathrm{ppm}\right)$ after being treated with $\mathrm{H}_{2} \mathrm{O}_{2}$ and formation of 3 -sulfoxides $\left(m / z\right.$ 434.1474, $\left.\mathrm{C}_{18} \mathrm{H}_{28} \mathrm{O}_{9} \mathrm{NS}^{+}, \Delta 1.2 \mathrm{ppm}\right)$ and 3 -sulfones $\left(\mathrm{m} / z\right.$ 450.1423, $\mathrm{C}_{18} \mathrm{H}_{28} \mathrm{O}_{10} \mathrm{NS}^{+}, \Delta-1.1$ ppm). 


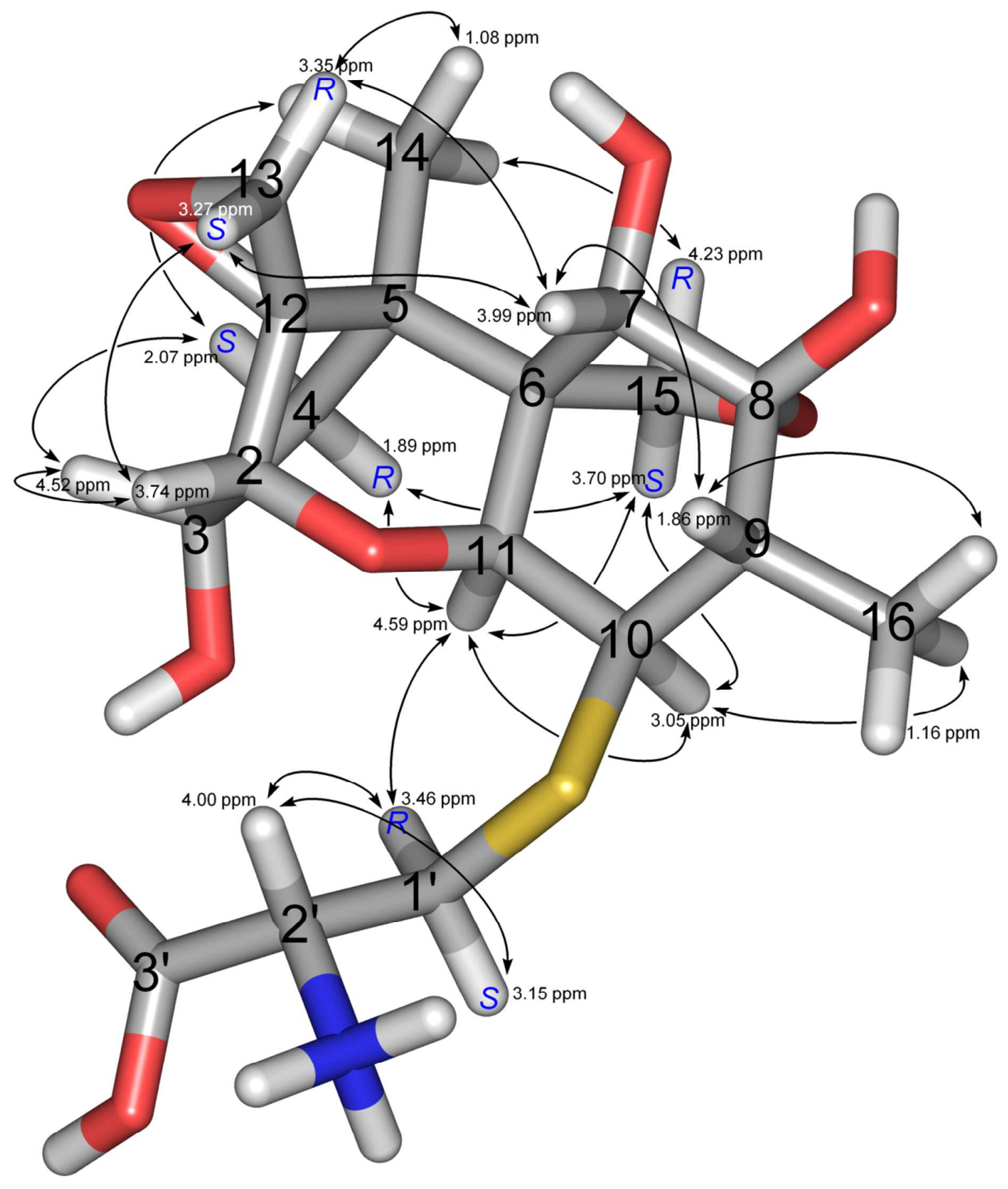

Figure S52. 3-Dimensional model of the hemiketal form of DON-Cys Michael adduct 3b, showing correlations observed in the ROESY NMR spectrum that confirm addition of the cysteine thiol at C10 and establishing the stereochemistry at C-9 and C-10. The four pairs of pro- $S$ and pro- $R$ methylene protons are labeled in blue text as $S$ and $R$, respectively. 